\title{
DOCUMENTACIÓN SOBRE CONVENTOS FRANCISCANOS FEMENINOS EN EL ARCHIVO DIOCESANO DE MÉRIDA-BADAJOZ
}

\author{
POR \\ Ma Guadalupe Pérez Ortiz \\ Biblioteca Seminario San Atón de Badajoz \\ Y \\ Agustín Vivas Moreno \\ Universidad de Extremadura
}

\begin{abstract}
RESUMEN
El presente trabajo tiene por objeto el análisis de la documentación franciscana, en su rama femenina, ubicado en el fondo antiguo del Archivo Diocesano de Mérida-Badajoz, actualmente denominado Archivos Eclesiásticos de MéridaBadajoz. Para ello, tras unas breves notas sobre la historia y organización de dicho Archivo, realizamos un análisis de la documentación desde múltiples perspectivas: su condición de manuscrito o impreso, cronología, topografía, contenidos, especificándose la documentación existente para cada convento. El estudio concluye con el catálogo de los documentos custodiados en la entidad.
\end{abstract}

PALABRAS CLAVES: Análisis documental/Archivo Diocesano de Mérida-Badajoz/ Conventos franciscanos/ Documentación franciscana/

\section{FEMALE DOCUMENTATION FRANCISCAN CONVENT IN THE ARCHIVO DIOCESANO DE MÉRIDA-BADAJOZ}

\begin{abstract}
The present work takes as an object the analysis of the Franciscan papers, in its feminine branch, located in the ancient fund of the Diocesan File of MeridaBadajoz, at present named Ecclesiastic Files of Merida-Badajoz. For it, after a few brief notes on the history and organization of the above mentioned File, we realize an analysis of the papers from multiple perspectives: its condition of manuscript
\end{abstract}


or form, chronology, topography, contents, the existing papers being specified for every convent. The study concludes with the catalog of the documents guarded in the entity.

KEY WORDS: Documentary analysis. Archivo Diocesano de Mérida-Badajoz. Franciscan convents. Franciscan documentation.

\author{
Recibido/Received 09-01-2011 \\ Aceptado/Accepted 06-09-2014
}

\title{
INTRODUCCIÓN
}

Este artículo tiene como objetivo principal el análisis de documentos de la orden de san Francisco, en su rama femenina (clarisas, concepcionistas y tercera orden), que se hayan ubicados en el fondo antiguo del Archivo Diocesano de MéridaBadajoz. Su desarrollo es consecuencia de un trabajo previo en el que se estudiaban los documentos producidos por los conventos franciscanos masculinos ${ }^{1}$ que habitaron en la provincia de Badajoz y que pronto verá la luz. Por ello, se convertía en una tarea vital estudiar qué ocurrió en el panorama conventual franciscano femenino. La suma de los dos estudios nos permitirá conocer la magnitud que la orden de san Francisco tuvo desde antiguo en los pueblos de la Baja Extremadura. Su significación es tal que el acceso a ambos trabajos nos muestra un abanico amplísimo de contenidos que nos permitirán conocer la orden desde los aspectos más variopintos (lenguas, cronología, tipografías, contenidos, etc.).

Para alcanzar los objetivos se han empleado unos recursos metodológicos que se basan en la aplicación de las diversas herramientas. En primer lugar, técnicas archivísticas, que se fundamentaron en el análisis exhaustivo de cada una de las piezas documentales (documentos sueltos) y las unidades archivísticas (expedientes), tanto en sus caracteres internos como externos. Además, realizamos un estudio de las procedencias documentales, así como un análisis institucional para conocer las entidades productoras de la documentación. Incluyendo diversos análisis sectoriales: cronológico, volumen documental, topográfico e idiomático. El resultado de esta metodología son las tablas de contenido y el catálogo documental. En segundo término, el análisis histórico, por el que procedimos a analizar la documentación desde el punto de vista del investigador interesado en la historia, obteniendo como resultados las características generales e históricas de la documentación. Por último, el empleo de las tecnologías de la información, para la realización del catálogo

${ }^{1}$ Pérez Ortiz, G.; Vivas Moreno, A. «Documentación sobre conventos franciscanos masculinos en el Archivo Diocesano de Mérida-Badajoz». Archivo Iberoamericano. Revista Franciscana de estudios históricos. (Evaluándose). 
documental que nos permite la consulta rápida por medio de un interfaz que permitiera al usuario la búsqueda y recuperación de la información de una forma sencilla pero eficaz. El resultado es un gestor documental automatizado.

Un breve estado de la cuestión nos lleva a conocer que existen un amplio conjunto de trabajos e investigaciones sobre las órdenes religiosas muy especialmente la franciscana. Ahora bien, dicha cuestión queda alejada de nuestra investigación, en la que debemos centrarnos en los archivos conventuales de dicha orden y en los trabajos que ven la luz partiendo de la documentación en ellos custodiada. Limitándonos a ello observamos la existencia de variados estudios ${ }^{2}$ que ponen en relieve la documentación relativa a la orden franciscana en sus diversas ramas, cuestión que ha interesado a muchos archiveros e investigadores en nuestro país. Estos trabajos cobran especial significación en Iberoamérica, donde los franciscanos desarrollaron una importantísima labor que se ve plasmada en diversos estudios ${ }^{3}$ que tienen como punto de partida la documentación custodiada en sus archivos. Ahora bien, y tras el análisis de la bibliografía, podemos observar que se trata de un tema muy recurrente en el siglo xx que decrece en producción bibliográfica a medida que transcurren los años.

\section{El Archivo Diocesano de MéridA-Badajoz: aproXimación a SU Historia}

Escasos son los datos que conocemos de este archivo, puesto que carece de una historia que analice su fundación y desarrollo, la procedencia de sus fondos,

\footnotetext{
${ }^{2}$ Aguilera, A. 2010. «Vida en clausura: estudio de las patentes de los ministros franciscanos conservados en el archivo del convento de Santa Clara de Borja.» Cuadernos de Historia Moderna. 35: 97-117; ídem. 2009. Relación de los fondos documentales del convento de de Santa Clara de Borja. Zaragoza: Institución Fernando el Católico; Baucells, J. 1980. «Documentación franciscana en el Archivo Capitular de Barcelona.» Archivo Iberoamericano. 40: 339-382; Carnicero, J. 2005. «Inventario de los manuscritos del archivo los PP. Franciscanos de Santiago de Compostela.» Estudios Mindonenses. 21: 487-545; Martino Alba, P. 2013. «Los franciscanos en los archivos nacionales», en A. Bueno, Los franciscanos y el contacto de las lenguas y culturas. Madrid; Moreno, A. 2001. «La huella franciscana en los archivos...» Conferencias del VI Curso de Verano.... 371-380; Pastrana, A. 1990. «Extremadura en el archivo Ibero-Oriental», en S. García, Extremadura en la evangelización del Nuevo Mundo: 625-683. Madrid: Turner; Varela Bueno, C. 1988. «Documentos franciscanos en el archivo de Protocolos de Sevilla.» Archivo Iberoamericano. 48: 189-192.

${ }^{3}$ Abad,A. 1989. «El archivo franciscano Ibero-oriental; historia y fuentes» en F. Solado; F. Rodao; L. Togores, El Extremo Oriente Ibérico. Madrid: 55-63; Gil, P. 1984. Registro general alfabético del archivo franciscano de la Provincia Castellana de san Gregorio Magno. Madrid; Garabal, T. 1994. «Documentos clarianos en el archivo franciscano Ibero-Oriental.» Archivo Iberoamericano. 54: 213-214; Heras, J; Gutiérrez, L. 2004. Archivos franciscanos de Lima. Madrid: Fundación Mapfre; Ídem. 1997. «Principales archivos y bibliotecas de la orden franciscana en Perú.» Archivo Iberoamericano. 57: 225-228; Maas, O. 1915. Viajes de misioneros franciscanos a la conquista del nuevo mundo. Documentos del Archivo General de Indias. Sevilla: Imprenta san Antonio; Reyes, R. 1992. «Expediciones y viajes de franciscanos en los libros de registro del Archivo General de Indias.» Archivo Iberoamericano. 52: 205-208.
} 
las ubicaciones en las que se instaló, así como el personal que estuvo al frente del mismo. Tras la consulta de algunos estudios sobre la Diócesis de Badajoz ${ }^{4}$ podemos afirmar que su nacimiento se sitúa coetáneo a la reestructuración del Obispado, hacia el 1255 de la mano del obispo fray Pedro Pérez. Si tenemos en cuenta que fueron las cláusulas emanadas del Concilio de Trento (1545-1563) las que determinaron la obligatoriedad de crear archivos diocesanos o episcopales, debemos afirmar que en el Obispado Pacense existía un archivo previo, aunque su uso era poco significativo.

Conocemos de la mano del historiador don Alberto González Rodríguez que se situaba en el interior del Palacio Episcopal, el cual se localizaba próximo a la Iglesia de Santa María del Castillo. Su ubicación originaria es desconocida, alojándose desde los momentos iniciales, de los que tenemos constancia, en el llamado "Almacén del Rey" que en 1380 fue consolidado como sede episcopal tras ser donado a la Iglesia por el rey Juan I de Castilla a don Fernando Suárez de Figueroa. ${ }^{5}$ Sabemos que el Episcopado se mantuvo allí hasta 1705, fecha en la que el obispo don Juan Marín de Rodezno (1681-1706) decidió su traslado debido a la explosión de un polvorín cercano. ${ }^{6}$ Se conserva en la entidad un expediente de la época que da prueba de este hecho. En él, el archivero, don Matías Sutil, manifestó que encontrándose en la Guerra de Sucesión cae una bomba que ocasionó graves daños al archivo. Esta situación hace que el que Obispado sea trasladado a un nuevo edificio, situado en la calle que unía el Campo de San Francisco con el de San Juan, el cual había sido donado por doña Ana Márquez Negrete. En estas dependencias se producen cambios importantes. El primero de ellos viene de la mano del obispo don Francisco Valero y Losa (1705-1715) que en 1707 nombró como archivero a don Antonio Gómez Fabra. La segunda de las medidas fue efectuada por el obispo don Pedro Francisco de Levanto y Vibando (1715-1729), estaba relacionada con la ubicación física del mismo, puesto que desde su instauración en las nuevas dependencias, se situaba en un cuarto en la planta baja, en el cual la humedad había hecho que más de

\footnotetext{
${ }^{4}$ Aldea Vaquero, Q.; Marín Martínez, T.; Vives Gatell, J. 1972-1987. Diccionario de Historia Eclesiástica de España. Madrid: Instituto Enrique Florez. I: 170-171; López López, T. 2000. «La diócesis de Badajoz: Historia ya conclusa.» Boletín de la Real Academia de Extremadura de las Letras y las Artes V; López López, T. 1999. Los obispos de Badajoz: catálogos y consagraciones. Coloquios Históricos de Extremadura, 1999; Sarmiento Pérez, J. 2005. Reforma beneficial en la Diócesis de Badajoz durante la crisis del Antiguo Régimen (1769-1841). Badajoz: Diputación Provincial; Solano de Figueroa y Altamirano, J. 1929-1932. Historia eclesiástica de la ciudad y obispado de Badajoz. Badajoz: Diputación; Ídem. 2013. Historia eclesiástica de la ciudad y obispado de Badajoz. Edición anotada por Francisco Tejada Vizuete. Badajoz: Diputación, Departamento de Publicaciones; Solar y Taboada, A. 1945. Historia eclesiástica de la ciudad y obispado de Badajoz, continuación de la escrita por Juan Solano de Figueroa. Badajoz; Suárez de Figueroa, D. 1976. Historia de la Ciudad de Badajoz. Badajoz.

${ }^{5}$ González Rodríguez, A. 1999. Historia de Badajoz. Badajoz: Universitas: 189-190.

${ }^{6}$ Asociación de Archiveros de la Iglesia. 2000. «Aportación del director del Archivo Diocesano don Eladio Menéndez Venegas.» Guía de los Archivos de la Iglesia en España, 2000.
} 
trescientos pleitos hubieran quedado reducidos a polvo. Por ello, se produce su traslado a la planta superior del edificio. ${ }^{7}$

Ya en el siglo XIX, la Revolución Francesa fue un hecho de terribles consecuencias para la Iglesia española y su patrimonio. El Obispado de Badajoz no se vio libró de ataques y en particular, su archivo fue asaltado. La invasión supuso la pérdida de un gran número de expedientes entre los que se encontraban actas de fundación de parroquias, conventos y documentación contable. ${ }^{8}$ En el siglo xx, la Guerra Civil Española (1936-1939) no supuso un motivo de pérdidas documentales importantes, puesto que el mayor deterioro que sufrieron los documentos fue por el caos que se produjo en el intento de salvaguardarlos. En la segunda mitad del siglo xx, el archivo sufre cuatro traslados. Más tarde, el Obispado adquiere la Casa del Cordón (1995), y traslada allí sus dependencias. Para el archivo se designa la parte sótano. ${ }^{9}$ El siglo XXI comienza como una etapa de cambios en la Archidiócesis de Mérida-Badajoz. En el 2003 es nombrado arzobispo don Santiago García Aracil. Su interés por salvaguardar el patrimonio eclesiástico y ponerlo a disposición de cuantos lo puedan necesitar, le ha llevado a tomar una decisión de suma relevancia. Se trata de la unificación de los fondos diocesano y catedralicio, con la perspectiva de que en un tiempo, los archivos de la Archidiócesis queden reunidos. ${ }^{10}$

El Archivo Diocesano de Mérida-Badajoz custodio de la documentacióN conVENTUAL FRANCISCANA FEMENINA

La documentación sobre conventos conservada en el fondo antiguo del ADMEBA se encuentra almacenada en legajos. En total, se distribuye entre 146, de los cuales 34 son procedentes del archivo del "Obispado," puesto que recogen documentación de localidades que, en el ámbito eclesiástico, han dependido del Obispado de Badajoz. Por su parte, los 112 legajos restantes se ubican en el archivo del "Priorato de San Marcos de León" y son los que custodian la documentación de localidades que pertenecían, hasta su desaparición en 1873, al Priorato que lleva su nombre.

Además, debemos señalar que se conservan 1495 agrupaciones documentales sobre conventos, distribuidas entre 85 entidades adscritas a 7 órdenes religiosas: San Agustín, San Francisco, Santo Domingo, Carmelo Descalzo, San Jerónimo,

\footnotetext{
${ }^{7}$ Ibídem, p. 38.

${ }^{8}$ Aldea Vaquero, Q.; Marín Martínez, T.; Vives Gatell, J. 1972-1987: 262-263.

${ }^{9}$ Montes, J. J. 2002. «Entrevista con don Eladio Méndez Venegas, Archivero Diocesano.» Revista Iglesia en Camino. 459: Contraportada.

${ }^{10}$ Información facilitada por don Francisco Tejada Vizuete, delegado episcopal del patrimonio de la Archidiócesis de Mérida-Badajoz, al periódico Hoy el sábado 4 de mayo de 2006.
} 
Santísima Trinidad y Compañía de Jesús. Dentro de este grupo de documentos hemos seleccionado los que se refieren a la orden de San Francisco y exclusivamente los que tienen que ver con su rama femenina, dado que los relativos a la masculina han quedado ya abordados en otros estudio,${ }^{11}$ para establecer una investigación que abordará principalmente dos objetivos: por un lado, la confección de un catálogo de documentos franciscanos; y por otro, el análisis de esta documentación en el que serán expuestas las características resultantes de carácter cuantitativo, topográfica, idiomático, temático, etc.

\section{Documentación manuscrita o impresa}

Si abordamos la documentación emitida por los conventos franciscanos femeninos por su condición de ser manuscrita o impresa podemos afirmar que existe un predominio absoluto de los documentos que han sido redactados a mano frente a los impresos. Se conservan 716 agrupaciones documentales manuscritas $(99,8 \%)$ frente a un documento $(0,2 \%)$ que incorpora una parte manuscrita y otra impresa. ${ }^{12}$ Este último es la secularización perpetua de una religiosa perteneciente al convento de las Mercedes Descalzas de la ciudad de Badajoz. Naturalmente, los documentos manuscritos abordarán todo tipo de contenidos (secularizaciones, cuentas, elecciones, visitas, educandas, pleitos, etc.), así como presentarán un eje cronológico amplísimo que se extenderá desde el siglo XVI al XX.

\section{Análisis cronológico}

En lo referente al análisis cronológico, la documentación se distribuye entre un amplio margen que abarca desde el siglo XVI al siglo Xx. De estos últimos cabe señalar que son documentos que no llevan una fecha de datación exacta y que han sido encuadrados en este periodo por los hechos a los que hacen referencia. Suponemos que los 9 casos que encontramos, que representan el 1,3\% de la documentación, se sitúan muy a principios de este siglo. Respecto al resto de la documentación reseñar que existen 4 documentos cuya fecha de datación se fija en el siglo XVI (0,5\%), 110 documentos en el siglo XVII (15,3\%), 109 lo hacen en el siglo XVIII $(15,2 \%)$, concentrándose el mayor volumen documental en el siglo XIX con 458 documentos $(63,8 \%)$. Además, aparecen 7 agrupaciones documentales que carecen de fecha de datación $(3,9 \%)$.

\footnotetext{
${ }^{11}$ Respecto a la documentación franciscana emitida por conventos franciscanos masculinos brevemente indicar que en el fondo antiguo del Archivo Diocesano de Mérida-Badajoz se custodian un total de 174 agrupaciones documentales sobre la rama masculina de la orden de san Francisco, tanto de la rama Descalza (93 agrupaciones documentales) como de la Observante (81 agrupaciones).

${ }^{12}$ Véase doc. 55.
} 
Estudiar cronológicamente la documentación sería una tarea específica que a buen seguro pondría de manifiesto datos muy interesantes sobre esta orden. Sin embargo, es este estudio queremos presentar exclusivamente los datos más significativos. Por ello, dentro de este apartado queremos hacer mención al siglo XIX dado su amplio volumen y en especial al periodo que abarca desde 1821 a 1836 por su mayor volumen documental. Esta situación viene respaldada por una época muy significativa para la Iglesia católica y la conventualidad española. Muchas reformas y vaivenes sufrieron por estas fechas nuestros conventos. Especialmente duras fueron muchas medidas cuando fueron aplicadas a entes femeninas, que por aquel entonces ganaban en número y en población a las masculinas. La documentación da prueba de ello. Son especialmente abundantes, en este marco cronológico, los expedientes de secularización que llevaban a las religiosas franciscanas a solicitar su salida de la orden. Este hecho ocurría de forma similar cuando analizábamos la situación en la conventualidad franciscana masculina.

\section{Análisis topográfico}

En lo referente a la topografía debemos señalar que es muy variada. Este hecho nos lleva a establecer subdivisiones que nos permitan acercarnos al entramado geográfico que la documentación presenta. Por ello, hemos establecido tres grandes subdivisiones: provincia de Badajoz, otras localidades españolas y Roma.

Provincia de Badajoz: son los documentos en que aparecen poblaciones pertenecientes a la provincia de Badajoz los que se muestran en un mayor número de ocasiones. Hemos contabilizado 37 localidades que aparecen en más de 800 ocasiones (Zafra, Mérida, Almendralejo, Jerez de los Caballeros, Fregenal de la Sierra, Llerena, Badajoz, Los Santos, Fuentes de León, Fuente del Maestre, Oliva de la Frontera, Higuera la Real, Segura de León, Bienvenida, Campanario, Alburquerque, etc). De entre ellas cabe destacar sobre manera las poblaciones de Badajoz (184 apariciones) y Llerena (235 apariciones). Este hecho queda respaldado en que ambas localidades son cabeceras de las jurisdicciones eclesiásticas, que hasta la ejecución de la Bula Quo Gravius, existían en la provincia de Badajoz. El resto de localidades se muestran porque de ellas provienen conventos y religiosos franciscanos.

Otras localidades españolas: queremos reflejar aquí otras poblaciones que están fuera del ámbito extremeño. El número de localidades y de apariciones desciende considerablemente. Las ciudades que aparecen en la documentación son: Madrid (57 apariciones), Sevilla (1), Galaroza (1), Guadalcanal (2), Aracena (2), Almodóvar del Campo (1) y Palma del Río (1). En cuanto a la procedencia madrileña, la más importante, se debe a que son varios los documentos emitidos tanto por el Ministerio de Gracia y Justicia (vertiente civil), como por la Nunciatura Apostólica Española (vertiente eclesiástica). 
Roma: es la tercera de las categorías establecidas presentando una significación escasa dado que aparece únicamente en tres ocasiones. Son documentos específicos que tienen que ver con resoluciones que van a ser aplicadas en conventualidades franciscanas extremeñas

\section{Análisis de contenido}

Comenzaremos este apartado con una gran tabla que mostrará los conventos franciscanos femeninos de los que existe alguna documentación en el Archivo Diocesano de Mérida-Badajoz y el volumen de documentos producidos por cada una de estas entidades

Tabla I

CONVENTOS FRANCISCANOS FEMENINOS QUE APARECEN EN DOCUMENTOS DEL ARCHIVO DIOCESANO DE MÉRIDABADAJOZ: volumen documental

\begin{tabular}{|l|l|r|}
\hline \multicolumn{1}{|c|}{ CONVENTO } & \multicolumn{1}{|c|}{ LOCALIDAD } & DOC \\
\cline { 1 - 2 } Concepción & Almendral & 12 \\
\hline Santa Clara & Almendralejo & 31 \\
\hline Nuestra Señora de las Mercedes & Badajoz & 51 \\
\hline Monasterio de Santa Ana & Badajoz & 32 \\
\hline La Asunción & Barcarrota & 14 \\
\hline Santa Clara & Campanario & 1 \\
\hline Santa Clara & Fregenal de la Sierra & 12 \\
\hline La Santísima Trinidad & Jerez de los Caballeros & 14 \\
\hline Nuestra Señora de Gracia & Jerez de los Caballeros & 22 \\
\hline Santa Clara & Llerena & 59 \\
\hline Santa Isabel & Llerena & 42 \\
\hline Santa Clara & Mérida & 2 \\
\hline Santa Clara & Montijo & 10 \\
\hline Santa Clara & Villafranca de los Barros & 24 \\
\hline Santa Clara & Zafra & 12 \\
\hline TOTAL CLARISAS & & 346 \\
\hline
\end{tabular}

Hispania Sacra, LXVII

135, enero-junio 2015, 61-168, ISSN: 0018-215X, doi: 10.3989/hs.2015.003 


\begin{tabular}{|c|c|c|c|}
\hline CONVENTO & LOCALIDAD & DOC & \multirow{10}{*}{ Concepcionistas } \\
\hline Concepción & Almendralejo & 11 & \\
\hline Concepción & Cabeza del Buey & 24 & \\
\hline Concepción & Fuente de Cantos & 27 & \\
\hline Concepción & Fuente del Maestre & 42 & \\
\hline Concepción & Llerena & 31 & \\
\hline Concepción & Mérida & 58 & \\
\hline Limpia Concepción & Segura de León & 90 & \\
\hline Concepción & Valencia del Ventoso & 14 & \\
\hline Concepción & Villanueva de la Serena & 21 & \\
\hline TOTAL CONCEPCIONISTAS & & 258 & \\
\hline Concepción & Bienvenida & 19 & \multirow{10}{*}{$\begin{array}{l}\text { Tercera Orden } \\
\text { franciscana }\end{array}$} \\
\hline Santa Lucía & Badajoz & 23 & \\
\hline Concepción & Burguillos & 29 & \\
\hline Madre de Dios & Jerez de los Caballeros & 29 & \\
\hline Nuestra Señora de la Luz & Jerez de los Caballeros & 10 & \\
\hline Consolación & Jerez de los Caballeros & 26 & \\
\hline Nstra. Sñra de la Esperanza & Jerez de los Caballeros & 6 & \\
\hline Santa Marina & Zafra & 5 & \\
\hline La Cruz de Cristo & Zafra & 5 & \\
\hline Concepción & Zalamea de la Serena & 1 & \\
\hline TOTAL TERCERA ORDEN & & 112 & \\
\hline
\end{tabular}

Como puede observarse en relación a las entidades conventuales en la geografía de la Baja Extremadura, y siempre según la documentación ubicada en este archivo, existieron mayor número de entidades pertenecientes a la rama de clarisas franciscanas (15 entidades con 346 conventos) que a la de concepcionistas ( 9 entidades con 258 conventos) y a la tercera orden (10 entidades con 112 documentos). 
Veamos los contenidos principales por conventos:

Convento de la Purísima Concepción de Almendral. Los dos únicos documentos que de esta entidad se conservan permiten el estudio de las profesiones perpetuas de las novicias María del Carmen Pérez y Sinforosa Guzmán.

Convento de Santa Clara de Almendralejo. De este convento existe una importante documentación que permite el estudio de los siguientes contenidos:

- Salida conventual de religiosas destino Baños de Alange para el restablecimiento de salud. Es una documentación que aparece únicamente en esta entidad.

- Reparaciones conventuales. La documentación da constancia de las obras que se efectuaron entre 1858 y 1861 con varios documentos.

- Tomas de hábito y profesiones de la religiosas: $\mathrm{M}^{\mathrm{a}}$ Piedad Nieto, Florencia Pilar, Ma Concepción Murillo, Matilde Gómez, Ramona González, Amalia Vargas y $\mathrm{M}^{\mathrm{a}}$ Amparo Sánchez.

- Secularizaciones perpetuas de María González e Isabel Sánchez. No se incluyen las causas de solicitud.

- Elecciones conventuales para determinar el cargo de abadesa.

- Índice de religiosas y cargos. Es una documentación abundante en el siglo XIX cuando tras las reformas se solicita con asiduidad a los conventos den prueba de su configuración para su mantenimiento o supresión.

Convento de Nuestra Señora de las Mercedes Descalzas de Badajoz. De esta importante entidad, presente a día de hoy en la ciudad de Badajoz, se conservan documentos que nos permiten analizar un nutrido conjunto de temas:

- Pleitos con particulares por propiedades y con otros conventos. Prueba de ello es el litigio que mantuvo con el convento de Santa Lucía por una deuda.

- Elecciones y restructuración de cargos conventuales.

- Reparación conventual tras la ocupación de las tropas francesas al convento que fue utilizado durante un tiempo como cuartel de las mismas. Se trata de una documentación singular que pone de manifiesto unos hechos históricos que se dieron en un escaso número de ocasiones y que sin duda serán de interés para muchos historiadores.

- Tomas de hábitos y profesiones de María Santo Toribio, María Fernández, Francisca Javiera y Rafaela Martínez. 
- El tema que mejor puede ser analizado tomando esta conventualidad es el de las secularizaciones perpetuas dado que aparece hasta en 15 ocasiones: Antonia Fabia, $\mathbf{M}^{\mathrm{a}}$ Rodríguez, Juana y Micaela Vázquez, Rosalía de la Presentación, María Rodríguez, Ana García, María Henríquez, Ma Carmen Sáez, $M^{\mathrm{a}}$ Carmen Martínez, Isabel Fernández, M $^{\mathrm{a}}$ Pilar Martín, $\mathbf{M}^{\mathrm{a}}$ Soledad Martín, Juana Alvarado y Juana Domínguez.

- Además puede ser analizado el tema de menores de edad que entran en clausuras para su formación espiritual y académica en los expedientes de Antonia Fabra y $\mathrm{M}^{\mathrm{a}}$ Pilar Barbosa.

Convento de Santa Ana de Badajoz. El vigente convento de franciscanas permite el estudio de los siguientes temas:

- Pleitos. Los documentos que de esta temática se conservan enfrentan al convento con particulares por incumplimiento de censos, testamentos y por deudas.

- Inspecciones a la clausura para estudiar la observancia de la Regla.

- Entrada de la educanda Inés Paula Ramona, de la que no se conserva ningún otro documento que de prueba de su trayectoria.

- Secularizaciones. Se conserva de este convento la secularización temporal de la religiosa $\mathrm{M}^{\mathrm{a}}$ Pilar Núnez y las perpetuas de las religiosas Rita Laguna, Ramona Laguna, Josefa Delgado, $\mathrm{M}^{\mathrm{a}}$ Bárbara Domaica y Ana Blanco.

- El tema que mejor puede ser estudiado en relación a este convento dado al volumen documental es el de las tomas de hábito y profesiones. Aparece hasta en 12 ocasiones: $\mathrm{M}^{\mathrm{a}}$ Núñez, Benigna Gutiérrez, $\mathrm{M}^{\mathrm{a}}$ de la Asunción, Fernanda Domínguez, Teresa de la Asunción, $\mathrm{M}^{\mathrm{a}}$ Dolores Rubiales, Isabel Rubio, Bonifacia Enríquez, Ana Caballero, Felipa Riofrío, Ana de Bernarda e Isabel Núñez.

Convento de la Asunción de Barcarrota. De esta entidad conventual conservamos documentación relacionada con tres contenidos:

- Religiosas enclaustradas. Se trata de dos relaciones nominales que se solicitan para dar constancia de la composición del convento en el siglo XIX.

- Tomas de hábitos y profesiones perpetuas de las religiosas: Josefa de la Concepción, $\mathrm{M}^{\mathrm{a}}$ Coriana, $\mathrm{M}^{\mathrm{a}}$ Josefa Soriano, Josefa Mendoza, Francisca de Santa Teresa, Josefa Flores, Francisca Hernández, Ma de Santa Rita, M ${ }^{\mathrm{a}}$ Febrero, $\mathrm{M}^{\mathrm{a}}$ del Corazón de Jesús y Ana de Chaves.

- Readmisión de las secularizadas María Dolores Pedroso y Josefa Palomo. No es un tema habitual, y por ello queremos reflejar la importancia de que aparezca en esta entidad, el que religiosas secularizadas pidan su readmisión 
al convento. Normalmente las que solicitaban una secularización temporal, como debe ser el caso, tiempo después pedían la permanente.

Convento de Santa Clara de Campanario. El único documento que de esta entidad se conserva es la relación de las religiosas enclaustradas que se solicita en el siglo XIX para dar constancia de la situación poblacional de la clausura.

Convento de Santa Clara de Fregenal de la Sierra. Aunque no se conserva una abundante documentación la existente nos permite el estudio de los siguientes temas:

- Tomas de hábito y profesiones de $\mathrm{M}^{\mathrm{a}}$ Jaramillo, $\mathrm{M}^{\mathrm{a}}$ Pilar Infame, Ana Hurtado, Josefa Armijo y Antonia Herrera.

- Traslado de religiosas por supresión del convento al de la misma orden de Montijo.

- Elecciones conventuales.

- Nómina de enclaustradas.

Convento de la Santísima Trinidad de Jerez de los Caballeros. Como en el caso anterior no es una documentación abundante aunque nos permite analizar las siguientes temáticas:

- El tema fundamental en esta conventualidad, como en otras muchas, es el relativo a tomas de hábito y profesiones perpetuas con 8 expedientes: $\mathrm{M}^{\mathrm{a}}$ Carmen Bustos, Francisca Aparicio, Manuela Aparicio, M ${ }^{\mathrm{a}}$ Dolores López, $\mathrm{M}^{\mathrm{a}}$ Josefa Chacón, Mariana López, Antonia Quevedo e Inés Gómez.

- Otra documentación: relación de religiosas enclaustradas, venta de tierras pertenecientes al convento para subsistencia y fundación de capellanía.

Convento de Santa Clara de Llerena. Sobre esta entidad se conserva una abundante documentación que nos permite el estudio de las siguientes cuestiones:

- Educandas. Son abundantes los expedientes de niñas que ingresan en el convento para su formación integral: Lucía Núñez, Luisa Yanes, Rita Fernández y Antonia Durán. No existe documentación posterior de ninguna de ellas.

- Exploración de voluntades. Aparece por primera vez esta temática en las conventualidades franciscanas femeninas. Son documentos que acreditan los deseos que llevan a las religiosas a querer profesar en la orden franciscana. Se conserva un nutrido conjunto: Vicenta Chávez, Leonor Chávez, $\mathbf{M}^{\mathrm{a}}$ de Retamosa, Juana Vera, Isabel Herrera, $\mathbf{M}^{\mathrm{a}}$ José Gómez, Ana Vera, Antonia Hererra, Dolores Gallardo, Josefa Pérez, Teresa Lacodre y Teresa Rufo. 
- Secularizaciones perpetuas de Carmen Moriño y María Belarde.

- Cuentas. Existe una nutrida documentación que nos permite el estudio de la economía conventual en los años 1853 a 1876. Podemos observar las dificultades económicas por las que fueron atravesando.

- Otra documentación. Además, en menor medida, encontramos pleitos por deudas con particulares, ventas de propiedades conventuales para subsistir y cuestiones relativas a herencias, bienes y obras pías.

Convento de Santa Isabel de Llerena. De este conventual se conserva una abundante documentación que da prueba de la importancia que la entidad tuvo:

- Cuentas. Aparecen dos expedientes que nos permiten analizar su situación económica en dos fechas dispares: 1554 y 1727 . Por tanto, de los escasos documentos que de franciscanas se custodian del siglo Xvi uno de ellos se sitúa en esta entidad.

- Exploración de voluntades de novicias próximas a profesar. Se trata de un tema ampliamente respaldado por varios documentos, los que se refieren a: Úrsula Liasa, Clara Delgado, Manuela Ferrán, Antonia Molano, Antonia Asensio, Antonia Maeso, Juana Moreno, Antonia Pérez, Catalina Soto, Ana Miranda, Ana González, M ${ }^{\mathrm{a}}$ Encarnación Jara, M ${ }^{\mathrm{a}}$ Lara, Ma Manuela Montero y $\mathrm{M}^{\mathrm{a}}$ Josefa Jara.

- Secularizaciones perpetuas. Como en el caso anterior son varios los documentos que de esta temática se custodian: Antonia cabeza, Josefa de Figueroa, $M^{\mathrm{a}}$ Rodríguez, Joaquina de San Francisco y María Josefa López.

- Documentación económica. Es de singular importancia esta documentación dad • o que son expedientes que manifiestan donaciones que las religiosas o sus familiares han realizado al convento por vía herencia, censo o testamento. Lo cotidiano es que fueran personas ajenas al convento las que realizaran este tipo de donaciones.

- Otra documentación. Además podemos analizar documentos sobre deudas, salidas conventuales de las religiosas, arrendamientos de tierras y traslado de la comunidad tras el cierre de la entidad a otro conventual en Mérida.

Convento de Santa Clara de Mérida. La documentación que de la entidad se conserva en el archivo nos muestra los siguientes contenidos:

- Cuentas. Por medio de tres documentos nos acercamos a la realidad económica de la entidad a principios del siglo XVII.

- Venta de propiedades conventuales. No era inusual que las entidades conventuales vendieran algunas de sus pertenencias para poder subsistir, 
especialmente en determinados momentos. En este documento se nos muestra la venta de una casa.

- Salida de clausura de religiosas temporalmente.

- Traslados. Aparecen tres expedientes que muestran como varias religiosas de esta entidad son trasladas, bajo su petición, al convento de Santa Clara de Montijo. Este proceso lleva una serie de trámites que tenían que ser validados en el obispado.

- Secularizaciones perpetuas. Como en el resto de entidades existe una abundante documentación sobre esta materia. Así encontramos los expedientes de: María Morgado, Josefa Salgero, Isabel González y Antonia Vallejo.

Convento de Santa Clara de Montijo. Los contenidos que pueden ser analizados tomando como base la documentación de esta entidad en el archivo son:

- Toma de hábito de Isidora Vargara.

- Salida temporal de la religiosa María Gragera.

- Secularización perpetua de la religiosa Valentina de san Antonio.

- Nómina de religiosas enclaustradas.

- Traslado de religiosas. Nos referimos a los tres expedientes que fueron tramitados desde el convento de santa Clara de Mérida para que tres religiosas de su clausura pudieran ser admitidas en esta montijana. El análisis de esta documentación nos permite observar la continuidad del proceso, hecho que en muchos casos no es posible.

Convento de Santa Clara de Villafranca de los Barros. Los contenidos que quedan patentes tras el análisis de esta documentación son fundamentalmente:

- Tomas de hábito y profesiones perpetuas. Como en otras entidades existe un nutrido conjunto de documentos al respecto: Isabel Alvarado, Teresa Gordillo, $\mathbf{M}^{\mathrm{a}}$ Encarnación Berjano, $\mathrm{M}^{\mathrm{a}}$ Antonia Díaz, $\mathrm{M}^{\mathrm{a}}$ Gordillo, $\mathrm{M}^{\mathrm{a}}$ Antonia Morales, Isabel González, María Antúnez.

- Cuentas. La economía conventual del siglo XVII puede quedar perfectamente analizada si tomamos como base la documentación que se alberga al respecto.

- Elecciones conventuales. Son varios los procesos electorales que pueden ser estudiados acercándonos al funcionamiento del organigrama conventual (1801-1821-1830).

- Cuestiones económicas. Por una parte podemos analizar documentos que nos muestran la llegada de bienes al convento por diferentes vías: 
donaciones, testamentos, capellanías, etc. y por otra, analizaremos también las necesidades conventuales que les llevan a la venta de algunos de estos bienes para subsistir.

Convento de Santa Clara de Zafra. De esta entidad se custodian documentos sobre:

- Profesiones perpetuas. Existe un nutrido grupo al respecto: Guadalupe Toro, $\mathrm{M}^{\mathrm{a}}$ Antonia Rodríguez, $\mathrm{M}^{\mathrm{a}}$ Natividad González, Tomasa Gómez, Francisca Méndez y Josefa Carrasco.

- Educandas. Existe únicamente un expediente, el relativo a la niña María José Berjano que entra en el convento para su formación.

- Relación nominal de enclaustradas. Documentación que aparece en muchas ent • idades y que es consecuencia de la situación que atravesaron los conventos en el siglo XIX.

Convento de la Concepción de Almendralejo. De esta entidad se custodia en el archivo documentación sobre:

- Cuentas. Se trata del grupo más voluminoso, permitiéndonos un estudio exhaustivo de las cuestiones económicas que afectaron al convento en el siglo XVII.

- Otra documentación: además podemos acceder a documentos sobre pleitos, deudas, inspección de clausura y elecciones.

Convento de la Concepción de Cabeza del Buey. La escasa documentación que de esta entidad se conserva nos acerca a la relación de enclaustradas de dicho convento durante el siglo XIX.

Convento de la Concepción de Fuente de Cantos. No son muchos los documentos que se custodian de esta entidad. Los existentes nos acercan a la venta de tierras, solares y casas para la subsistencia del convento y a cuentas de principios del siglo XVII.

Convento de la Concepción de Fuente del Maestre. Existe un grupo importante de documentos relativos a esta entidad. Su análisis nos permite conocer con mayor profundidad las siguientes temáticas conventuales:

- Cuentas. El gran número de documentos sobre contabilidad conventual existente nos acerca a un conocimiento muy preciso de la realidad económica vivida por la entidad durante el siglo XVII y XVIII.

- Elecciones. Aparece un significativo conjunto de documentos sobre elecciones que nos permiten conocer los procesos electorales llevados a término en $1735,1760,1802,1824,1827$. 
- Educandas. Accedemos a la entrada conventual de las menores María Sánchez y Cándida Sánchez, por orfandad.

- Profesiones perpetuas. Como en otras entidades existe documentación sobre esta temática. Se trata de las profesiones de $\mathrm{M}^{\mathrm{a}}$ Granada Ruiz, Julia Mármol y Gregoria Fernández.

- Otra documentación: además, aparecen documentos sobre enclaustradas, pleitos y dotes. Hasta el momento no habíamos accedido a documentación sobre dotes. No por ello debemos olvidar la importancia de dicho proceso en las clausuras.

Convento de la Concepción de Llerena. De esta entidad existen en el archivo un importante grupo de documentos que nos acercan a las siguientes temáticas:

- Pleitos. Ponen de manifiesto las disputas surgidas entre la entidad y particulares, incluso el propio mayordomo conventual, por cuestiones relativas a deudas e impagos.

- Exploración de voluntades. Como en otros casos se conservan estos documentos que nos acercan al espíritu y deseos que llevan a las novicias a querer profesar en la orden. Existen los relativos a: Ana Mencía, $\mathbf{M}^{\mathrm{a}}$ Contador, $\mathrm{M}^{\mathrm{a}}$ Godoy, Josefa de san Lorenzo, Inés Contador, $\mathrm{M}^{\mathrm{a}}$ Dolores Martín.

- Secularizaciones perpetuas. Al contrario que en otras entidades únicamente existen dos expedientes: Juana Nepomuceno y Antonia Zambrano.

- Dotes. Como en otro convento anterior aparece documentación sobre dotes, acercándonos a este proceso que fue vital dentro de las clausuras.

- Otra documentación: existen también documentos sobre herencias, salidas de clausuras y elecciones conventuales.

Convento de la Concepción de Mérida. De este convento se conserva un importante grupo de documentos que nos permiten acceder a un variado grupo de temáticas:

- Cuentas. La abundante documentación que de este tema se conserva nos permite acceder a la realidad económica que se vivió en la entidad durante principios del siglo XVII y la última mitad del siglo XIX.

- Tomas de hábito y profesiones. Es sin lugar a dudas el tema más importante dentro de esta entidad dado que aparece en muchas ocasiones: Juana Bautista, Juana Berruta, Ana $\mathrm{M}^{\mathrm{a}}$ Moreno, Ana Zamora, Francisca Torrado, $\mathrm{M}^{\mathrm{a}}$ Dolores Muñoz, Josefa Caballero, Isabel Pin, Petra Viso, Sebastiana Pimentel, Francisca Vélez, Gabriela Ávalos y Gabriela Muñoz. 
- Índice de religiosas. Se trata de un tema que aparece en repetidas ocasiones. No es más que una relación nominal de las religiosas que habitaban la clausura durante el siglo XIX. Su redacción era fundamental para controlar la población conventual y así poder tomar medidas supresoras si el volumen de la misma descendía.

- Exploración de voluntades de las novicias Josefa Monago y Rota Ocas.

- Otros documentos: existen contenidos sobre pleitos, nombramientos de capellanes y elecciones.

Convento de la Concepción de Segura de León. Se conserva una abundante documentación relativa a esta entidad que nos permite el estudio de las siguientes cuestiones:

- Tomas de hábito y profesiones. es la temática de la que se conserva un mayor volumen documental. Nos permite conocer los procesos de: $\mathrm{M}^{\mathrm{a}}$ Ramírez, $\mathrm{M}^{\mathrm{a}}$ Rodríguez, $\mathrm{M}^{\mathrm{a}}$ Garrido, Antonia de Cristo, $\mathrm{M}^{\mathrm{a}}$ de Velasco, Josefa Espinosa, Catalina de Santa Teresa, Catalina Rodríguez, Catalina de la Asunción, Juana Rodríguez, Ángela Melado, Mª Dolores Márquez, Beatriz Núñez y Ma Ignacia Velasco.

- Educandas. La entrada de menores de edad en las clausuras fue un hecho habitual en las clausuras de antaño. Prueba de ello son las incorporaciones de las niñas: $\mathrm{M}^{\mathrm{a}}$ Ramona Carrasco, Francisca Lergo y $\mathrm{M}^{\mathrm{a}}$ de la Concepción.

- Cuentas. Es otro de los temas más importantes relativos a esta entidad dado que el amplio volumen de documentos nos permite conocer la situación económica desde el siglo XVII al XIX.

- Dotes. Como en otros conventos las dotes conventuales son nuevamente un hecho que genera abundante documentación. Esta entidad de prueba de ello.

- Elecciones conventuales. Los procesos electorales pueden ser analizados en varias fechas partiendo de esta documentación.

- Otros documentos: existen además pleitos, ventas de propiedades para subsistencia, inspecciones, documentos que acreditan la voluntad de los fundadores, etc.

Convento de la Concepción de Valencia del Ventoso. De esta entidad pueden ser analizadas dos cuestiones fundamentalmente:

- Educandas. Es decir, los expedientes de menores de edad que ingresaban en las clausuras, en estos casos, por orfandad: $\mathrm{M}^{\mathrm{a}}$ Hidalgo, $\mathrm{M}^{\mathrm{a}}$ Delgado y Sabrina Barroso. 
- Tomas de hábito y profesiones. Existe un nutrido conjunto de documentos al respecto: Gregoria García, Dolores Sánchez, Alejandra Noriega, Aureliana Abuja, María Marín, María de Santa Teresa, Ma Rosario Sáenz, María Soriano y María Bellido.

Convento de la Concepción de Villanueva de la Serena. El único documento que se conserva de dicha entidad es la relación de enclaustradas que a mediados del siglo XIX fue requerida a todas las clausuras.

Convento de la Concepción de Bienvenida. La documentación que de esta entidad se conserva nos acerca a las siguientes temáticas:

- Exploración de voluntades. Como ya hemos analizado en otros conventos se trata de cuestionarios que se realizaban a novicias próximas a profesar para analizar sus deseos. De este convento se custodian 4 expedientes: Juana Macías, Leonor Herrera, Ana Coca y Gervasia Álvarez.

- Secularizaciones perpetuas. Al igual que en otros muchos conventos las secularizaciones perpetuas aparecen en esta entidad: Antonia Vemero, Juana Benero, las hermanas Teresa y María José Chaves que aducen la necesidad de cuidad a sus padres enfermos y $\mathrm{M}^{\mathrm{a}}$ Carmen Pardillo.

- Pleitos. Guarda este convento una interesante documentación sobre un pleito que puso en discordia al convento con el alcalde de Usagre por la pertenecía de unas tierras.

Convento de Santa Lucía de Badajoz. De esta desaparecida entidad conventual pacense se conservan contenidos sobre:

- Tomas de hábito y profesiones. Como en la mayoría de conventos franciscanos femeninos aparece este tipo de documentación en los casos de: Joaquina Rita, Isabel de los Dolores y Rosa María Águeda.

- Pleitos. Existe una interesante documentación relativa a esta temática que ponen de manifiesto al convento como demandante ante otros conventos y un hospital de la ciudad de Badajoz y como demandado por un particular por cuestiones de deudas.

- Inspecciones. Aparecen en esta entidad dos visitas efectuadas por el obispo Marín de Rodezno para inspección de la clausura que aportan datos relevantes. Se trata de una documentación que no había aparecido hasta el momento dado que otras visitas de las que aquí hemos hecho alusión no habían sido efectuadas por obispos.

- Elecciones. Existe un grupo de documentos que nos acerca al proceso de reestructuración del organigrama conventual en varios periodos. 
Convento de la Concepción de Burguillos. Sobre este convento se conserva una documentación muy específica:

- Tomas de hábito y profesiones. De los 9 expedientes que se conservan sobre esta entidad franciscana 8 pertenecen a esta temática. Así pueden ser estudiados los casos relativos a: Josefa Navarro, Isabel Ma Martínez, Ana María Arteaga, Carmen Carvajal, Mª Josefa Carretero, Basilia Galván, Beatriz Piña y $\mathrm{M}^{\mathrm{a}}$ Caballero.

- Enclaustradas. Como en una mayoría de entidades existe un documento del siglo XIX que expone nominalmente las religiosas enclaustradas de la entidad.

Convento de Madre de Dios de Jerez de los Caballeros. De esta entidad jerezana se conserva una documentación que nos acerca a los siguientes contenidos:

- Tomas de hábito y profesiones perpetuas. Se custodian hasta 4 expedientes al respecto. Los relativos a: $\mathrm{M}^{\mathrm{a}}$ Josefa Galán, Josefa Barreto, $\mathrm{M}^{\mathrm{a}}$ Martínez y Rosalía Navarro.

- Salida de clausura. Se trata de un expediente que pone de manifiesto la salida temporal de la religiosa Brígida Quevedo. La importancia de esta documentación es que poco después la religiosa solicita su secularización perpetua. De este modo y tras el análisis de ambos documentos podemos fijar una continuidad de procesos.

- Secularizaciones perpetuas. Como ya hemos señalado se conserva la secularización de Brígida Quevedo, de su hermana $\mathrm{M}^{\mathrm{a}}$ Concepción y de las religiosas $\mathrm{M}^{\mathrm{a}}$ Coba y $\mathrm{M}^{\mathrm{a}}$ Pilar Conejo.

Convento de Nuestra Señora de la Luz de Jerez de los Caballeros. De esta otra entidad jerezana se conserva una documentación que permite el estudio de las siguientes temáticas:

- Tomas de hábito y profesiones. Como ocurre en la gran mayoría de entidades femeninas la documentación sobre profesiones siempre aparece. En este caso con tres expedientes: Micaela Marín, Joaquina Marino, $\mathbf{M}^{\mathrm{a}}$ Ángeles Bermejo.

- Secularizaciones perpetuas. Se trata de otra de las temáticas por antonomasia de la documentación franciscana femenina. En este caso con 4 expedientes: Ana Soto, Josefa López, Vicenta Triviño y $\mathrm{M}^{\mathrm{a}}$ Jara.

- Otra documentación: salidas temporales de clausuras, nómina de enclaustradas y admisiones conventuales. Este último documento es significativo dado que se data en 1813 fecha en la que los conventos solían estar experimentando el fenómeno contrario, es decir, salidas de clausuras y 
secularizaciones. Sin embargo de esta entidad se conserva un documento que da fe de la entrada de nuevas religiosas a la entidad a principios del siglo XIX.

Convento de la Consolación de Jerez de los Caballeros. Existe una abundante documentación sobre esta entidad que nos acerca a los siguientes contenidos:

- Tomas de hábito y profesiones perpetuas. Como en el resto de conventuales donde aparecen más de un documento, las tomas de hábito se convierten en temática de suma importancia. De esta entidad se conservan 8 expedientes: Josefa Cano, Josefa Becerra, Agustina Meléndez, Mónica Menéndez, $\mathbf{M}^{\mathrm{a}}$ Encarnación Pérez, Isabel Vázquez, $\mathrm{M}^{\mathrm{a}}$ Isabel y Feliciana Pimentel.

- Secularizaciones perpetuas de las religiosas Inés Pallejo y Mónica Menéndez. Hecho significativo dado que sólo ocurre en este conventual, en el archivo se conserva el documento por el que la religiosa Mónica Menéndez toma sus hábitos en la entidad y años después queda secularizada.

- Otra documentación. Aparece documentación sobre cuentas del siglo XIX, pleitos, elecciones conventuales, relación de religiosas enclaustradas y visita obispal. En este caso es el obispo don Mateo Delgado Moreno el que inspecciona la clausura. Destacar esta visita dado que en toda la documentación franciscana femenina solo se llevan a término dos visitas obispales, la que acabamos de citas y la del obispo Marín de Rodezno. En el resto de casos son emisarios los que las ejecutan.

Convento de Nuestra Señora de la Esperanza de Jerez de los Caballeros. De este convento jerezano se conservan en el archivo diocesano documentos que permiten el estudio de las siguientes cuestiones:

- Tomas de hábito y profesiones perpetuas. Como en el resto de caso son los expedientes personales de las religiosas: $\mathrm{M}^{\mathrm{a}}$ Carmen Montero, Francisca de Santa Isabel, $\mathrm{M}^{\mathrm{a}}$ Carmen de San Francisco, $\mathrm{M}^{\mathrm{a}}$ Concepción Soler y Antonia de san Cayetano.

- Otra documentación: además se conserva la solicitud de salida temporal de la clausura de la religiosa $M^{a}$ Concepción Jara para su restablecimiento de salud y la secularización perpetua de María Paruano.

Convento de Santa Marina de Zafra. Los documentos que de esta entidad se conservan nos acercan a los siguientes contenidos:

- Profesión perpetua de la religiosa Isabel de San Francisco. De la que no se conserva su expediente de toma de hábito. 
- Enclaustradas. Aporta este convento además de la relación general de las religiosas enclaustradas en el siglo XIX dos expedientes particulares, los que se refieren a las religiosas Juana López y a $\mathrm{M}^{\mathrm{a}}$ Teresa López. Se trata de un caso singular dado que lo normal, como ya habrán observado, son relaciones nominales generales.

Convento de la Cruz de Cristo de Zafra. Se trata de una documentación homogénea dado que únicamente se conservan los expedientes de tomas de hábito y profesiones de las religiosas Ángela de las Eras, Manuela Rastrollo, Ana Ma Loza, Dionisio de la Encarnación y Vicenta Jiménez.

Convento de la Concepción de Zalamea de la Serena. El único expediente que se conserva pone de manifiesto la relación nominal de religiosas enclaustradas en esta entidad durante el siglo XIX.

\section{Conclusiones}

- En primer lugar, señalar la importancia que la conventualidad femenina franciscana tuvo en la Baja Extremadura desde el siglo XVI al siglo XIX. De ello dan debida prueba los más de 700 documentos pertenecientes a las 34 entidades religiosas de las que el Archivo Diocesano de Mérida-Badajoz guarda documentación.

- En segundo lugar, la conventualidad franciscana femenina aporta a la investigación todo tipo de contenidos relacionados con el panorama religioso conventual desde los siglos XVI al XIX. A través del fondo estudiado se puede acceder a un conocimiento exhaustivo del funcionamiento interno y externo de un convento franciscano, cuestión que puede ser extrapolada a cualquier otra orden religiosa.

- En tercer lugar, se da una notoria primacía de la conventualidad franciscana femenina tanto en número de entidades como en documentación respecto a la rama masculina de la orden franciscana.

- Por último, los contenidos fundamentales que aporta la documentación franciscana femenina en el Archivo Diocesano de Mérida-Badajoz nos acercan a los procesos de toma de hábitos y profesiones perpetuas en sus entidades, exploraciones de voluntades de novicias próximas a profesar y a secularizaciones, especialmente perpetuas. Pero además podemos conocer de primera mano otras temáticas tales como pleitos, cuentas, elecciones conventuales o inspecciones de las clausuras. 
BIBLIOGRAFÍA

Abad, A. 1989. «El archivo franciscano Ibero-oriental; historia y fuentes» en F. Solado; F. Rodao; L. Togores, El Extremo Oriente Ibérico. Madrid: 55-63.

Aguilera, A. 2009. Relación de los fondos documentales del convento de de Santa Clara de Borja. Zaragoza: Institución Fernando el Católico.

Aguilera, A. 2010. «Vida en clausura: estudio de las patentes de los ministros franciscanos conservados en el archivo del convento de Santa Clara de Borja.» Cuadernos de Historia Moderna. 35: 97-117.

Aldea Vaquero, Q.; Marín Martínez, T.; Vives Gatell, J. 1972-1987. Diccionario de Historia Eclesiástica de España. Madrid: Instituto Enrique Florez.

Asociación de Archiveros de la Iglesia. 2000. «Aportación del director del Archivo Diocesano don Eladio Menéndez Venegas.» Guía de los Archivos de la Iglesia en España, 2000.

Baucells, J. 1980. «Documentación franciscana en el Archivo Capitular de Barcelona.» Archivo Iberoamericano. 40: 339-382.

Carnicero, J. 2005. «Inventario de los manuscritos del archivo los PP. Franciscanos de Santiago de Compostela.» Estudios Mindonenses. 21: 487-545.

Garabal, T. 1994. «Documentos clarianos en el archivo franciscano IberoOriental.» Archivo Iberoamericano. 54: 213-214.

Gil, P. 1984. Registro general alfabético del archivo franciscano de la Provincia Castellana de san Gregorio Magno. Madrid.

González Rodríguez, A. 1999. Historia de Badajoz. Badajoz: Universitas.

Heras, J; Gutiérrez, L. 1997. «Principales archivos y bibliotecas de la orden franciscana en Perú.» Archivo Iberoamericano. 57: 225-228.

Heras, J; Gutiérrez, L. 2004. Archivos franciscanos de Lima. Madrid: Fundación Mapfre.

López López, T. 1999. Los obispos de Badajoz: catálogos y consagraciones. Coloquios Históricos de Extremadura, 1999.

López López, T. 2000. «La diócesis de Badajoz: Historia ya conclusa.» Boletín de la Real Academia de Extremadura de las Letras y las Artes V.

Maas, O. 1915. Viajes de misioneros franciscanos a la conquista del nuevo mundo. Documentos del Archivo General de Indias. Sevilla: Imprenta san Antonio. 
Martino Alba, P. 2013. «Los franciscanos en los archivos nacionales», en A. Bueno, Los franciscanos y el contacto de las lenguas y culturas. Madrid.

Montes, J. J. 2002. «Entrevista con don Eladio Méndez Venegas, Archivero Diocesano.» Revista Iglesia en Camino. 459: Contraportada.

Moreno, A. 2001. «La huella franciscana en los archivos...» Conferencias del VI Curso de Verano...: 371-380.

Pastrana, A. 1990. «Extremadura en el archivo Ibero-Oriental», en S. García, Extremadura en la evangelización del Nuevo Mundo: 625-683. Madrid: Turner.

Pérez Ortiz, G.; Vivas Moreno, A. «Documentación sobre conventos franciscanos masculinos en el Archivo Diocesano de Mérida-Badajoz». Archivo Iberoamericano. Revista Franciscana de estudios históricos. (Evaluándose).

Reyes, R. 1992. «Expediciones y viajes de franciscanos en los libros de registro del Archivo General de Indias.» Archivo Iberoamericano. 52: 205-208.

Sarmiento Pérez, J. 2005. Reforma beneficial en la Diócesis de Badajoz. durante la crisis del Antiguo Régimen (1769-1841). Badajoz: Diputación Provincial.

Solano de Figueroa y Altamirano, J. 1929-1932. Historia eclesiástica de la ciudad y obispado de Badajoz. Badajoz: Diputación.

Solano de Figueroa y Altamirano, J. 2013. Historia eclesiástica de la ciudad y obispado de Badajoz. Edición anotada por Francisco Tejada Vizuete. Badajoz: Diputación, Departamento de Publicaciones.

Solar y Taboada, A. 1945. Historia eclesiástica de la ciudad y obispado de Badajoz, continuación de la escrita por Juan Solano de Figueroa. Badajoz.

Suárez de Figueroa, D. 1976. Historia de la Ciudad de Badajoz. Badajoz.

Varela Bueno, C. 1988. «Documentos franciscanos en el archivo de Protocolos de Sevilla.» Archivo Iberoamericano. 48: 189-192. 
Catálogo

1 ADME/BA-CONVENTO-20 bis-(52) 1828,mayo,5/ 1828,junio,28.Almendral

Profesión perpetua de María del Carmen Pérez en el convento de la Purísima Concepción de Almendral.

Manuscrito; 2 folios y 2 cuartillas; Castellano; Buena

2 ADME/BA-CONVENTO-20 bis-(53)

1831,octubre,9/ 1831,octubre,18.Almendral-Badajoz

Profesión de Sinforosa Guzmán en el convento de la Purísima Concepción de Almendral. Manuscrito; 3 folios y 1 cuartilla; Castellano; Buena

\section{ADME/BA-CONVENTO-210-8491}

1857, Junio,23.Almendralejo/1857,Junio,27.Llerena

Salida del convento de Santa Clara de Almendralejo a Baños de Alange de la abadesa Catalina Ruiz. Manuscrito; 2 folios; Castellano; Buena

4 ADME/BA-CONVENTO-210-8494

1861, Mayo,17.Almendralejo

Informe de la abadesa Catalina Ruiz del Convento de Santa Clara de Almendralejo pidiendo que sea el sacerdote Andrés Rodríguez Gata el que se encargue de la supervisión de las reparaciones.

Manuscrito; 1 folio; Castellano; Buena

\section{ADME/BA-CONVENTO-210-8495}

1861,Septiembre,22.Almendralejo

Proyecto de reparación del Convento de Santa Clara de Almendralejo.

Manuscrito; 1 folio; Castellano; Buena

6 ADME/BA-CONVENTO-210-8496

1861,Junio,12.Almendralejo/1861,Junio,17.Llerena

Salida del Convento de Santa Clara de Almendralejo a Baños de Alange de la religiosa Manuela Barrientos.

Manuscrito; 1 folio; Castellano; Buena

7 ADME/BA-CONVENTO-210-8493 1860,Octubre,8.Almendralejo/1861, Noviembre, 2.Llerena

Toma de hábitos de María Piedad Nieto Rangel, en el convento de Santa Clara de Almendralejo.

Manuscrito; 19 folios; Castellano; R. (desgaste de tintas)

8 ADME/BA-CONVENTO-424-17478

1776,Febrero,11/1776,Febrero,12. Almendralejo

Informe de la puesta a censo de una casa perteneciente al Convento de Santa Clara de Almendralejo. Manuscrito; 5 folios; Castellano; R (manchas de humedad)

Hispania Sacra, LXVII

135, enero-junio 2015, 61-168, ISSN: 0018-215X, doi: 10.3989/hs.2015.003 
9 ADME/BA-CONVENTO-424-17479 n 1 1791,Enero,25/1791,Enero,26.Almendralejo

Elección de abadesa en el Convento de Santa Clara de Almendralejo.

Manuscrito; 4 folios; L. Procesal; Buena, Castellano

10 ADME/BA-CONVENTO-424-17479 n³ 1810,Julio,20.Almendralejo/1810,Julio,26.Llerena

Salida del Convento de Santa Clara de Almendralejo a Baños de Alange de Isabel Bolaños.

Manuscrito; 1 folio; Castellano; Buena

11 ADME/BA-CONVENTO-424-17479n ${ }^{\circ} 4$ 1832,Julio,14/1832,Agosto,18. Almendralejo-Llerena Entrada al convento de Santa Clara de Almendralejo de María González.

Manuscrito; 3 folios; Castellano; Buena

12 ADME/BA-CONVENTO-424-17479n5 1846 ,Julio,18/1846,Agosto,(sd).Almendralejo-Llerena

Salida del Convento de Santa Clara de Almendralejo a Baños de Alange de María González.

Manuscrito; 4 folios; Castellano; Buena

13 ADME/BA-CONVENTO-424-17479nº $\quad$ 1848,Julio,10.Almendralejo/1848,Julio,21. Llerena

Salida del Convento de Santa Clara de Almendralejo a Baños de Alange de María González.

Manuscrito; 4 folios; Castellano; Buena

14 ADME/BA-CONVENTO-424-17479nº7

1846,Octubre,10. Almendralejo

Mandato del juez Agustín Cáceres para que el sacerdote de Almendralejo seleccione nueva abadesa para el convento de Santa Clara de dicha ciudad.

Manuscrito; 1 folio; Castellano; Buena

15 ADME/BA-CONVENTO-424-17479n8 1848,Junio,2.Almendralejo/1849,Junio,15.Llerena

Salida del convento de Santa Clara de Almendralejo a Baños de Alange de María González.

Manuscrito; 2 folios; Castellano; Buena

16 ADME/BA-CONVENTO-424-17479n9 1857, Octubre,25.Almendralejo/1857, Octubre,31.Llerena

Salida del convento de Santa Clara de Almendralejo a Baños de Alange de María Hurtado.

Manuscrito; 2 folios; Castellano; Buena

17 ADME/BA-CONVENTO-424-17479n ${ }^{\circ} 10$

1855,agosto,15.Almendralejo

Índice de religiosas del Convento de Santa Clara de Almendralejo, así como las funciones desempeñadas por las mismas.

Manuscrito; 1 folio; Castellano; Buena 
18 ADME/BA-CONVENTO-424-17479nº 11

1851,Noviembre,22/ 1851,Noviembre,29.Almendralejo

Elección de abadesa en el convento de Santa Clara de Almendralejo.

Manuscrito; 4 folios y 4 cuartillas; Castellano; Buena

19 ADME/BA-CONVENTO-424-17479n ${ }^{\circ} 12$

1861 ,Julio,1.Almendralejo

Informe de la abadesa Ana González sobre salidas en el Convento de Santa Clara de Almendralejo.

Manuscrito; 1 cuartilla; Castellano; Buena

20 ADME/BA-CONVENTO-424-17479n ${ }^{\circ} 13$

1862,Маyo,3/1864,Abril,5.Almendralejo

Toma de hábito y profesión perpetua de Florencia Pilar en el convento de Santa Clara de Almendralejo.

Manuscrito; 22 folios; Castellano; Buena

21 ADME/BA-CONVENTO-424-17479nº14

1863,Julio,5.Almendralejo/1863,Julio,7.Llerena

Salida del Convento de Santa Clara de Almendralejo a Baños de Alange de la religiosa Ramona Álvarez.

Manuscrito; 3 folios; Castellano; Buena

22 ADME/BA-CONVENTO-424-17479n ${ }^{\circ} 16$

1866,Junio,8/1866,Junio,20.Almendralejo

Toma de hábito de María de la Concepción Murillo en el convento de Santa Clara de Almendralejo. Manuscrito; 10 folios; Castellano; Buena

23 ADME/BA-CONVENTO-424-17479n ${ }^{017}$

1851,Noviembre,20/ 1851, Noviembre,28. Almendralejo

Nombramiento de priora y elección de abadesa en el convento de Santa Clara de Almendralejo.

Manuscrito; 5 folios y 8 cuartillas; Castellano; Buena

24 ADME/BA-CONVENTO-424-17479nº 18

1853,Julio,(sd)Madrid/ 1853,Octubre,25.Almendralejo

Secularización perpetua de Sor María González religiosa del convento de Santa Clara de Almendralejo.

Manuscrito; 3 folios y 4 cuartillas; Castellano y Latín; Buena

25 ADME/BA-CONVENTO-424-17479n ${ }^{\circ} 19$

1860,Octubre,8/1860,Diciembre,1

Almendralejo-Llerena Toma de hábito de Matilde Gómez del Castillo en el convento de Santa Clara de Almendralejo.

Manuscrito; 7 folios; Castellano; Buena

Hispania Sacra, LXVII

135, enero-junio 2015, 61-168, ISSN: 0018-215X, doi: 10.3989/hs.2015.003 
26 ADME/BA-CONVENTO-424-17479nº20 1853,Octubre,20.Almendralejo/

1854,Abril,8.Llerena

Profesión perpetua de Isabel Sánchez Barrientos en el convento de Santa Clara de Almendralejo.

Manuscrito; 22 folios; Castellano; Buena

27 ADME/BA-CONVENTO-424-17479n²1

1860,Octubre,8/1862,Agosto,8. Almendralejo-Llerena

Toma hábito y profesión perpetua de Ramona González en el convento de Santa Clara de Almendralejo.

Manuscrito; 22 folios; Castellano; Buena

28 ADME/BA-CONVENTO-424-17479n²2

1861,Marzo,10/1863,Mayo,17. Almendralejo-Llerena

Toma hábito y profesión perpetua de Amalia Vargas en el convento de Santa Clara de Almendralejo.

Manuscrito; 21 folios; Castellano; Buena.

29 ADME/BA-CONVENTO-424-17479n ${ }^{023}$

1860,octubre,8/1861,Diciembre,3. Almendralejo-Llerena

Toma hábito y profesión perpetua de María Amparo Sánchez Barrientos en el convento de Santa Clara.

Manuscrito; 21 folios; Castellano; R (desgaste de tintas)

30 ADME/BA-CONVENTO-1237-40494

1872,Marzo,1/1872,marzo,31.Almendralejo

Nombramiento de capellán del convento de Santa Clara de Almendralejo a Antonio González.

Manuscrito; 4 folios; Buena; Castellano

31 ADME/BA-CONVENTO-210-8492 1

858,Marzo,22.Almendralejo

Reforma en las instalaciones del convento de Santa Clara de Almendralejo.

Manuscrito; 1 folio; Castellano; Buena

32 ADME/BA-CONVENTO-23-440n²2

1836,abril,25.Almendralejo

Nómina de religiosas enclaustradas en el convento de santa Clara de Almendralejo.

Manuscrito; 5 folios; Castellano; Buena

33 ADME/BA-CONVENTO-23-(3)

1837,octubre,16.Almendralejo

Nomina de religiosas enclaustradas existentes en el convento de Santa Clara de Almendralejo.

Manuscrito; 1 folio; Castellano; Buena 
34 ADME/BA-CONVENTO-14-242

1725 ,abril,20.Badajoz

Informe del obispo a la Congregación del Concilio sobre Juana Manuela Casas del convento de Nuestra Señora de las Mercedes Descalzas de Badajoz.

Manuscrito; 15 folios; Castellano; Buena

35 ADME/BA-CONVENTO-14-249

1791,febrero,11/ 1791,julio,27.Badajoz

Pleito de Miguel del Castillo contra María de Guadalupe, religiosa en el convento de Nuestra Señora de las Mercedes Descalzas de Badajoz, sobre la propiedad de unas casas.

Manuscrito; 19 folios (2 folios en blanco) y 1 cuartilla; Castellano; Buena

36 ADME/BA-CONVENTO-14-(1)

1733,octubre,10.Badajoz.

Fundación del convento de las Mercedes Descalzas de Badajoz.

Manuscrito; 3 folios; Castellano; Buena

37 ADME/BA-CONVENTO-14-(2)

1827,mayo,21.Badajoz

Elección de priora y oficialas del convento de las Mercedes Descalzas de Badajoz. 1827

Manuscrito; 2 folios; Castellano; Buena

38 ADME/BA-CONVENTO-14-(6)

1705,septiembre,12.Badajoz.

Pleito del convento de Las Mercedes Descalzas de Badajoz contra el convento de Santa Lucía de la misma ciudad por deudas.

Manuscrito; 3 folios (1folio en blanco); Castellano; R (manchas y roturas)

39 ADME/BA-CONVENTO-15-(1)

1812,agosto,17.Badajoz

Reparación del convento de las Mercedes Descalzas de Badajoz por la ocupación de tropas francesas.

Manuscrito; 2 folios dobles (1 folio en blanco); Castellano; Buena

40 ADME/BA-CONVENTO-15-(4)

1812,septiembre,5/1812,septiembre,24.

Badajoz Renuncia de la abadesa en el convento de las Mercedes Descalzas de Badajoz.

Manuscrito; 2 folios; Castellano; Buena

41 ADME/BA-CONVENTO-15-(5)

1812,septiembre,5. Badajoz.

Elección de abadesa y oficialas en el convento de las Mercedes Descalzas de Badajoz. 1812

Manuscrito; 2 folios; Castellano; Buena

Hispania Sacra, LXVII

135, enero-junio 2015, 61-168, ISSN: 0018-215X, doi: 10.3989/hs.2015.003 
42 ADME/BA-CONVENTO-15-(6)

1812,septiembre,5.Badajoz

Reparación del convento de las Mercedes Descalzas de Badajoz por la ocupación de tropas francesas.

Manuscrito; 2 folios; Castellano; Buena

43 ADME/BA-CONVENTO-15-(7)

1824,febrero,4.Badajoz

Elección de abadesa y oficialas en el convento de las Mercedes Descalzas de Badajoz, 1824.

Manuscrito; 2 folios; Castellano; Buena

44 ADME/BA-CONVENTO-15-(8)

1824,mayo,9.Badajoz

Elección de vicaria en el convento de las Mercedes Descalzas de Badajoz, 1824.

Manuscrito; 1 folio; Castellano; Buena

45 ADME/BA-CONVENTO-17-314

1720,agosto,6/ 1720,agosto,17. Badajoz.

Pleito del convento de las Mercedes Descalzas de Badajoz contra Pedro Alcántara.

Manuscrito; 10 folios (1 folio en blanco); Castellano; Buena

46 ADME/BA-CONVENTO-17-315

1651 ,noviembre,13/1652,enero,22.Badajoz

Pleito de Antonio Megías, pastelero, contra el convento de las Mercedes Descalzas de Badajoz.

Manuscrito; 6 folios y 1 cuartilla; L. Procesal; R (manchas), Castellano

47 ADME/BA-CONVENTO-17-317

1707 ,abril,5/1707,abril,11.Badajoz

Pleito de Francisco Herrera contra su hermana la religiosa del convento de las Mercedes Descalzas Antonia Herrera.

Manuscrito; 6 folios; Castellano; R (pliegues)

48 ADME/BA-CONVENTO-17-(1)

1722,junio,6/ 1722,junio,11.Badajoz

Profesión perpetua de María Santo Toribio en el convento de las Mercedes Descalzas de Badajoz.

Manuscrito; 5 folios; Castellano; Buena

49 ADME/BA-CONVENTO-17-(6)

1710,mayo,24/ 1711,febrero,18.Badajoz

El convento de las Mercedes Descalzas de Badajoz sobre el embargo de frutos en la Albuera.

Manuscrito; 6 folios; Castellano; Buena

50 ADME/BA-CONVENTO-17-(7)

1823,mayo,26. (Badajoz)

Traslado de religiosas del convento Madre de Dios de Valverde de Badajoz al convento de las Mercedes Descalzas de la misma ciudad.

Manuscrito; 2 folios (1 folio en blanco); Castellano; Buena 
51 ADME/BA-CONVENTO-24-455

1821,mayo,10/1821,noviembre,17.Badajoz-Madrid

Secularización perpetua de Antonia Fabia del convento de las Mercedes Descalzas de Badajoz.

Manuscrito; 4 folios; Castellano y Latín; Buena

52 ADME/BA-CONVENTO-24-459

1821,diciembre,18/1822,marzo,30.

Badajoz Secularización perpetua de María del Carmen Rodríguez de Santa Bárbara religiosa del convento de las Mercedes Descalzas de Badajoz.

Manuscrito; 4 folios; Castellano y Latín; Buena

\section{ADME/BA-CONVENTO-24-464}

1821,junio,2/ 1830,diciembre,3.Badajoz-Madrid

Secularización perpetua de Juana y Micaela Vázquez en el convento de las Mercedes Descalzas de Badajoz.

Manuscrito; 12 folios y 1 cuartilla; Castellano y Latín; Buena

54 ADME/BA-CONVENTO-24-483

1821,enero,30/1821,noviembre,5.Badajoz-Madrid Secularización de Rosalía de la Presentación del convento de las Mercedes Descalzas de Badajoz.

Manuscrito; 4 folios; Castellano y Latín; Buena

55 ADME/BA-CONVENTO-24-489

1821,marzo,11/1822,marzo,20.Badajoz-Madrid.

Secularización de María Rodríguez en el convento de las Mercedes Descalzas de Badajoz.

Manuscrito e impreso;4 folios; Castellano y Latín; Buena

56 ADME/BA-CONVENTO-24-495

1821,enero,30/1822,octubre,26.Badajoz-Madrid.

Secularización de Ana García del convento de las Mercedes Descalzas de Badajoz.

Manuscrito; 4 folios; Castellano y Latín; Buena

57 ADME/BA-CONVENTO-15-(10)

1827 ,mayo,10.Badajoz

Elección de abadesa y oficialas en el convento de las Mercedes Descalzas de Badajoz.

Manuscrito; 2 folios; Castellano; Buena

58 ADME/BA-CONVENTO-16-272

1709,enero,2/1709,enero,15.Badajoz

Rotura de la clausura en el Convento de las Mercedes Descalzas de Badajoz.

Manuscrito; 18 folios; Castellano; R (roturas y manchas)

59 ADME/BA-CONVENTO-16-273n ${ }^{0} 1$

1774,enero,9.Badajoz

Elección de abadesa en el convento de las Mercedes Descalzas de Badajoz.

Manuscrito; 5 folios (1 folio en blanco) y 1 cuartilla; Castellano; Buena

Hispania Sacra, LXVII

135, enero-junio 2015, 61-168, ISSN: 0018-215X, doi: 10.3989/hs.2015.003 
60 ADME/BA-CONVENTO-16-273n²

1777,enero,8/1777,enero,9.Badajoz

Elección de abadesa en el convento de las Mercedes Descalzas de Badajoz.

Manuscrito; 5 folios y 1 cuartilla; Castellano; Buena

61 ADME/BA-CONVENTO-16-273n³

1784,marzo,15/1784,marzo,17.Badajoz.

Toma de hábito en el convento de las Mercedes Descalzas de María Fernández de la Peña.

Manuscrito; 5 folios y 1 cuartilla introductoria; Castellano; Buena

62 ADME/BA-CONVENTO-16-273n4

1779,abril,13.Badajoz.

Entrada en el convento de las Mercedes Descalzas de Antonia Fabra como educanda.

Manuscrito; 2 folios y 1 cuartilla; Castellano; Buena

63 ADME/BA-CONVENTO-16-273n5

1787 ,septiembre,17/1787,octubre,10.Badajoz

Entrada en el convento de las Mercedes Descalzas de María Pilar Barbosa como educanda por ser menor de edad.

Manuscrito; 6 folios y 1 cuartilla; Castellano; Buena

64 ADME/BA-CONVENTO-16-273n6

1786,julio,24/1786,julio,27.Badajoz

Toma de hábitos en el convento de las Mercedes Descalzas de Francisca Javiera.

Manuscrito; 4 folios; Castellano; Buena

65 ADME/BA-CONVENTO-16-273n ${ }^{07}$

1804,agosto,29/1804,agosto,31.Badajoz

Toma de hábitos en el convento de las Mercedes Descalzas de Teresa Zoido Miguel.

Manuscrito; 3 folios y 1 cuartilla; Castellano; Buena

66 ADME/BA-CONVENTO-16-273n8

1803 ,diciembre,6/1804,marzo,7.Badajoz.

Entrada de una doncella en el convento de las Mercedes Descalzas de Badajoz por encontrarse enferma la actual.

Manuscrito; 10 folios y 1 cuartilla; Castellano; Buena

67 ADME/BA-CONVENTO-16-274

1674,noviembre,3/ 1674,noviembre,24.Badajoz

El convento de las Mercedes Descalzas por comunicación indebida con el convento de San Onofre,

Manuscrito; 4 folios; L. Procesal; R (incompleto)

68 ADME/BA-CONVENTO-20-(3)

1835,mayo,22.Badajoz

Elecciones en el convento de las Mercedes Descalzas de Badajoz.

Manuscrito; 2 folios; Castellano; Buena 
69 ADME/BA-CONVENTO-20-(4)

1830,mayo,10.Badajoz

Elecciones de abadesa y oficiales en el convento de las Mercedes Descalzas de Badajoz.

Manuscrito; 2 folios; Castellano; Buena

70 ADME/BA-CONVENTO-20-(10)

1852,marzo,6.Badajoz

Elecciones conventuales de abadesa en el convento de las Mercedes Descalzas de Badajoz.

Manuscrito; 1 folio; Castellano; Buena

71 ADME/BA-CONVENTO-11-450n¹

1853,noviembre,16/1862,febrero,17.Badajoz

Cuentas de reparación del convento de las Mercedes Descalzas de Badajoz.

Manuscrito; 16 folios (2 folios en blanco); Castellano; Buena

72 ADME/BA-CONVENTO-11-450n²

1858 ,diciembre,13/1862,febrero,27.Badajoz

Cuentas de reparación del convento de las Mercedes Descalzas de Badajoz.

Manuscrito; 10 folios ( 1 folio en blanco) y 3 cuartillas; Castellano; Buena

73 ADME/BA-CONVENTO-11-(3)

1838,enero,4.Badajoz

Traslado de religiosa del convento suprimido de Santa Catalina de Badajoz al de las Mercedes Descalzas de la misma ciudad.

Manuscrito; 1 cuartilla; Castellano; Buena

74 ADME/BA-CONVENTO-23-440nº 20

1836,abril,19/ 1336,julio,7.Badajoz

Nómina de religiosas enclaustradas en los conventos de Badajoz.

Manuscrito; 14 folios (8 folios en blanco); Castellano; Buena

75 ADME/BA-CONVENTO-25-519

1821,enero,30/1821,octubre,26.Badajoz-Madrid

Secularización perpetua de María Pilar Alvarado del convento de las Mercedes Descalzas de Badajoz.

Manuscrito; 4 folios; Castellano y Latín; Buena

76 ADME/BA-CONVENTO-25-524

1821,octubre,5/1821,noviembre,17.Badajoz-Madrid

Secularización perpetua de $M^{a}$ Carmen Martínez del convento de las Mercedes Descalzas de Badajoz.

Manuscrito; 4 folios; Castellano y Latín; Buena

Hispania Sacra, LXVII

135, enero-junio 2015, 61-168, ISSN: 0018-215X, doi: 10.3989/hs.2015.003 
77 ADME/BA-CONVENTO-25-525

1821 ,enero,30/ 1821,octubre,29.Badajoz-Madrid

Secularización perpetua de Isabel Fernández del convento de las Mercedes Descalzas de Badajoz.

Manuscrito; 4 folios; Castellano y Latín; Buena

78 ADME/BA-CONVENTO-25-528

1821 ,enero,30/1821,octubre,26.Badajoz-Madrid

Secularización perpetua de María Pilar Martín del convento de las Mercedes Descalzas de Badajoz. Manuscrito; 4 folios; Castellano y Latín; Buena

79 ADME/BA-CONVENTO-25-529

1821,marzo,11/ 1821,diciembre,29.Badajoz-Madrid

Secularización perpetua de María Soledad Martín del convento de las Mercedes Descalzas de Badajoz.

Manuscrito; 4 folios; Castellano y Latín; Buena

80 ADME/BA-CONVENTO-25-536n ${ }^{0} 1$

1821 ,enero,30/1821,octubre,26.Badajoz-Madrid

Secularización perpetua de Juana Alvarado del convento de las Mercedes Descalzas de Badajoz.

Manuscrito; 4 folios; Castellano y Latín; Buena

81 ADME/BA-CONVENTO-25-536n²

1821,enero,30/1821,octubre,29.Badajoz-Madrid

Secularización perpetua de Juana Domínguez del convento de las Mercedes Descalzas de Badajoz.

Manuscrito; 4 folios; Castellano y Latín; Buena

82 ADME/BA-CONVENTO-25-536n 3

1822,marzo,11/1822,diciembre,24.Badajoz-Madrid

Secularización perpetua de María Henríquez del convento de las Mercedes Descalzas de Badajoz.

Manuscrito; 4 folios; Castellano y Latín; Buena

83 ADME/BA-CONVENTO-25-536n4 $\quad$ 1821,mayo,10/ 1821, noviembre,11.Badajoz-Madrid

Secularización perpetua de María del Carmen Sáez, religiosa de velo negro, del convento de las Mercedes Descalzas de Badajoz.

Manuscrito; 4 folios; Castellano y Latín; Buena

84 ADME/BA-CONVENTO-25bis-(68)

1827,marzo,6/1827,junio,4.Badajoz

Toma de hábito de Rafaela Martínez en el convento de las Mercedes Descalzas de Badajoz.

Manuscrito; 2 folios; Castellano; Buena

85 ADME/BA-CONVENTO-14-236

1776,noviembre,20/ 1778,octubre,20. Badajoz.

Pleito del convento de Santa Ana de Badajoz por deudas.

Manuscrito; 46 folios; Castellano; Buena 
86 ADME/BA-CONVENTO-14-238

1821 ,junio,20/ 1825,octubre,26. Badajoz

Exposición de la conducta rebelde de una religiosa secularizada de nombre Gabriela Valencia del convento de Santa Ana de Badajoz.

Manuscrito; 10 folios y 1 cuartillas; Castellano; Buena

87 ADME/BA-CONVENTO-14-241

1868,septiembre,1/1868,septiembre,5.Badajoz.

Compra de una finca por el Convento de Santa Ana de Badajoz.

Manuscrito; 2 folios (1 folio en blanco); Castellano; Buena

88 ADME/BA-CONVENTO-14-245 1827, diciembre,22. Montijo/ 1828, enero,30.Badajoz-Roma

Entrada al convento de Santa Ana de Badajoz de Inés Paula Ramona, menor de edad como educanda.

Manuscrito; 5 folios (1 folio en blanco); Castellano y Latín; Buena

89 ADME/BA-CONVENTO-15-263

1703,febrero,20. Badajoz/1703,mayo,15. Badajoz

Pleito del convento de Santa Ana de Badajoz contra Juan Gómez por incumplimiento de censos.

Manuscrito; 30 folios; Castellano; R (Manchas y tintas desgastadas)

90 ADME/BA-CONVENTO-17-305

1806,noviembre,16/ 1806,noviembre,22.Badajoz.

Profesión perpetua de María Núñez en el convento de Santa Ana de Badajoz.

Manuscrito; 3 folios; Castellano; R (desgaste de tintas)

91 ADME/BA-CONVENTO-17-306n'1

1686,noviembre,3/1687,marzo,3.Badajoz

Pleito de Juana Lobo, religiosa del convento de Santa Ana de Badajoz, contra los herederos de Manuel de Ávila sobre fincas que éste le dejo a la religiosa.

Manuscrito; 17 folios y 1 cuartilla; L. Procesal; R (desgaste de tintas)

92 ADME/BA-CONVENTO-17-306n²

1683,septiembre,21/1683,octubre,23.Badajoz

Pleito del convento de Santa Ana de Badajoz contra el arcediano de la villa por deudas.

Manuscrito; 26 folios (3 folios en blanco); L. Procesal; Buena

\section{ADME/BA-CONVENTO-24-457}

1848,mayo,22 /1848,junio,8.Badajoz-Madrid

Secularización temporal de María del Pilar Núñez del convento de Santa Ana de Badajoz.

Manuscrito; 8 folios; Castellano y Latín; Buena

Hispania Sacra, LXVII

135, enero-junio 2015, 61-168, ISSN: 0018-215X, doi: 10.3989/hs.2015.003 
94 ADME/BA-CONVENTO-24-477

1822,marzo,2/1822, marzo,26.Badajoz-Madrid.

Secularización de Rita Laguna religiosa de velo negro del convento de Santa Ana de Badajoz.

Manuscrito e impreso; 5 folios; Castellano y Latín; Buena

95 ADME/BA-CONVENTO-24-492

1822,febrero,2.Madrid/1822,marzo,26.Badajoz.

Secularización de Ramona Laguna del convento de Santa Ana de Badajoz.

Manuscrito; 4 folios; Castellano y Latín; Buena

96 ADME/BA-CONVENTO-24-499

1821,febrero,22/ 1821,octubre,30.Badajoz-Madrid.

Secularización de Josefa Delgado del convento de Santa Ana de Badajoz.

Manuscrito; 4 folios; Castellano y Latín; Buena

97 ADME/BA-CONVENTO-16-287

1849,abril,26.Badajoz

Traslado de la religiosa Antonia Álvarez del convento de los Remedios al de Santa Ana

Manuscrito;4 folios; Castellano y Latín; Buena

98 ADME/BA-CONVENTO-20-393n ${ }^{0} 1$

1721,septiembre,13/ 1721,octubre,16.Badajoz

Pleito de Francisco Lozano contra el convento de religiosas de Santa Ana de Badajoz por deudas.

Manuscrito; 32 folios; Castellano; Buena

99 ADME/BA-CONVENTO-20-393n²

1718,septiembre,3/ 1719,octubre,16.Badajoz

Pleito de Francisco Lozano Herrero contra el convento de Santa Ana de Badajoz por incumplimiento de deudas.

Manuscrito; 18 folios; Castellano; Buena

100 ADME/BA-CONVENTO-18-(4)

1836,febrero,27.Badajoz

Visita al convento de Santa Ana de Badajoz para inspección de la clausura.

Manuscrito; 1 folio; Castellano; Buena

101 ADME/BA-CONVENTO-18-(5)

1836,marzo,4.Badajoz

Visita al convento de Santa Ana de Badajoz para inspección de la clausura.

Manuscrito; 1 folio; Castellano; Buena

102 ADME/BA-CONVENTO-23-440n²0

1836,abril,19/ 1336,julio,7.Badajoz

Nómina de religiosas enclaustradas en los conventos de Badajoz.

Manuscrito; 14 folios (8 folios en blanco); Castellano; Buena 
103 ADME/BA-CONVENTO-23-452 1823,marzo,6.Badajoz/ 1826,enero,19.Madrid

Entrada al convento de Santa Ana de Badajoz de Gabriela Valencia, religiosa secularizada. Manuscrito; 15 folios (3 folios en blanco); Castellano; Buena

104 ADME/BA-CONVENTO-25-527 1821,septiembre,25/ 1821,octubre,30.Badajoz-Madrid

Secularización perpetua de María Bárbara Domaica del convento de Santa Ana de Badajoz.

Manuscrito; 4 folios; Castellano y Latín; Buena

105 ADME/BA-CONVENTO-25-535

1821 ,febrero,25/1821, noviembre,8.Badajoz-Madrid

Secularización perpetua de Ana Blanco del convento de Santa Ana de Badajoz.

Manuscrito; 3 folios; Castellano y Latín; Buena

106 ADME/BA-CONVENTO-25bis-(2)

1829 ,enero,3/ 1829,enero,5.Badajoz

Profesión perpetua de Benigna Gutiérrez en el convento de Santa Ana de Badajoz.

Manuscrito; 2 folios y 1 cuartilla; Castellano; Buena

107 ADME/BA-CONVENTO-25bis-(3)

1829,enero,12/ 1829,enero,14.Badajoz

Profesión perpetua de María de la Asunción en el convento de Santa Ana de Badajoz.

Manuscrito; 2 folios y 1 cuartilla; Castellano; Buena

108 ADME/BA-CONVENTO-25bis-(16)

1825,marzo,19/ 1825,marzo,20.Badajoz

Profesión perpetua de Fernanda Domínguez en el convento de Santa Ana de Badajoz.

Manuscrito; 4 folios; Castellano; Buena

109 ADME/BA-CONVENTO-25bis-(17)

1825,junio,12/ 1825,junio,20.Badajoz

Profesión perpetua de Teresa de la Asunción en el convento de Santa Ana de Badajoz.

Manuscrito; 2 folios y 1 cuartilla; Castellano; Buena

110 ADME/BA-CONVENTO-25bis-(18)

1826,septiembre,27/1826,octubre,6.Badajoz

Profesión de María Dolores Rubiales en el convento de Santa Ana de Badajoz.

Manuscrito; 2 folios y 1 cuartilla; Castellano; Buena

111 ADME/BA-CONVENTO-25bis-(19)

1827,junio,29/ 1827,agosto,3.Badajoz

Profesión de Isabel Rufo como religiosa de velo blanco en el convento de Santa Ana de Badajoz.

Manuscrito; 2 folios y 1 cuartilla; Castellano; Buena

Hispania Sacra, LXVII

135, enero-junio 2015, 61-168, ISSN: 0018-215X, doi: 10.3989/hs.2015.003 
112 ADME/BA-CONVENTO-25bis-(20) 1827,enero,21/ 1827,enero,25.Badajoz

Profesión perpetua de Bonifacia Enríquez en el convento de Santa Ana de Badajoz.

Manuscrito; 2 folios y 1 cuartilla; Castellano; Buena

113 ADME/BA-CONVENTO-25bis-(21)

1829,septiembre,7/1829,septiembre,11.Badajoz

Profesión perpetua de Ana Caballero en el convento de Santa Ana de Badajoz.

Manuscrito; 2 folios y 1 cuartilla; Castellano; Buena

114 ADME/BA-CONVENTO-25bis-(22)

1831,noviembre,22/1831,noviembre,24.Badajoz

Profesión perpetua de Felipa Riofrío en el convento de Santa Ana de Badajoz.

Manuscrito; 2 folios y 1 cuartilla; Castellano; Buena

115 ADME/BA-CONVENTO-25bis-(40)

1829,mayo,11/1829,mayo,15.Badajoz

Profesión perpetua de Ana de Bernarda en el convento de Santa Ana Badajoz.

Manuscrito; 2 folios y 1 cuartilla; Castellano; Buena

116 ADME/BA-CONVENTO-25bis-(41)

1831,abril,5/1831,abril,14.Badajoz

Profesión perpetua de Inés Núñez como novicia de coro en el convento de Santa Ana Badajoz.

Manuscrito; 2 folios y 1 cuartilla; Castellano; Buena

117 ADME/BA-CONVENTO-20 bis-(12)

1828,octubre,16/ 1828,noviembre,30.Barcarrota

Profesión perpetua de Josefa de la Concepción en el convento de Nuestra Señora de la Asunción de Barcarrota.

Manuscrito; 4 folios y 1 cuartilla; Castellano; Buena

118 ADME/BA-CONVENTO-20 bis-(13)

1824,julio,10/ 1826,noviembre,17.Barcarrota

Toma de hábito y profesión perpetua de María Coriana en el convento de la Asunción de Barcarrota.

Manuscrito; 7 folios y 1 cuartilla; Castellano; Buena

119 ADME/BA-CONVENTO-20 bis-(14)

1827,febrero,11 /1827,marzo,19.Barcarrota

Toma de hábito de María Josefa Soriano en el convento de la Asunción de Barcarrota.

Manuscrito; 3 folios y 1 cuartilla; Castellano; Buena

120 ADME/BA-CONVENTO-20 bis-(15) ${ }^{\circ}$

1828,marzo,20 /1829,junio,13.Barcarrota.

Toma de hábito y profesión perpetua de Josefa Mendoza en el convento de la Asunción de Barcarrota.

Manuscrito; 7 folios y 1 cuartilla; Castellano; Buena 
121 ADME/BA-CONVENTO-20 bis-(16) 1828,octubre,16/ 1828,octubre,30.Barcarrota

Profesión perpetua de Francisca de Santa Teresa en el convento de la Asunción de Barcarrota. Manuscrito; 4 folios y 1 cuartilla; Castellano; Buena

122 ADME/BA-CONVENTO-20 bis-(17) 1826,agosto,3/ 1827,noviembre,21.Barcarrota

Toma de hábito y profesión perpetua de $M^{a}$ Josefa Flores en el convento de la Asunción de Barcarrota.

Manuscrito; 6 folios y 1 cuartilla; Castellano; Buena

123 ADME/BA-CONVENTO-20 bis-(18)

1824,agosto,19/1824,noviembre,16.Barcarrota.

Toma de hábito de Francisca Hernández en el convento de la Asunción de Barcarrota.

Manuscrito; 2 folios y 1 cuartilla; Castellano; Buena

124 ADME/BA-CONVENTO-20 bis-(19)

1826,julio,19/1826,agosto,15.Barcarrota

Profesión perpetua de la novicia María de Santa Rita en el convento de la Asunción de Barcarrota.

Manuscrito; 5 folios y 1 cuartilla; Castellano; Buena

125 ADME/BA-CONVENTO-20 bis-(20) 1824, agosto,10.Fregenal de la Sierra/ 1825 ,enero,6.Barcarrota Toma de hábito de María Febrero en el convento de la Asunción de Barcarrota.

Manuscrito; 2 folios y 1 cuartilla; Castellano; Buena

126 ADME/BA-CONVENTO-20 bis-(21) 1824,noviembre,2/ 1824, diciembre,24.Bararrota -Madrid Ratificación de la profesión de María del Corazón de Jesús del convento de la Asunción de Barcarrota.

Manuscrito; 3 folios y 1 cuartilla; Castellano; Buena

127 ADME/BA-CONVENTO-20 bis-(22)

1824,agosto,12/1824,septiembre,16.Barcarrota

Readmisión en el convento de la Asunción de Barcarrota de la secularizadas María Dolores Pedroso y Josefa Palomo.

Manuscrito; 3 folios y 1 cuartilla; Castellano; Buena

128 ADME/BA-CONVENTO-20 bis-(23) 1824,mayo,10.Corte de Peleas /1825,junio,17.Barcarrota Ratificación de la profesión de Ana de Chaves del convento de la Asunción de Barcarrota.

Manuscrito; 6 folios y 1 cuartilla; Castellano; Buena

Hispania Sacra, LXVII

135, enero-junio 2015, 61-168, ISSN: 0018-215X, doi: 10.3989/hs.2015.003 
129 ADME/BA-CONVENTO-20 bis-(24)

1824,julio,8.Almoharín/ 1826,noviembre,15.Barcarrota

Toma de hábito de Rosa Gil en el convento de la Asunción de Barcarrota.

Manuscrito; 7 folios y 1 cuartilla; Castellano; Buena

130 ADME/BA-CONVENTO-23-440n 1

1836,abril,25.Barcarrota

Nómina de religiosas enclaustradas en el convento de la Asunción de Barcarrota.

Manuscrito; 7 folios (4 folios en blanco); Castellano; Buena

131 ADME/BA-CONVENTO-23-440n 4

1836,abril,25.Campanario

Nómina de religiosas enclaustradas en el convento de Santa Clara de Campanario.

Manuscrito; 7 folios (3 folios en blanco); Castellano; Buena

132 ADME/BA-CONVENTO-20 bis-(25)

1830 ,septiembre,19/

1830,octubre,6.Fregenal de la Sierra

Profesión perpetua de María Jaramillo en el convento de Santa Clara de Fregenal de la Sierra.

Manuscrito; 3 folios y 2 cuartillas; Castellano; Buena

133 ADME/BA-CONVENTO-20 bis-(27)

1818,marzo,29/ 1818,mayo,13.

Fregenal de la Sierra -Badajoz

Toma de hábito de María del Pilar Infame en el convento de Santa Clara de Fregenal de la Sierra.

Manuscrito; 4 folios y 1 cuartilla; Castellano; Buena

134 ADME/BA-CONVENTO-20 bis-(30)

1824,enero,15/1824,febrero,27.Fregenal de la

Sierra -Badajoz Profesión perpetua de Ana Hurtado en el convento de Santa Clara de Fregenal de los Caballeros.

Manuscrito; 4 folios; Castellano; Buena

135 ADME/BA-CONVENTO-20 bis-(31) 1829, octubre,3 /1830, febrero,21.Fregenal de la Sierra

Profesión perpetua de Josefa Armijo en el convento de Santa Clara de Fregenal de los Caballeros.

Manuscrito; 3 folios y 2 cuartillas; Castellano; Buena

136 ADME/BA-CONVENTO-20 bis-(33) 1828, agosto,7/ 1828, noviembre,6.Fregenal -Badajoz

Profesión perpetua de Antonia Herrera en el convento de Santa Clara de Fregenal de los Caballeros.

Manuscrito; 3 folios y 2 cuartillas; Castellano; Buena 
137 ADME/BA-CONVENTO-11-(4)

1838,agosto,13.Badajoz

Traslado de religiosas del convento suprimido de Santa Clara de Fregenal de la Sierra al de la misma orden en Montijo.

Manuscrito; 2 cuartillas; Castellano; Buena

138 ADME/BA-CONVENTO-23-440n 5

[19--].(Fregenal de la Sierra)

Nómina de religiosas enclaustradas en los conventos de la Paz y Santa Clara de Fregenal de la Sierra.

Manuscrito; 5 folios (2 folios en blanco); Castellano; Buena

\section{ADME/BA-CONVENTO-26-664}

1773,abril,12/1773,septiembre,26. Fregenal de la Sierra•Badajoz-Roma

Salida de la religiosa Luisa Roza del convento de Santa Clara de Fregenal para toma de baños. Manuscrito; 18 folios (2 folios en blanco) y 1 cuartilla; Castellano y Latín; Buena

140 ADME/BA-CONVENTO-27-676 1789, junio,13/1789,junio,18.Fregenal de la Sierra

Lugar inapropiado para la confesión en el convento de Santa Clara de Fregenal de la Sierra.

Manuscrito; 3 folios; Castellano; Buena

141 ADME/BA-CONVENTO-28-715

1826,agosto,8.Madrid/1827,marzo,9.Badajoz-Fregenal

Entrada de una doncella en el convento de Santa Clara de Fregenal de la Sierra.

Manuscrito; 11 folios (1 folio en blanco); Castellano y Latín; Buena

142 ADME/BA-CONVENTO-28-706n $\mathbf{3}$ 1821,septiembre,15/1821, septiembre,20. Badajoz-Fregenal Elección de abadesa en el convento de Santa Clara de Fregenal de la Sierra.

Manuscrito; 1 folio; Castellano; Buena

143 ADME/BA-CONVENTO-29-756

1852,julio,20.Fregenal de la Sierra/ 1853,abril,5.Badajoz-Madrid

Traslado de la religiosa Josefa Armijo del convento de Santa Clara al de la Paz en Fregenal.

Manuscrito; 10 folios (1 folio en blanco) y 2 cuartillas; Castellano y Latín; Buena

144 ADME/BA-CONVENTO-20 bis-(68)

1818,junio,1/1826,julio,2. Jerez de los Caballeros-Badajoz

Toma de hábito y profesión perpetua de María del Carmen Bustos en el convento de la Trinidad de Jerez de los Caballeros.

Manuscrito; 3 folios y 5 cuartillas; Castellano; Buena

Hispania Sacra, LXVII

135, enero-junio 2015, 61-168, ISSN: 0018-215X, doi: 10.3989/hs.2015.003 
145 ADME/BA-CONVENTO-20 bis-(69) 1824 ,noviembre, $20 / 1824$,noviembre, 24 . Jerez de los Caballeros

Toma de hábito de Francisca Aparicio y Holgado en el convento de la Trinidad de Jerez de los Caballeros.

Manuscrito; 2 folios y 1 cuartilla; Castellano; Buena

146 ADME/BA-CONVENTO-20 bis-(74)

1827,marzo,10/

1828,febrero,22.Jerez de los Caballeros

Toma de hábito y profesión perpetua de María Dolores López en el convento de la Trinidad de Jerez de los Caballeros.

Manuscrito; 8 folios ( 2 folios en blanco) y 2 cuartillas; Castellano; Buena

147 ADME/BA-CONVENTO-20 bis-(82)

1824,noviembre,20/ 1824,noviembre,24. Jerez de los Caballeros

Toma de hábito de Manuela Aparicio en el convento de la Trinidad de Jerez de los Caballeros.

Manuscrito; 2 folios y 1 cuartilla; Castellano; Buena

148 ADME/BA-CONVENTO-20 bis-(89)

1832,julio,8/ 1832,octubre, 7 . Jerez de los Caballeros -Badajoz

Profesión perpetua de María Josefa Chacón en el convento de la Trinidad de Jerez de los Caballeros.

Manuscrito; 8 folios ( 1 folio en blanco) y 1 cuartilla; Castellano; Buena

149 ADME/BA-CONVENTO-20 bis-(95)

1832,octubre,13/ 1824,diciembre,12. Jerez de los Caballeros

Ratificación de la profesión de Mariana López en el convento de la Trinidad de Jerez de los Caballeros.

Manuscrito; 6 folios ( 1 folio en blanco) y 1 cuartilla; Castellano; Buena

150 ADME/BA-CONVENTO-23-440n ${ }^{0} 17$

[19--].(Jerez de los Caballeros)

Nómina de religiosas enclaustradas en los conventos de Jerez de los Caballeros.

Manuscrito; 11 folios (6 folios en blanco); Castellano; Buena

151 ADME/BA-CONVENTO-23-(7)

1837,noviembre,8.Jerez de los Caballeros

Nomina de religiosas enclaustradas existentes en el convento de la Trinidad de Jerez de los Caballeros.

Manuscrito; 2 folios; Castellano; Buena 
152 ADME/BA-CONVENTO-37-1056 (sd).(Jerez de los Caballeros)/1673, diciembre,24.Badajoz

Venta de tierras pertenecientes al convento de la Trinidad de Jerez de los Caballeros.

Manuscrito; 5 folios; L. Procesal; R (desgaste de tintas)

153 ADME/BA-CONVENTO-37-1052

1674,(sm),(sd).Jerez de los Caballeros

Fundación de una capellanía en el convento de la Trinidad de Jerez de los Caballeros.

Manuscrito; 32 folios (4 folios en blanco); L. Procesal; Buena

154 ADME/BA-CONVENTO-40-1136n 1

1784,junio,7.Badajoz/1784,agosto,5. Jerez de los Caballeros

Profesión perpetua de Antonia de Quevedo en el convento de la Trinidad de Jerez de los Caballeros. Manuscrito; 6 folios; Castellano; Buena

155 ADME/BA-CONVENTO-40-1136n 2

1785, octubre,11.Jerez de los Caballeros

Profesión perpetua de la novicia Inés Gómez en el convento de la Trinidad de Jerez de los

Caballeros.

Manuscrito; 4 folios; Castellano; R (incompleto)

156 ADME/BA-CONVENTO-41-1156

1816,noviembre7.Jerez de los Caballeros/ 1817 ,febrero,1. Badajoz

Salida de la clausura de la religiosa Nicolasa Galván del convento de la Trinidad de Jerez de los Caballeros.

157 ADME/BA-CONVENTO-41-1155

1814,(sm),(sd).Jerez de los Caballeros

Autos ocasionados por la religiosa profesa del convento de la Trinidad María de la Concepción.

Manuscrito; 37 folios; Castellano; Buena

158 ADME/BA-CONVENTO-20 bis-(66) 1824,noviembre,10/ 1824,noviembre,17.Jerez -Badajoz

Toma de hábito de Isabel Márquez en el convento de Nuestra Señora de Gracia de Jerez.

Manuscrito; 2 folios; Castellano; Buena

159 ADME/BA-CONVENTO-20 bis-(67)

1816, diciembre,9/1818,junio, 10 . Jerez de los Caballeros-Badajoz

Toma de hábito y profesión perpetua de Ramona Juliana Conejo en el convento de Nuestra Señora de Gracia de Jerez de los Caballeros.

Manuscrito; 11 folios y 1 cuartilla; Castellano; Buena

Hispania Sacra, LXVII

135, enero-junio 2015, 61-168, ISSN: 0018-215X, doi: 10.3989/hs.2015.003 
160 ADME/BA-CONVENTO-20 bis-(76)

1829 ,octubre,18.Trigueros/ 1829,octubre,27.Jerez -Badajoz

Toma de hábito de María del Carmen Pérez en el convento de Nuestra Señora de Gracia de Jerez de los Caballeros.

Manuscrito; 4 folios y 1 cuartilla; Castellano; Buena

161 ADME/BA-CONVENTO-20 bis-(78)

1829,septiembre,4.Trigueros/1829,octubre,27.-Jerez

Toma de hábito de María del Carmen Romero en el convento de Nuestra Señora de Gracia de Jerez de los Caballeros.

Manuscrito; 4 folios y 1 cuartilla; Castellano; Buena

162 ADME/BA-CONVENTO-20 bis-(79)

1830,marzo,11/1830,marzo,17. Jerez de los Caballeros -Oliva

Toma de hábito de Catalina Solís en el convento de Nuestra Señora de Gracia de Jerez.

Manuscrito; 4 folios y 1 cuartilla; Castellano; Buena

163 ADME/BA-CONVENTO-20 bis-(80)

1830,septiembre,17.Galaroza/1830,octubre,12. Jerez -Badajoz

Toma de hábito de Luisa Ceverino en el convento de Nuestra Señora de Gracia de Jerez de los Caballeros.

Manuscrito; 4 folios y 1 cuartilla; Castellano; Buena

164 ADME/BA-CONVENTO-20 bis-(85)

1819,mayo,11.Encinasola/ 1819,mayo,28.Jerez -Badajoz

Toma de hábito de Isabel Agudo en el convento de Nuestra Señora de Gracia de Jerez de los Caballeros.

Manuscrito; 5 folios ( 1 folio en blanco) y 1 cuartilla; Castellano; Buena

165 ADME/BA-CONVENTO-20 bis-(86) 1824,octubre,13/ 1824,octubre,26.Jerez de los Caballeros Toma de hábito de Josefa Becerra como novicia de coro en el convento de Nuestra Señora de Gracia de Jerez de los Caballeros.

Manuscrito; 2 folios y 1 cuartilla; Castellano; Buena

166 ADME/BA-CONVENTO-20 bis-(88)

1832,abril,24.Higuera la Reall 1836,junio,26. Jerez-Badajoz

Toma de hábito de Francisca Jacinta Regalado en el convento de Nuestra Señora de Gracia de Jerez. de los Caballeros.

Manuscrito; 4 folios y 1 cuartilla; Castellano; Buena 
167 ADME/BA-CONVENTO-20 bis-(93)

1832 ,enero, $1 / 1833$,enero, 20 . Jerez de los Caballeros -Badajoz

Toma de hábito y profesión perpetua de María Antonia Cárdenas como religiosa de velo blanco en el convento de Nuestra Señora de Gracia de Jerez de los Caballeros.

Manuscrito; 8 folios y 1 cuartilla; Castellano; Buena

168 ADME/BA-CONVENTO-20 bis-(94)

1829,septiembre,3.Galaroza/

1831 ,enero,23.Jerez-Badajoz

Profesión perpetua de Josefa Ceverino y Victoria Carrasco en el convento de Nuestra Señora de Gracia de Jerez de los Caballeros.

Manuscrito; 10 folios y 1 cuartilla; Castellano; Buena

169 ADME/BA-CONVENTO-23-440n ${ }^{\circ} 17$

[19--].(Jerez de los Caballeros)

Nómina de religiosas enclaustradas en los conventos de Jerez de los Caballeros.

Manuscrito; 11 folios (6 folios en blanco); Castellano; Buena

170 ADME/BA-CONVENTO-23-(6)

1837,noviembre,12.Jerez de los Caballeros

Nomina de religiosas enclaustradas existentes en el convento de Nuestra Señora de Gracia de Jerez. de los Caballeros.

Manuscrito; 2 folios; Castellano; Buena

171 ADME/BA-CONVENTO-36-1006

1652,(sm),(sd).Jerez de los Caballeros

Visita al convento de Nuestra Señora de Gracia de Jerez de los Caballeros para inspección.

Manuscrito; 2 folios (1 folio en blanco); L. Procesal; Buena

172 ADME/BA-CONVENTO-36-1007 1657,(sm),(sd)/1657, diciembre,19.Jerez de los Caballeros

Cuestionario para la exploración de la voluntad de novicias en el convento de Nuestra Señora de Gracia de Jerez de los Caballeros.

Manuscrito; 6 folios (1 folio en blanco); L. Procesal; R (roturas)

173 ADME/BA-CONVENTO-44-1219

1858,enero,18.Jerez/1862,agosto,2.Badajoz-Madrid

Reparación del convento de Nuestra Señora de Gracia de Jerez de los Caballeros.

Manuscrito; 13 folios (3 folios en blanco) y 4 cuartillas; Castellano; Buena

174 ADME/BA-CONVENTO-38-1066

1700,agosto,21.Badajoz/1700,septiembre,3.Jerez

Elección de abadesa en el convento de Gracia de Jerez de los Caballeros.

Manuscrito; 5 folios; Castellano; Buena

Hispania Sacra, LXVII

135, enero-junio 2015, 61-168, ISSN: 0018-215X, doi: 10.3989/hs.2015.003 
175 ADME/BA-CONVENTO-40-1137n 1

1786,enero,15.Badajoz/1786,enero,19. Jerez de los Caballeros

Profesión perpetua de la novicia Inés Tuno en el convento de Gracia de Jerez de los Caballeros.

Manuscrito; 6 folios; Castellano; Buena

176 ADME/BA-CONVENTO-41-1160 1816,abril,16.Badajoz/1816, abril,30.Jerez de los Caballeros Elección de priora en el convento de Gracia de Jerez de los Caballeros.

Manuscrito; 6 folios (1 folio en blanco); Castellano; Buena

177 ADME/BA-CONVENTO-42-1175n ${ }^{0} 1 \quad 1821$,abril,3/1821, noviembre,9.Badajoz-Madrid-Jerez Secularización perpetua de la religiosa María Dolores Núñez del convento de Gracia de Jerez de los Caballeros.

Manuscrito; 5 folios; Castellano y Latín; Buena

178 ADME/BA-CONVENTO-42-1178nº4 1821, mayo,16/1822, mayo,7.Badajoz-Jerez -Madrid

Secularización perpetua de la religiosa Inés de Trepo del convento de Gracia de Jerez de los Caballeros.

Manuscrito; 5 folios; Castellano y Latín; Buena

179 ADME/BA-CONVENTO-43-1205nº 1

1834,febrero,18.Badajoz/1834,febrero,25.Jerez

Elecciones de priora y oficialas en el convento de Nuestra Señora de Gracia de Jerez.

Manuscrito; 4 folios; Castellano; Buena

180 ADME/BA-CONVENTO-23-440n9

1836,abril,24/ 1836,abril,28.Llerena

Nómina de religiosas enclaustradas en los conventos de Llerena.

Manuscrito; 13 folios (5 folios en blanco); Castellano; Buena

181 ADME/BA-CONVENTO-91-3931

(sd).(Llerena)/1796,septiembre,22.Llerena

Venta de una propiedad del convento de Santa Clara de Llerena.

Manuscrito; 6 folios (1 folio en blanco); Castellano; Buena

182 ADME/BA-CONVENTO-91-3932

1577,julio,13.Llerena

Entrada al convento de Santa Clara de Llerena de Lucía Núñez, menor de edad, como educanda.

Manuscrito; 3 folios (1 folio en blanco); L. Bastarda; Buena 
183 ADME/BA-CONVENTO-91-3933

1864/1866.Llerena

Cuentas de cargo y data del convento de Santa Clara de Llerena 1864 a 1866.

Manuscrito; 2 folios ( 1 folio en blanco)y 6 cuartillas; Castellano; Buena

184 ADME/BA-CONVENTO-91-3933bis

1876.Llerena

Cuentas del convento de Santa Clara de 1876 de Llerena presentadas por la priora Dolores Gil.

Manuscrito; 2 folios; Castellano; Buena

185 ADME/BA-CONVENTO-91-3934

1859.Llerena

Cuentas de cargo y data del convento de Santa Clara de Llerena.

Manuscrito; 11 folios; Castellano; Buena

186 ADME/BA-CONVENTO-91-3935

1712,noviembre,9.Llerena

Pleito contraído por el convento de Santa Clara de Llerena.

Manuscrito; 1 folio; Castellano; R (incompleto)

187 ADME/BA-CONVENTO-254-11096

1614,(sm),(sd).Llerena

Inventario de bienes del convento de Santa Clara de Llerena.

Manuscrito; 7 folios; L. Procesal; R (bordes rotos)

188 ADME/BA-CONVENTO-254-11097

1860,junio,25.Madrid/1860,octubre,27.Llerena

Reparación del convento de Santa Clara de Llerena.

Manuscrito; 5 folios y 4 cuartillas; Castellano; Buena

189 ADME/BA-CONVENTO-254-11098

1862,enero, $1 / 1864$,junio,30.Llerena

Entrada de una menor en el convento de Santa Clara de Llerena para educanda.

Manuscrito; 12 folios ( 2 en blanco) y 2 cuartillas; Castellano; Buena

190 ADME/BA-CONVENTO-254-11099

1864,marzo,15/1866,abril,12.Llerena

Renuncia de la presidenta del convento de Santa Clara de Llerena.

Manuscrito; 5 folios y 8 cuartillas ; Castellano; Buena

191 ADME/BA-CONVENTO-254-11100

1871,junio,30/1871,julio,1.Llerena

Secularización perpetua de Carmen Moriño del convento de Santa Clara de Llerena

Manuscrito; 4 folios (2 folios en blanco); Castellano; Buena

Hispania Sacra, LXVII

135, enero-junio 2015, 61-168, ISSN: 0018-215X, doi: 10.3989/hs.2015.003 
192 ADME/BA-CONVENTO-254-11101

Deuda a favor del convento de Santa Clara de Llerena.

Manuscrito; 2 folios; Castellano; R (incompleto)

193 ADME/BA-CONVENTO-482-19027n 2

1670,enero,14/1671,octubre,12.Llerena

Exploración de voluntades de novicias próximas a su profesión en conventos de Llerena.

Manuscrito; 20 folios (5 folios en blanco); L. Procesal; Buena

194 ADME/BA-CONVENTO-482-19036

1863,mayo,1.Llerena

Traslado de misas del convento de Santa Clara de Llerena a la parroquia de Santiago.

Manuscrito; 2 folios; Castellano; Buena

195 ADME/BA-CONVENTO-482-19037

1654,diciembre,11.Llerena

Pleito de Diego López de Castro contra el convento de Santa Clara de Llerena, por deudas.

Manuscrito; 3 folios; Castellano; Buena

196 ADME/BA-CONVENTO-482-19040

1675 ,febrero,2.Llerena

Exploración de la voluntad de Leonor de Chaves en el convento de Santa Clara de Llerena.

Manuscrito; 2 folios; L. Procesal; Buena

197 ADME/BA-CONVENTO-482-19040bis

1704,febrero,15.Llerena

Exploración de la voluntad de María de Retamosa en el convento de Santa Clara de Llerena.

Manuscrito; 2 folios; Castellano; Buena

198 ADME/BA-CONVENTO-482-19040bis

1743,julio,2.Llerena

Exploración de la voluntad de Juana de la Vera en el convento de Santa Clara de Llerena.

Manuscrito; 2 folios; Castellano; Buena

199 ADME/BA-CONVENTO-482-19040bis

1744,abril,19.Llerena

Exploración de la voluntad de Isabel de Herrera en el convento de Santa Clara de Llerena.

Manuscrito; 2 folios; Castellano; Buena

200 ADME/BA-CONVENTO-482-19040bis

1748,agosto,18.Llerena

Exploración de la voluntad de María Jesús Gómez en el convento de Santa Clara de Llerena.

Manuscrito; 2 folios; Castellano; Buena 
201 ADME/BA-CONVENTO-482-19040bis

1788,octubre,28.Llerena

Exploración de la voluntad de Ana de la Vera en el convento de Santa Clara de Llerena.

Manuscrito; 2 folios; Castellano; Buena

202 ADME/BA-CONVENTO-482-19040bis

1744,abril,19.Llerena

Exploración de la voluntad de Antonia María Herrero en el convento de Santa Clara de Llerena.

Manuscrito; 2 folios; Castellano; Buena

203 ADME/BA-CONVENTO-482-19044

1788 ,febrero,8.Llerena

Exploración de la voluntad de Dolores Gallardo en el convento de Santa Clara de Llerena.

Manuscrito; 2 folios; Castellano; Buena

204 ADME/BA-CONVENTO-482-19044bis

1784,febrero,7.Llerena

Exploración de la voluntad de Josefa Pérez en el convento de Santa Clara de Llerena.

Manuscrito; 2 folios; Castellano; Buena

205 ADME/BA-CONVENTO-482-19044bis

1799,noviembre,12.Llerena

Exploración de la voluntad de Teresa Lacodre en el convento de Santa Clara de Llerena.

Manuscrito; 2 folios; Castellano; Buena

206 ADME/BA-CONVENTO-482-19044bis

1800,mayo,19.Llerena

Exploración de la voluntad de Teresa Rufo en el convento de Santa Clara de Llerena.

Manuscrito; 2 folios; Castellano; Buena

207 ADME/BA-CONVENTO-482-19038

1642,mayo,28/1642,noviembre,8.Llerena

Herencia, procedente de una obra pía, a favor del convento de Santa Clara de Llerena.

Manuscrito; 12 folios; L. Procesal; R (roturas, folio ilegible, manchas, pliegues)

208 ADME/BA-CONVENTO-482-19041

1759,junio,9/1770,abril,22.Llerena

Réditos de un censo perteneciente al convento de Santa Clara de Llerena.

Manuscrito; 23 folios; Castellano; R (manchas de humedad)

209 ADME/BA-CONVENTO-482-19043

(sd).(Llerena)/1793,julio,25.Llerena

Censo de tierras pertenecientes al convento de Santa Clara de Llerena.

Manuscrito; 10 folios (1 folio en blanco); Castellano; Buena

Hispania Sacra, LXVII

135, enero-junio 2015, 61-168, ISSN: 0018-215X, doi: 10.3989/hs.2015.003 
210 ADME/BA-CONVENTO-482-19045

1821,octubre,29/1821, diciembre,10.Llerena

Secularización perpetua de la religiosa María de Belarde en el convento de la Santa Clara de Mérida.

Manuscrito; 8 folios (1 folio en blanco); Castellano y Latín.; Buena

211 ADME/BA-CONVENTO-482-19046

(sd).(Llerena)/1821, agosto,31.Llerena

Elecciones de abadesa y oficialas en el convento de Santa Clara de Llerena.

Manuscrito; 6 folios; Castellano; Buena

213 ADME/BA-CONVENTO-482-19046bis

1854,agosto,29.Llerena/(sd).(Llerena)

Elección de abadesa en el convento de Santa Clara de Llerena.

Manuscrito; 3 folios (1 folio en blanco); Castellano; Buena

214 ADME/BA-CONVENTO-482-19047

1851,noviembre,22/1851,noviembre,23.Llerena

Visita al convento de Santa Clara de Llerena para afianzamiento de la Regla.

Manuscrito; 3 folios; Castellano; Buena

215 ADME/BA-CONVENTO-482-19047bis

1853,febrero,25/1853,marzo,2.Llerena

Acreditación de la enclaustrada Josefa de San Antonio del convento de Santa Clara de Llerena.

Manuscrito; 2 cuartillas; Castellano; Buena

216 ADME/BA-CONVENTO-482-19047bis

1856,enero,3.Llerena

Cuentas del convento de Santa Clara de Llerena.

Manuscrito; 2 folios; Castellano; Buena

217 ADME/BA-CONVENTO-482-19048

1857,octubre,5.Llerena

Defunciones de religiosas del convento de Santa Clara de Llerena.

Manuscrito; 4 folios (2 folios en blanco) y 1 cuartilla; Castellano; Buena

218 ADME/BA-CONVENTO-482-19049

1855,abril,23/1858,julio,1.Llerena

Relación nominal de religiosas en el convento de Santa Clara de Llerena.

Manuscrito; 4 folios dobles y 2 cuartillas; Castellano; Buena

219 ADME/BA-CONVENTO-482-19050

1873,marzo,31/1873,abril,6.Llerena

Nombramiento de sacristán en el convento de Santa Clara de Llerena.

Manuscrito; 2 folios; Castellano; Buena 
220 ADME/BA-CONVENTO-482-19050bis

1860,mayo,12.Llerena

Certificado médico de una religiosa del convento de Santa Clara de Llerena expedido por Blas García.

Manuscrito; 1 folio; Castellano; Buena

221 ADME/BA-CONVENTO-482-19051 1873,diciembre,16.Llerena/1873,octubre,14.Guadalcanal

Entrada como educanda de Luisa Claudia Yanes en el convento de Santa Clara de Llerena.

Manuscrito; 6 folios; Castellano; Buena

222 ADME/BA-CONVENTO-482-19051bis

1873 , noviembre, $24 / 1873$,noviembre, 26. Llerena

Entrada al convento de Santa Clara de Llerena de Rita Fernández, menor de edad.

Manuscrito; 4 folios (1 folio en blanco); Castellano; Buena

223 ADME/BA-CONVENTO-482-19062bis

1813,noviembre,24/1813,noviembre,26.Llerena

Entrada como educanda de Antonia Durán, menor de edad, en el convento de

Santa Clara de Llerena.

Manuscrito; 5 folios; Castellano; Buena

224 ADME/BA-CONVENTO-482-(8)

1752,junio,15.Llerena

Cartas de censura a favor del convento de Santa Clara de Llerena.

Manuscrito; 1 folio; Castellano; Buena

225 ADME/BA-CONVENTO-482-(9)

1734,julio,31.Llerena

Deuda de alhajas al convento de Santa Clara de Llerena.

Manuscrito; 1 folio; Castellano; Buena

226 ADME/BA-CONVENTO-483-19070

1671,(sm),(sd).Llerena

Memorial de bienes a favor de Magdalena Arévalo del convento de Santa Clara de Llerena.

Manuscrito; 5 folios; L. Procesal; Buena

227 ADME/BA-CONVENTO-588-22413

1701,agosto,23/1711,marzo,18.Llerena

El convento de Santa Clara de Llerena sobre el patronato de la capilla del convento.

Manuscrito; 44 folios (2 folios en blanco); Castellano; Buena

228 ADME/BA-CONVENTO-588-22414

1718,junio,8.Llerena/1718,junio,8.Fuente del Arco

Herencia a favor de dos religiosas del convento de Santa Clara de Llerena.

Manuscrito; 4 folios (1 folio en blanco); Castellano; Buena

Hispania Sacra, LXVII

135, enero-junio 2015, 61-168, ISSN: 0018-215X, doi: 10.3989/hs.2015.003 
229 ADME/BA-CONVENTO-588-22414bis

1853,marzo,4.Llerena

Estado de máxima pobreza en el convento de Santa Clara de Llerena.

Manuscrito; 2 folios; Castellano; Buena

230 ADME/BA-CONVENTO-588-22414bis

1751,septiembre,18.Llerena

Rotura del arca de caudales del convento de Santa Clara de Llerena.

Manuscrito; 1 folio; Castellano; Buena

231 ADME/BA-CONVENTO-588-(1)

$1858,(\mathrm{sm}),(\mathrm{sd})$. Llerena

Recibos de pagos en el convento de Santa Clara de Llerena.

Manuscrito; 12 cuartillas; Castellano; Buena

232 ADME/BA-CONVENTO-693-25276

1814,abril,14.Aracena/1814,mayo,4.Llerena

Nulidad de la profesión de María Josefa Carmona Gómez del convento de Santa Clara de Llerena.

Manuscrito; 14 folios (1 folio en blanco); Castellano; Buena

\section{ADME/BA-CONVENTO-1128-35971bis}

1796,diciembre,10.Llerena

Exploración de la voluntad de la novicia Vicenta Chávez en el convento de Santa Clara de Llerena.

Manuscrito; 2 folios; Castellano; Buena

234 ADME/BA-CONVENTO-1128-35980

1720,julio,20/1720,septiembre,20.Llerena-Madrid

Abandono de la clausura de una religiosa del convento de Santa Clara de Llerena por quebrantamiento.

Manuscrito; 19 folios (2 folios en blanco); Castellano; Buena

235 ADME/BA-CONVENTO-1185-37930

1788 ,agosto,30.Llerena

Fundación de la capellanía de Lorenzo de Figueroa en el convento de Santa Clara de Llerena.

Manuscrito; Libro; Castellano; Buena

236 ADME/BA-CONVENTO-1216-39426

(sd).(Llerena)/1673,diciembre,3.Llerena

Pleito entre Diego López de Castro y el convento de Santa Clara de Llerena.

Manuscrito; 4 folios y 1 cuartilla; Castellano y Latín; Buena

237 ADME/BA-CONVENTO-1219-39536

(sd).(Llerena)/1796,mayo,4.Llerena

Venta de unas casas pertenecientes al convento de Santa Clara de Llerena.

Manuscrito; 8 folios; Castellano; Buena 
238 ADME/BA-CONVENTO-1251-41316

(sd).(Llerena)/1694,marzo,13.Llerena

Deuda contraída con el convento de Santa Clara de Llerena.

Manuscrito; 6 folios; L. Procesal; Buena

239 ADME/BA-CONVENTO-23-440nº

1836,abril,24/ 1836,abril,28.Llerena

Nómina de religiosas enclaustradas en los conventos de Llerena.

Manuscrito; 13 folios (5 folios en blanco); Castellano; Buena

240 ADME/BA-CONVENTO-90-3898

1654,marzo,2/1654,marzo,20.Llerena

Petición de pago de una deuda contraída contra una religiosa del convento de Santa Isabel de Llerena.

Manuscrito; 4 folios; L. Procesal; Buena

241 ADME/BA-CONVENTO-91-3968

1779,abril,30.Llerena

Celebración de novenario en el convento de Santa Isabel de Llerena.

Manuscrito; 4 folios (1 folio en blanco); Castellano; Buena

242 ADME/BA-CONVENTO-785-28083

1760,octubre,31/1760,noviembre,28.Llerena

Arrendamiento de tierras del convento de Santa Isabel de Llerena.

Manuscrito; 10 folios (2 folios en blanco); Castellano; Buena

243 ADME/BA-CONVENTO-482-19026

1660,mayo,3.Llerena

Exploración de la voluntad de Úrsula Liasa en el convento de Santa Isabel de Llerena.

Manuscrito; 2 folios; L. Procesal; R (incompleto)

244 ADME/BA-CONVENTO-482-19027n²

1670,enero,14/1671,octubre,12.Llerena

Exploración de voluntades de novicias próximas a su profesión en conventos de Llerena.

Manuscrito; 20 folios (5 folios en blanco); L. Procesal; Buena

245 ADME/BA-CONVENTO-482-19052

1554,(sm),(sd).Llerena

Cuentas del convento de Santa Isabel de Llerena de 1554.

Manuscrito; Libro; L. Bastarda; R (manchas, roturas, pliegues)

246 ADME/BA-CONVENTO-482-19053

1597,julio,2/1604,junio,14.Llerena

Incumplimiento de un censo a favor del convento de Santa Isabel de Llerena.

Manuscrito; 25 folios; L. Procesal; R (manchas, roturas)

Hispania Sacra, LXVII

135, enero-junio 2015, 61-168, ISSN: 0018-215X, doi: 10.3989/hs.2015.003 
247 ADME/BA-CONVENTO-482-19054 1603 ,enero,13/1625,junio,2.Llerena

Herencia a favor de una religiosa del convento de Santa Isabel de Llerena.

Manuscrito; 17 folios; L. Procesal; R (desgaste de tintas)

248 ADME/BA-CONVENTO-482-19056

1627,enero,17.Llerena

Cesión de posesiones a favor de la religiosa Francisca Blasco del convento de Santa Isabel de Llerena.

Manuscrito; 5 folios; L. Procesal; R (manchas de humedad)

249 ADME/BA-CONVENTO-482-19057

1677,octubre,10.Llerena

Exploración de la voluntad de Clara Josefa Delgado en el convento de Santa Isabel de Llerena.

Manuscrito; 2 folios; L. Procesal; Buena

250 ADME/BA-CONVENTO-482-19059

1739,septiembre,29.Llerena

Exploración de la voluntad de Manuela Josefa de Ferrán en el convento de Santa Isabel de Llerena. Manuscrito; 2 folios; Castellano; Buena

251 ADME/BA-CONVENTO-482-19059bis

1739 ,septiembre,9.Llerena

Exploración de la voluntad de Josefa de Vargas en el convento de Santa Isabel de Llerena.

Manuscrito; 2 folios; Castellano; Buena

252 ADME/BA-CONVENTO-482-19059bis

$1743,(\mathrm{sm}),(\mathrm{sd})$. Llerena

Exploración de la voluntad de Antonia Molano en el convento de Santa Isabel de Llerena.

Manuscrito; 2 folios; Castellano; Buena

253 ADME/BA-CONVENTO-482-19059bis

1745 ,febrero,26.Llerena

Exploración de la voluntad de Antonia Maeso en el convento de Santa Isabel de Llerena.

Manuscrito; 2 folios; Castellano; Buena

254 ADME/BA-CONVENTO-482-19059bis

1750,marzo,19.Llerena

Exploración de la voluntad de Juana Manuela Moreno en el convento de Santa Isabel de Llerena.

Manuscrito; 2 folios; Castellano; Buena

255 ADME/BA-CONVENTO-482-19059bis

1759,marzo,18.Llerena

Exploración de la voluntad de Antonia Pérez en el convento de Santa Isabel de Llerena.

Manuscrito; 2 folios; Castellano; Buena 
256 ADME/BA-CONVENTO-482-19059bis

1750,mayo,19.Llerena

Exploración de la voluntad de Catalina de Soto en el convento de Santa Isabel de Llerena.

Manuscrito; 2 folios; Castellano; Buena

257ADME/BA-CONVENTO-482-19059bis

1772,febrero,17.Llerena

Exploración de la voluntad de Ana Miranda en el convento de Santa Isabel de Llerena.

Manuscrito; 2 folios; Castellano; Buena

258 ADME/BA-CONVENTO-482-19059bis

1790,octubre,9.Llerena

Exploración de la voluntad de Ana María González en el convento de Santa Isabel de Llerena.

Manuscrito; 3 folios; Castellano; Buena

259 ADME/BA-CONVENTO-482-19060

1766,agosto,20/1766,agosto,30.Llerena

Censo de unas tierras pertenecientes a una religiosa del convento de Santa Isabel de Llerena.

Manuscrito; 4 folios; Castellano; Buena

260 ADME/BA-CONVENTO-482-19061

1798 ,febrero,7/1792,octubre,20.Llerena

Incumplimiento de una dote de una novicia en el convento de Santa Isabel de Llerena.

Manuscrito; 11 folios; Castellano; Buena

261 ADME/BA-CONVENTO-482-19062

1799 ,septiembre,5.Llerena

Exploración de la voluntad de María de la Encarnación Jara en el convento de Santa Isabel de Llerena.

Manuscrito; 2 folios; Castellano; Buena

262 ADME/BA-CONVENTO-482-19062bis

1799, septiembre,5.Llerena

Exploración de la voluntad de María Lara Gómez en el convento de Santa Isabel de Llerenal

Manuscrito; 2 folios; Castellano; Buena

263 ADME/BA-CONVENTO-482-19062bis

1814,mayo,4.Llerena/(sd)(Llerena)

Salida temporal de la clausura de María Manuela Montero del convento de Santa Isabel de Llerena.

Manuscrito; 4 folios; Castellano; Buena

264 ADME/BA-CONVENTO-482-19063 1821, septiembre,29/1821, noviembre,6.Llerena-Madrid

Secularización perpetua de la religiosa Jacinta Durán en el convento de Santa Isabel de Llerena.

Manuscrito; 7 folios; Castellano y Latín; Buena

Hispania Sacra, LXVII

135, enero-junio 2015, 61-168, ISSN: 0018-215X, doi: 10.3989/hs.2015.003 
265 ADME/BA-CONVENTO-482-19063bis $\quad$ 1821, marzo,20/1821, noviembre,6.Llerena-Madrid

Secularización perpetua de la religiosa Antonia Cabeza en el convento de Santa Isabel de Llerena.

Manuscrito; 7 folios (1 folio en blanco); Castellano y Latín; R (roturas)

266 ADME/BA-CONVENTO-482-(1) 1821,septiembre,26.Madrid/1821, noviembre,13.Llerena Secularización perpetua de la religiosa María Rodríguez en el convento de Santa Isabel de Llerena. Manuscrito; 5 folios y 1 cuartilla; Castellano y Latín; Buena

267 ADME/BA-CONVENTO-482-(2) 1821,septiembre,26.Madrid/1821, noviembre,13.Llerena Secularización perpetua de Joaquina de San Francisco en el convento de Santa Isabel de Llerena. Manuscrito; 5 folios y 1 cuartilla; Castellano y Latín; Buena

268 ADME/BA-CONVENTO-482-(3) 1822,marzo,21/1822,mayo,22.Llerena-Madrid

Secularización perpetua de Encarnación López Jara en el convento de Santa Isabel de Llerena. Manuscrito; 4 folios (1 folio en blanco) y 2 cuartillas; Castellano; Buena

269 ADME/BA-CONVENTO-482-(4) 1822,marzo,21/1822,mayo,22.Llerena-Madrid

Secularización perpetua de la María Josefa López en el convento de Santa Isabel de Llerena. Manuscrito; 4 folios (1 folio en blanco); Castellano; Buena

270 ADME/BA-CONVENTO-482-(5) 1772,febrero,23.Llerena

Exploración de la voluntad de Josefa Agustina de Figueroa en el convento de Santa Isabel de Llerena.

Manuscrito; 2 folios; Castellano; Buena

271 ADME/BA-CONVENTO-1128-35964n ${ }^{\circ 2}$ (sd).(Llerena)/1606,marzo,10.Llerena

Deuda del convento de Santa Isabel al convento de Sebastián sitos en Llerena.

Manuscrito; 2 folios; L. Procesal; R (incompleto, roturas)

272 ADME/BA-CONVENTO-1128-35971bis 1796,noviembre,16.Llerena

Exploración de la voluntad de la novicia María Josefa Jara en el convento de Santa Isabel de Llerena.

Manuscrito; 2 folios; Castellano; R (manchas)

273 ADME/BA-CONVENTO-1128-35979bis

1821,mayo,10.Llerena/1821,mayo,23.Madrid

Salida de la clausura del convento de Santa Isabel de Llerena.

Manuscrito; 1 folio; Castellano; Buena 
274 ADME/BA-CONVENTO-1128-35979bis

(sd).(Llerena)/1821,mayo,8.Llerena

Renuncia de la abadesa del convento de Santa Isabel de Llerena.

Manuscrito; 1 folio; Castellano; Buena

275 ADME/BA-CONVENTO-1175-37439

1801,noviembre,16.Madrid-Llerena

Salida de la clausura de Jacinta Durana del convento de Santa Isabel de Llerena.

Manuscrito; 6 folios (1 folio en blanco); Castellano; Buena

276 ADME/BA-CONVENTO-1189-38100bis

(sd).(Llerena)/1727,noviembre,20.Llerena

Cuentas del convento de Santa Isabel de Llerena.

Manuscrito; 1 folio; Castellano; R (incompleto)

277 ADME/BA-CONVENTO-1251-41305

(sd).(Llerena)/1634,diciembre,2.Llerena

Deuda a la religiosa Beatriz Cabrera del convento de Santa Isabel de Llerena.

Manuscrito; 10 folios y 1 cuartilla; L. Procesal; Buena

278 ADME/BA-CONVENTO-1294-43249

(sd).(Llerena)/1669,agosto,18.Llerena

Sobre el patronazgo del convento de Santa Isabel de Llerena.

Manuscrito; 19 folios (1 folio blanco); L. Procesal; R (roturas)

279 ADME/BA-CONVENTO-1404-48239

1767.julio,31.Llerena

Diezmos por las tierras pertenecientes al convento de Santa Isabel de Llerena.

Manuscrito; 1 folio; Castellano; R (incompleto)

280 ADME/BA-CONVENTO-1343-45393

1838,julio,14/1838,julio,17.Llerena

Traslado de la campana del suprimido convento de Santa Isabel de Llerena.

Manuscrito; 2 folios; Castellano; Buena

281 ADME/BA-CONVENTO-11-(1)

1838,julio,3.Mérida/ 1838,julio,17.Badajoz

Traslado de religiosas del convento suprimido de santa Clara de Mérida.

Manuscrito; 1 cuartilla; Castellano; Buena

282 ADME/BA-CONVENTO-11-(7)

1838,julio,17.Badajoz

Traslado de religiosas de conventos suprimidos.

Manuscrito; 1 folio; Castellano; Buena

Hispania Sacra, LXVII

135, enero-junio 2015, 61-168, ISSN: 0018-215X, doi: 10.3989/hs.2015.003 
283 ADME/BA-CONVENTO-106-4527

Cuentas de cargo y data del convento de Santa Clara de Mérida.

Manuscrito; 40 folios (1 folio en blanco); L. Procesal; Buena

284 ADME/BA-CONVENTO-106-4529

1629.Mérida

Cuentas de cargo y data del convento de Santa Clara de Mérida.

Manuscrito; 55 folios (2 folios en blanco); L. Procesal; R (roturas)

285 ADME/BA-CONVENTO-504-20041

1802,agosto,11.Madrid-(Mérida)

Nulidad de profesión de Antonia Vallejo religiosa en el convento de Santa Clara de Mérida.

Manuscrito; 2 folios; Castellano; Buena

286 ADME/BA-CONVENTO-504-20041bis

1830,enero,14.Madrid/1830,febrero,16. Llerena-Mérida

Secularización de la religiosa de velo negro María Morgado en el convento de la Santa Clara de Mérida.

Manuscrito; 4 folios; Castellano y Latín; Buena

287 ADME/BA-CONVENTO-504-20041bis

1830,enero,14.Madrid/1830,febrero,16. Llerena-Mérida

Secularización de la religiosa de velo negro María Morgado en el convento de la Santa Clara de Mérida.

Manuscrito; 4 folios; Castellano y Latín; Buena

288 ADME/BA-CONVENTO-1146-(3)

1828,agosto,22.Mérida/1829,mayo,6.Llerena

Venta de una casa perteneciente al convento de Santa Clara de Mérida.

Manuscrito; 5 folios; Castellano; Buena

289 ADME/BA-CONVENTO-1146-(16)

1822,enero,2.Madrid/1822,febrero,23.Llerena-Mérida

Secularización perpetua de la religiosa Josefa Salguero del convento de Santa Clara de Mérida.

Manuscrito; 8 folios; Castellano y Latín; Buena

290 ADME/BA-CONVENTO-1146-(20)

1801,enero,7.Mérida

Renuncia de Antonia Vallejo a su estado religioso en el convento de Santa Clara de Mérida.

Manuscrito; 2 folios; Castellano; Buena 
291 ADME/BA-CONVENTO-1146-(21)

1801 ,abril,14.Mérida

Renuncia a su estado religioso en el convento de Santa Clara de Llerena.

Manuscrito; 2 folios; Castellano; Buena

292 ADME/BA-CONVENTO-1146-(22)

1802,junio,25.Mérida

Renuncia a su estado religioso en el convento de Santa Clara de Llerena.

Manuscrito; 1 cuartilla; Castellano; Buena

293 ADME/BA-CONVENTO-1146-(23)

1801,abril,25.Madrid/1801,mayo,5.Llerena-Mérida

Renuncia de una religiosa, a su estado, en el convento de Santa Clara de Llerena.

Manuscrito; 1 folio; Castellano; Buena

294 ADME/BA-CONVENTO-1146-(24)

1821,mayo,4.Mérida/1821,noviembre, 23.

Llerena-Madrid

Secularización perpetua de la religiosa Isabel María González del convento de Santa Clara de Mérida.

Manuscrito; 9 folios; Castellano y Latín; Buena

295 ADME/BA-CONVENTO-1146-(25) 1822,enero,2.Madrid/1822,febrero,23.Llerena-Mérida

Secularización perpetua de la religiosa profesa Antonia Vallejo del convento de Santa Clara de Mérida.

Manuscrito; 8 folios; Castellano; Buena

296 ADME/BA-CONVENTO-1146-(26) 1841,marzo,31.Mérida/1841.junio,30.Sevilla-Llerena

Salida de la clausura del convento de Santa Clara de Mérida de Juana de Arroyo.

Manuscrito; 8 folios (1 folio en blanco); Castellano; Buena

297 ADME/BA-CONVENTO-1146-(27)

1862,diciembre,7.Mérida/1863,marzo,23.Llerena

Traslado de una religiosa del convento de la Concepción de Mérida al de Santa Clara de Montijo.

Manuscrito; 2 folios; Castellano; Buena

298 ADME/BA-CONVENTO-1146-(28)

1864,octubre,3.Badajoz/1864,octubre,7. Montijo-Llerena

Traslado de una religiosa del convento de Santa Clara de Mérida al de Santa Clara de Montijo.

Manuscrito; 2 folios; Castellano; Buena

Hispania Sacra, LXVII

135, enero-junio 2015, 61-168, ISSN: 0018-215X, doi: 10.3989/hs.2015.003 
299 ADME/BA-CONVENTO-1146-(29)

1867,mayo,22.Mérida

Traslado de una religiosa del convento de Santa Clara de Mérida al de Santa Clara de Montijo.

Manuscrito; 2 folios; Castellano; Buena

300 ADME/BA-CONVENTO-1273-42347n ${ }^{0} 1$

1633,diciembre,1.Mérida

Cuentas de cargo y data del convento de Santa Clara de Mérida.

Manuscrito; 37 folios; L. Procesal; Buena

301 ADME/BA-CONVENTO-11-(4)

1838,agosto,13.Badajoz

Traslado de religiosas del convento suprimido de Santa Clara de Fregenal de la Sierra al de Montijo.

Manuscrito; 2 cuartillas; Castellano; Buena

302 ADME/BA-CONVENTO-23-440n ${ }^{0} 11$

[19--].(Montijo)

Nómina de religiosas enclaustradas en el convento de la Santa Clara de Montijo.

Manuscrito; 6 folios (3 folios en blanco); Castellano; Buena

303 ADME/BA-CONVENTO-23-(4)

1837,octubre,8.Montijo

Nomina de religiosas enclaustradas existentes en el convento de Santa Clara de Montijo.

Manuscrito; 2 folios; Castellano; Buena

304 ADME/BA-CONVENTO-716-25788

1855,agosto,18/1855, agosto,23.Montijo

Nombramiento de capellán en el convento de Santa Clara de Montijo.

Manuscrito; 2 cuartillas; Castellano; Buena

305 ADME/BA-CONVENTO-716-25788bis

1852,marzo,5.Montijo/1852,mayo,17.Mérida

Secularización perpetua de Valentina de San Antonio, lega del convento de Santa Clara de Montijo.

Manuscrito; 1 folio; Castellano; Buena

306 ADME/BA-CONVENTO-716-25805

1850,marzo,2/1850,mayo,5.Montijo-Mérida

Salida temporal de María Gragera del convento de Santa Clara de Montijo.

Manuscrito; 3 folios y 1 cuartilla; Castellano; Buena

307 ADME/BA-CONVENTO-282-12002

1859,octubre,29.Llerena/1861,junio,7.Montijo-Zafra

Toma de hábito de Isidora Vergara en el convento de Santa Clara de Montijo.

Manuscrito; 22 folios (1 folio en blanco); Castellano; Buena 
308 ADME/BA-CONVENTO-937-31506 1857,febrero,25/1857,abril,16.Montijo-Llerena

Nombramiento de capellán en el convento de Santa Clara de Montijo.

Manuscrito; 3 folios y 5 cuartillas; Castellano; Buena

309 ADME/BA-CONVENTO-1146-(28)

1864,octubre,3.Badajoz/1864,octubre,7. Montijo-Llerena

Traslado de una religiosa del convento de Santa Clara de Mérida al de Santa Clara de Montijo.

Manuscrito; 2 folios; Castellano; Buena

310 ADME/BA-CONVENTO-1146-(29)

1867,mayo,22.Mérida

Traslado de una religiosa del convento de Santa Clara de Mérida al de Santa Clara de Montijo.

Manuscrito; 2 folios; Castellano; Buena

311 ADME/BA-CONVENTO-208-8279

(sd).Villafranca de los Barros

Pago de la dote de una religiosa del convento de Santa Clara de Villafranca de los Barros.

Manuscrito; 2 folios (1 folio en blanco);Castellano; Buena

312 ADME/BA-CONVENTO-56-2727

(sd)/ 1678,mayo,5.Villafranca de los Barros-Llerena

Nombramiento de sargenta de cocina en el convento de Santa Clara de Villafranca de los Barros.

Manuscrito; 3 folios (1 folio en blanco); L. Procesal; Buena

\section{ADME/BA-CONVENTO-57-2751}

(sd).(Villafranca de los Barros)

Pedimento de bienes del mayordomo del convento de Santa Clara de Villafranca de los Barros.

Manuscrito; 124 folios; Castellano; Buena

\section{ADME/BA-CONVENTO-532-20861}

1816,mayo,27.Aceuchal/1816,mayo,29.

Villafranca de los Barros

Toma de hábito de Isabel Alvarado en el convento de Santa Clara de Villafranca de los Barros.

Manuscrito; 2 folios; Castellano; Buena

315 ADME/BA-CONVENTO-532-20861bis

1828 ,agosto, $4 / 1828$,agosto, 28 .

Villafranca de los Barros

Toma de hábito de Teresa Gordillo en el convento de Santa Clara de Villafranca de los Barros.

Manuscrito; 3 folios; Castellano; Buena

Hispania Sacra, LXVII

135, enero-junio 2015, 61-168, ISSN: 0018-215X, doi: 10.3989/hs.2015.003 
316 ADME/BA-CONVENTO-532-20861bis

1828,julio,29.Llerena/1828,agosto,11. Villafranca de los Barros

Toma de hábito de $M^{a}$ Encarnación Berjano en el convento de Santa Clara de Villafranca de los Barros.

Manuscrito; 4 folios; Castellano; Buena

317 ADME/BA-CONVENTO-532-20861bis

1833,junio,2/1833,junio,9. Villafranca de los Barros-Llerena

Profesión perpetua de María Gordillo en el convento de Santa Clara de Villafranca de los Barros.

Manuscrito; 6 folios; Castellano; Buena

318 ADME/BA-CONVENTO-532-20861bis $\quad$ 1828,septiembre, $9 / 1833$, septiembre,10.Villafranca Profesión perpetua de $M^{a}$ Antonia Morales en el convento de Santa Clara de Villafranca de los Barros.

Manuscrito; 8 folios (1 folio en blanco); Castellano; Buena

319 ADME/BA-CONVENTO-532-20861bis

1833,julio,25/1833,agosto, 1 . Villafranca de los Barros-Llerena

Toma de hábito de María Antonia Díaz en el convento de Santa Clara de Villafranca de los Barros. Manuscrito; 5 folios; Castellano; Buena

320 ADME/BA-CONVENTO-532-20861bis

1833,junio, $1 / 1833$,junio,5. Villafranca de los Barros-Llerena

Profesión perpetua de Isabel González en el convento de Santa Clara de Villafranca de los Barros.

Manuscrito; 5 folios y 1 cuartilla; Castellano; Buena

321 ADME/BA-CONVENTO-532-20862

1815,julio,24.Guadalcanal/1815,agosto,8. Villafranca de los Barros

Toma de hábito de María Antúnez en el convento de Santa Clara de Villafranca de los Barros.

Manuscrito; 2 folios; Castellano; Buena

322 ADME/BA-CONVENTO-532-20863

1705 ,enero,26.Villafranca /1705,enero,26. Fuente del Maestre

Herencia a favor del convento de Santa Clara de Villafranca de los Barros.

Manuscrito; 2 folios; Castellano; Buena 
323 ADME/BA-CONVENTO-532-20864

1801, septiembre,14.Llerena/1801, septiembre,16.

Villafranca

Elecciones de abadesa y oficialas en el convento de Santa Clara de Villafranca de los Barros.

Manuscrito; 5 folios; Castellano; Buena

324 ADME/BA-CONVENTO-532-20864bis $\quad$ 1827, agosto,11.Llerena/1827, agosto,23.Villafranca

Elecciones de abadesa en el convento de Santa Clara de Villafranca de los Barros.

Manuscrito; 5 folios; Castellano; Buena

325 ADME/BA-CONVENTO-532-20864bis

1830,octubre,23.Llerena/1830,noviembre,5. Villafranca

Elecciones de abadesa y oficialas en el convento de Santa Clara de Villafranca de los Barros.

Manuscrito; 4 folios; Castellano; Buena

326 ADME/BA-CONVENTO-532-20864bis

1830,octubre,23.Llerena/1830,noviembre,5. Villafranca

Elecciones de abadesa y oficialas en el convento de Santa Clara de Villafranca de los Barros.

Manuscrito; 4 folios; Castellano; Buena

327 ADME/BA-CONVENTO-532-20865

1855,octubre,20/1855, diciembre, 10 . Villafranca -Llerena

Venta de tierras pertenecientes al Santa Clara de Villafranca de los Barros para subsistencia. Manuscrito; 7 folios; Castellano; Buena

328 ADME/BA-CONVENTO-532-20865bis

1826,abril,22/1826,abril,27. Villafranca de los Barros-Llerena

Necesidad económica en el convento de Santa Clara de Villafranca de los Barros.

Manuscrito; 5 folios; Castellano; Buena

329 ADME/BA-CONVENTO-634-23756

1621,mayo,4.Villafranca de los Barros

Visita al convento de Santa Clara de Villafranca de los Barros para inspección de clausura.

Manuscrito; 9 folios; L. Procesal; Buena

330 ADME/BA-CONVENTO-969-32165

1698,febrero,20.Villafranca de los Barros

Cuentas del convento de Santa Clara de Villafranca de los Barros.

Manuscrito; 38 folios; L. Procesal; R (roturas)

Hispania Sacra, LXVII

135, enero-junio 2015, 61-168, ISSN: 0018-215X, doi: 10.3989/hs.2015.003 
331 ADME/BA-CONVENTO-1071-34382

1824,(sm),(sd).Villafranca de los Barros

Fundación de una capellanía en el convento de Santa Clara de Villafranca de los Barros

Manuscrito; 40 folios (2 folios en blanco); Castellano; Buena

332 ADME/BA-CONVENTO-1072-34386 1626,agosto,4.Fuente del Maestre/1627,febrero,12.

Villafranca

Testamento a favor de profesiones de religiosas en el convento de Santa Clara de Villafranca de los Barros.

Manuscrito; 25 folios (3 folios en blanco); L. Procesal; Buena

333 ADME/BA-CONVENTO-1273-42355

1634,noviembre,28.Villafranca de los Barros

Cuentas de cargo y data del convento de Santa Clara de Villafranca de los Barros.

Manuscrito; 54 folios; L. Procesal; Buena

334 ADME/BA-CONVENTO-1297-43379

1627,mayo,4.Villafranca de los Barros

Cuentas de cargo y dato del convento de Santa Clara de Villafranca de los Barros.

Manuscrito; 29 folios; L. Procesal; Buena

335 ADME/BA-CONVENTO-20 bis-(122)

1832,abril,16/ 1832,abril,26.Zafra/-Badajoz

Profesión perpetua de la novicia Guadalupe Toro en el convento de Santa Clara de Zafra.

Manuscrito; 4 folios y 1 cuartilla; Castellano; R (desgaste de bordes)

336 ADME/BA-CONVENTO-20 bis-(124) 1832,noviembre,9/ 1832,noviembre,19.Zafra-Badajoz

Profesión perpetua de las novicias María Antonia Rodríguez, organista y María Natividad González, cantora, en el convento de Santa Clara de Zafra.

Manuscrito; 4 folios y 1 cuartilla; Castellano; Buena

337 ADME/BA-CONVENTO-20 bis-(131)

1829,junio,29/ 1829,julio,11.Zafra-Badajoz

Profesión perpetua de Tomasa Gómez, lega, en el convento de Santa Clara de Zafra.

Manuscrito; 4 folios y 1 cuartilla; Castellano; Buena

338 ADME/BA-CONVENTO-20 bis-(140)

1829,noviembre,20/ 1829, diciembre,7.Zafra

Profesión perpetua de María Francisca Méndez en el convento de Santa Clara de Zafra.

Manuscrito; 4 folios y 1 cuartilla; Castellano; Buena 
339 ADME/BA-CONVENTO-20 bis-(141)

1824,marzo,3/ 1830,abril,4.Zafra-Badajoz

Profesión perpetua de Josefa Carrasco en el convento de Santa Clara de Zafra.

Manuscrito; 4 folios y 1 cuartilla; Castellano; Buena

340 ADME/BA-CONVENTO-20 bis-(147)

1857,abril,25.Zafra/ 1857,mayo,4.Badajoz

Entrada como educanda de María Josefa Berjano y Moreno en el convento de Santa Clara de Zafra.

Manuscrito; 4 folios (2 folios en blanco); Castellano y Latín; Buena

341 ADME/BA-CONVENTO-23-439

1837,octubre,8.Mérida/ 1837,octubre,20.Zafra

Secularizados de la provincia de Badajoz en el año 1837.

Manuscrito; 5 folios y 1 folio doble; Castellano; Buena

342 ADME/BA-CONVENTO-23-440n ${ }^{0} 19$

1836,marzo,28.Zafra

Nómina de religiosas enclaustradas en los conventos de Zafra.

Manuscrito; 14 folios ( 8 folios en blanco) y 1 cuartilla; Castellano; Buena

343 ADME/BA-CONVENTO-40-1132

1777.Zafra-Jerez de los Caballeros

Pleito entre la mesa Maestral de Jerez de los Caballeros y el convento de Santa Clara de Zafra.

Manuscrito; 494 folios; Castellano; R (desgaste de tintas)

344 ADME/BA-CONVENTO-82-2192

1674.Zafra

Escritura de bienes del convento de Santa Clara de Zafra.

Manuscrito; 21 folios; L. Procesal; M (roturas graves)

345 ADME/BA-CONVENTO-87-3105

1750.Zafra

Autos contra el convento de Santa Clara de Zafra por impago de diezmos.

Manuscrito; 51 folios; Castellano; Buena

346 ADME/BA-CONVENTO-89-3138

1797.Zafra

Fundación de una obra pía en el convento de Santa Clara de Zafra.

Manuscrito; 27 folios y 2 cuartillas; Castellano; Buena

347 ADME/BA-CONVENTO-210-8488

1678,Marzo,5.Almendralejo

Denuncia del Convento de la Concepción de Almendralejo a Fernando Nieto por deudas.

Manuscrito; 1 folio; L. Procesal; R (roturas y manchas de humedad)

Hispania Sacra, LXVII

135, enero-junio 2015, 61-168, ISSN: 0018-215X, doi: 10.3989/hs.2015.003 
348 ADME/BA-CONVENTO-210-8487 1

876,Octubre,30.Almendralejo

Petición de traslado de María Lobo e Isabel Mendoza al Convento de la Concepción en Valencia del Ventoso, ya que el convento de Almendralejo permanecía cerrado desde 1836.

Manuscrito; 1 folio; Castellano; Buena

349 ADME/BA-CONVENTO-424-17479n²2 1803,Julio,27.Llerena/1803,Agosto,6.Almendralejo Elección de abadesa en el Convento de la Concepción de Almendralejo.

Manuscrito; 7 folios; Castellano; Buena

350 ADME/BA-CONVENTO-1329-44902

1646,marzo,2.Almendralejo

Estado de cuentas del convento de la Concepción de Almendralejo.

Manuscrito; 48 folios; L. Procesal; R (bordes rotos y manchas de humedad)

351 ADME/BA-CONVENTO-1082-34505n ${ }^{0} 1$

1795, Febrero,2/1795,Febrero,10. Almendralejo

Visita al convento de la Concepción de Almendralejo para la revisión de cuentas.

Manuscrito; 6 folios; Castellano; Buena

352 ADME/BA-CONVENTO-1082-34505n²

1795 ,febrero,4/1795,febrero,10.Almendralejo

Visita al convento de la Concepción de Almendralejo, para revisión de cuentas.

Manuscrito; 21 folios; Castellano; Buena

353 ADME/BA-CONVENTO-1082-34505n 3

1798,Junio,11.Almendralejo

Cuentas de cargo y data del convento de la Concepción de Almendralejo, 1798.

Manuscrito; 21 folios; Castellano; Buena

354 ADME/BA-CONVENTO-836-29507

1630,(sm),(sd).Almendralejo

Cuentas de cargo y data del convento de la Concepción de Almendralejo, 1630.

Manuscrito; Libro; L. Procesal; Buena

355 ADME/BA-CONVENTO-1273-42356

1634,(sm),(sd).Almendralejo

Cuentas de cargo y data del convento de la Concepción de Almendralejo, 1634.

Manuscrito; 15 folios, L. Procesal; Buena

356 ADME/BA-CONVENTO-23-440n 22

1836,abril,25.Almendralejo

Nómina de religiosas enclaustradas en los conventos de Almendralejo.

Manuscrito; 5 folios; Castellano; Buena 
357 ADME/BA-CONVENTO-1273-42356 1634,(sm),(sd). Almendralejo

Cuentas de cargo y data del convento de la Concepción de Almendralejo.

Manuscrito; 68 folios; L. Procesal; Buena

358 ADME/BA-CONVENTO-23-440n ${ }^{0} 18$

1836,abril,2.Zalamea de la Serena

Nómina de religiosas enclaustradas en el convento de la Concepción de Zalamea de la Serena.

Manuscrito; 6 folios (2 folios en blanco); Castellano; Buena

359 ADME/BA-CONVENTO-20 bis-(132)

1827 ,enero,24/ 1827 ,febrero,7.Zafra-Badajoz

Profesión perpetua de Ángela de las Eras en el convento de la Cruz de Cristo.

Manuscrito; 4 folios (1 folio en blanco); Castellano; Buena

360 ADME/BA-CONVENTO-20 bis-(133)

1826,julio,18/ 1826,agosto,2.Zafra-Badajoz

Profesión perpetua de Manuela Rastrollo en el convento de la Cruz de Cristo.

Manuscrito; 3 folios; Castellano; Buena

361 ADME/BA-CONVENTO-20 bis-(136)

1810,septiembre,9/ 1810,noviembre,16.Zafra

Profesión perpetua de Ana María Loza como religiosa de coro en el convento de la Cruz de Cristo.

Manuscrito; 4 folios; Castellano; Buena

362 ADME/BA-CONVENTO-20 bis-(137)

1819 ,octubre,26.Zafra

Profesión perpetua de Dionisia de la Encarnación en el convento de la Cruz de Cristo.

Manuscrito; 5 folios (1 folio en blanco); Castellano; Buena

363 ADME/BA-CONVENTO-20 bis-(138) 1814,octubre,23/ 1814,noviembre,6.Zafra-Badajoz Profesión perpetua de Vicenta Jiménez en el convento de la Cruz de Cristo.

Manuscrito; 3 folios y 1 cuartilla; Castellano; Buena

364 ADME/BA-CONVENTO-20 bis-(129)

1833,octubre,21/ 1833,noviembre,14.Zafra-Badajoz

Profesión perpetua de Isabel de San Francisco en el convento de Santa Marina de Zafra.

Manuscrito; 6 folios ( 1 folio en blanco) y 1 cuartilla; Castellano; Buena

365 ADME/BA-CONVENTO-11-446n²1

1836,abril,30.Zafra

Datos de la enclaustrada Juana López Caballero en el convento de Santa Marina de Zafra.

Manuscrito; 7 folios (1 folio en blanco); Castellano; Buena

Hispania Sacra, LXVII

135, enero-junio 2015, 61-168, ISSN: 0018-215X, doi: 10.3989/hs.2015.003 
366 ADME/BA-CONVENTO-11-446n 22

1836,abril,30.Zafra

Datos de la enclaustrada María Teresa López en el convento de Santa Marina de Zafra.

Manuscrito; 6 folios; Castellano; Buena

367 ADME/BA-CONVENTO-23-440nº19

1836,marzo,28.Zafra

Nómina de religiosas enclaustradas en los conventos de Zafra.

Manuscrito; 14 folios (8 folios en blanco) y 1 cuartilla; Castellano; Buena

368 ADME/BA-CONVENTO-89-3158n9

1818.Zafra

Autos ocasionados por impagos al convento de Santa Marina de Zafra.

Manuscrito; 235 folios; Castellano; Buena

369 ADME/BA-CONVENTO-20 bis-(81)

1817,octubre,12/1817,octubre,31.Jerez -Badajoz

Profesión perpetua de María del Carmen Montero en el convento de la Esperanza de Jerez.

Manuscrito; 3 folios y 1 cuartilla; Castellano; Buena

370 ADME/BA-CONVENTO-20 bis-(84) 1826,noviembre,12/ 1826,diciembre,4.Jerez-Badajoz

Profesión perpetua de Francisca de Santa Isabel y María del Carmen de San Francisco en el convento de la Esperanza de Jerez de los Caballeros.

Manuscrito; 4 folios y 1 cuartilla; Castellano; Buena

371 ADME/BA-CONVENTO-20 bis-(91)

1832,septiembre,20/ 1832,octubre,20.Jerez-Badajoz

Profesión perpetua de $M^{a}$ Concepción Soler en el convento de la Esperanza De Jerez.

Manuscrito; 4 folios y 1 cuartilla; Castellano; Buena

372 ADME/BA-CONVENTO-40-1137n²

1783 ,diciembre,9.Badajoz/1784,enero,12.Jerez

Profesión perpetua de la novicia Antonia de San Cayetano en el convento de la Esperanza de Jerez.

Manuscrito; 6 folios; Castellano; Buena

373 ADME/BA-CONVENTO-42-1172

1820,diciembre,10.Madrid/1820,diciembre,22.

Badajoz-Jerez

Salida de la clausura de la religiosa María de la Concepción Jara del convento de la Esperanza de Jerez de los Caballeros.

Manuscrito; 10 folios y 1 cuartilla; Castellano y Latín; Buena 
374 ADME/BA-CONVENTO-42-1175n6

1821,marzo,12/1821,diciembre,21.

Badajoz-Madrid-Jerez

Secularización perpetua de María Paurano del convento de la Esperanza de Jerez de los Caballeros. Manuscrito; 4 folios; Castellano y Latín; Buena

375 ADME/BA-CONVENTO-10-207

1843,marzo,31.Madrid/ 1846,junio,20.Burguillos-Oliva•Badajoz-Olivenza-JerezAlmendral-Alconchel-Villalba-Valverde -Alburquerque-Talavera-Fregenal Real orden 31/3/1843 sobre iglesias que deben estar abiertas en conventos suprimidos.

Manuscrito e impreso; 18 folios ( 1 fol. blanco) y 24 cuartillas ( 6 cuartillas en blanco); Castellano; Buena

376 ADME/BA-CONVENTO-20 bis-(62)

1830.julio,31/ 1830,septiembre,8.Jerez-Badajoz

Toma de hábito de Josefa Cano en el convento de la Consolación de Jerez de los Caballeros.

Manuscrito; 3 folios y 1 cuartilla; Castellano; Buena

377 ADME/BA-CONVENTO-20 bis-(63)

1830,febrero,10/1831,abril,10.Jerez -Oliva-Badajoz

Toma de hábito y profesión perpetua de Josefa Becerra en el convento de la Consolación de Jerez.

Manuscrito; 6 folios y 1 cuartilla; Castellano; Buena

378 ADME/BA-CONVENTO-20 bis-(64)

1824,octubre,4/ 1824,octubre,12. Jerez de los Caballeros.

Toma de hábito de Agustina Meléndez en el convento de la Consolación de Jerez de los Caballeros.

Manuscrito; 2 folios y 1 cuartilla; Castellano; Buena

379 ADME/BA-CONVENTO-20 bis-(65)

1824 ,septiembre,27/ 1824,octubre,9. Jerez de los Caballeros

Profesión perpetua de Mónica Menéndez en el convento de la Consolación de Jerez.

Manuscrito; 2 folios y 1 cuartilla; Castellano; Buena

380 ADME/BA-CONVENTO-20 bis-(70)

1827,agosto,10.Jerez / 1829,diciembre,6.Olivares-Badajoz

Toma de hábito de María de la Encarnación Pérez en el convento de la Consolación de Jerez.

Manuscrito; 5 folios; Castellano; Buena

381 ADME/BA-CONVENTO-20 bis-(73)

1830,julio,31/1831,octubre, 18 .

Jerez-Badajoz-Fuentes de León

Toma de hábito y profesión perpetua de Isabel Vázquez en el convento de la Consolación de Jerez. Manuscrito; 9 folios y 1 cuartilla; Castellano; Buena

Hispania Sacra, LXVII

135, enero-junio 2015, 61-168, ISSN: 0018-215X, doi: 10.3989/hs.2015.003 
382 ADME/BA-CONVENTO-20 bis-(77)

1807 ,enero,10/ 1807,mayo,28. Jerez de los Caballeros-Badajoz

Profesión perpetua de María Isabel en el convento de la Consolación de Jerez de los Caballeros.

Manuscrito; 2 folios; Castellano; R (incompleto)

383 ADME/BA-CONVENTO-11-435

1600 ,mayo,1/ 1600,mayo,12. Jerez de los Caballeros-Badajoz

Toma de hábito de Feliciana María Pimentel en el convento de la Consolación de Jerez.

Manuscrito; 4 folios; L. Procesal; Buena

384 ADME/BA-CONVENTO-23-440n ${ }^{0} 17$

[19--].(Jerez de los Caballeros)

Nómina de religiosas enclaustradas en los conventos de Jerez de los Caballeros.

Manuscrito; 11 folios (6 folios en blanco); Castellano; Buena

385ADME/BA-CONVENTO-23-447

1812,noviembre,23.Valencia de Alcántara/ 1812,diciembre,10.Jerez

Abandono del convento de la Consolación de Jerez de los Caballeros.

Manuscrito; 4 folios; Castellano; Buena

386 ADME/BA-CONVENTO-38-1081

1750,junio,21.Badajoz/ 1750,junio,21.Jerez de los Caballeros

Declaraciones de enclaustradas en el convento de la Consolación de Jerez de los Caballeros.

Manuscrito; 17 folios; Castellano; Buena

387 ADME/BA-CONVENTO-38-1079

1775,julio,23.Badajoz/ 1775, agosto,3.Jerez de los Caballeros

Elección de abadesa en el convento de la Consolación de Jerez de los Caballeros.

Manuscrito; 15 folios; L. Procesal; Buena

388 ADME/BA-CONVENTO-40-1131

1760,(sm),(sd).Jerez de los Caballeros

Apelación de un pleito del convento de la Consolación de Jerez de los Caballeros.

Manuscrito; Libro; Castellano; R (desgaste de tinta)

389 ADME/BA-CONVENTO-40-1136n² $2 \mathrm{bis}$

1786,septiembre,12. Badajoz/

1786,septiembre,22.Jerez

Elección de abadesa en el convento de la Consolación de Jerez de los Caballeros.

Manuscrito; 4 folios; Castellano; Buena 
390 ADME/BA-CONVENTO-41-1149

1799 ,septiembre,19. Jerez / 1799 ,septiembre,23. Badajoz

Pleito convento de la Consolación de Jerez de los Caballeros.

Manuscrito; 6 folios y 1 cuartilla; Castellano; R (desgaste de tintas)

391 ADME/BA-CONVENTO-41-1160

1816,abril,16.Badajoz/

1816,abril,30.Jerez de los Caballeros

Elección de priora en el convento de Gracia y en el convento de la Consolación de Jerez.

Manuscrito; 6 folios (1 folio en blanco); Castellano; Buena

392 ADME/BA-CONVENTO-41-1154

1813,abril,6.Jerez de los Caballeros

Elección de abadesa en el convento de la Consolación de Jerez de los Caballeros.

Manuscrito; 2 folios; Castellano; Buena

\section{ADME/BA-CONVENTO-42-1182}

1824,septiembre,3.Jerez de los Caballeros

Visita del obispo Mateo Delgado y Moreno al convento de la Consolación de Jerez de los Caballeros para inspección de la clausura.

Manuscrito; 2 folios (1 folio en blanco); Castellano; Buena

394 ADME/BA-CONVENTO-42-1178n ${ }^{\circ} 1$

1821,marzo,2/1821,abril,5. Badajoz-Jerez de los Caballeros

Secularización perpetua de la religiosa Mónica Meléndez del convento de la Consolación de Jerez. Manuscrito; 4 folios; Castellano y Latín; Buena

395 ADME/BA-CONVENTO-42-1178n5 $\quad$ 1822,enero,30/1822,marzo,25.Badajoz-Jerez-Madrid Secularización perpetua de Inés Pallejo del convento de la Consolación de Jerez de los Caballeros. Manuscrito; 4 folios; Castellano y Latín; Buena

396 ADME/BA-CONVENTO-43-1197

1711,julio,24.Badajoz/1711,septiembre,15. Jerez de los Caballeros

Elecciones de priora y oficialas en el convento de la Consolación de Jerez de los Caballeros.

Manuscrito; 4 folios (1 folio en blanco); Castellano; Buena

397 ADME/BA-CONVENTO-43-1201

1832,(sm),(sd).Jerez de los Caballeros

Cuentas del convento de la Consolación de Jerez de los Caballeros.

Manuscrito; 58 folios; Castellano; Buena

Hispania Sacra, LXVII

135, enero-junio 2015, 61-168, ISSN: 0018-215X, doi: 10.3989/hs.2015.003 
398 ADME/BA-CONVENTO-43-1203

1834,abril,8.Jerez de los Caballeros

Cuentas del convento de la Consolación de Jerez de los Caballeros.

Manuscrito; 7 folios y 3 cuartillas; Castellano; Buena

399 ADME/BA-CONVENTO-43-1203bis

1833,(sm),(sd).Jerez de los Caballeros

Autos ocasionados por cuentas de mayordomía presentadas por el capellán Luis Martín Céspedes del convento de la Consolación de Jerez de los Caballeros.

Manuscrito; 23 folios y 1 cuartilla; Castellano; Buena

400ADME/BA-CONVENTO-43-1203bis

1834,junio,15.Jerez de los Caballeros

Salario indebido para el mayordomo del convento de la Consolación de Jerez de los Caballeros.

Manuscrito; 2 folios (1 folio en blanco); Castellano; Buena

401 ADME/BA-CONVENTO-23-440n 3

1836,abril,28.Cabeza del Buey

Nómina de religiosas enclaustradas en el convento de la Concepción de Cabeza del Buey.

Manuscrito; 5 folios (2 folios en blanco); Castellano; Buena

402 ADME/BA-CONVENTO-23-(8)

1837,octubre,31. Cabeza del Buey

Nomina de religiosas enclaustradas existentes en el convento de la Concepción de Cabeza del Buey.

Manuscrito; 1 folio; Castellano; Buena

403 ADME/BA-CONVENTO-23-(9)

1837,abril,26/1837,mayo,4.Cabeza del Buey

Impago de nómina de religiosa enclaustrada en el convento de la Concepción de Cabeza del Buey.

Manuscrito; 2 folios; Castellano; Buena

404 ADME/BA-CONVENTO-23-(10)

1837,noviembre,12.Cabeza del Buey

Nomina de religiosas enclaustradas existentes en el convento de la Concepción de Cabeza del Buey.

Manuscrito; 2 folios; Castellano; Buena

405 ADME/BA-CONVENTO-23-440n ${ }^{\circ} 7$

[19--].(Fuente de Cantos)

Nómina de religiosas enclaustradas en el convento de la Concepción de Fuente de Cantos.

Manuscrito; 4 folios (2 folios en blanco); Castellano; Buena

406 ADME/BA-CONVENTO-1273-42346

1634,(sm),(sd).Mérida

Cuentas de cargo y data del convento de la Concepción de Fuente de Cantos.

Manuscrito; 55 folios (1 folio en blanco); L. Procesal; Buena 
407 ADME/BA-CONVENTO-1297-43381

1627,septiembre,6.Fuente de Cantos

Cuentas de cargo y dato del convento de la Concepción de Fuente de Cantos.

Manuscrito; 41 folios; L. Procesal; Buena

408 ADME/BA-CONVENTO-1380-45966

1867,septiembre,18.Fuente de Cantos

Nombramiento de capellán en el convento de la Concepción de Fuente de Cantos.

Manuscrito; 4 folios; Castellano; Buena

409 ADME/BA-CONVENTO-1400-48095

(sd).(Fuente de Cantos)/1793,octubre,23. Fuente de Cantos

Venta de unas tierras pertenecientes al convento de la Concepción de Fuente de Cantos.

Manuscrito; 4 folios (1 folio en blanco); Castellano; Buena

410 ADME/BA-CONVENTO-1400-48097

(sd).(Fuente de Cantos)/1793,octubre,28. Fuente de Cantos

Venta de un solar perteneciente al convento de la Concepción de Fuente de Cantos.

Manuscrito; 4 folios; Castellano; Buena

411 ADME/BA-CONVENTO-1400-48098

(sd).(Fuente de Cantos)/1793,noviembre,11.

Fuente de Cantos

Venta de una casa de morada perteneciente al convento de la Concepción de Fuente de Cantos.

Manuscrito; 4 folios; Castellano; Buena

412 ADME/BA-CONVENTO-23-440n 6

[19--].(Fuente del Maestre)

Nómina de religiosas enclaustradas en el convento de la Concepción de Fuente del Maestre.

Manuscrito; 4 folios (2 folios en blanco); Castellano; Buena

413 ADME/BA-CONVENTO-358-15597n ${ }^{0} 1$

1646,(sm),(sd).Fuente del Maestre

Cuentas del convento de la Concepción de Fuente del Maestre.

Manuscrito; 53 folios (1 folio en blanco); L. Procesal; R (bordes rotos)

414 ADME/BA-CONVENTO-358-15597n²

1659,(sm),(sd).Fuente del Maestre

Cuentas del convento de la Concepción de Fuente del Maestre.

Manuscrito; 46 folios; L. Procesal; Buena

Hispania Sacra, LXVII

135, enero-junio 2015, 61-168, ISSN: 0018-215X, doi: 10.3989/hs.2015.003 
415 ADME/BA-CONVENTO-455-18304n ${ }^{\circ} 2$

1735 ,febrero,8.Fuente del Maestre

Elección de abadesa en el convento de la Concepción de la Fuente del Maestre.

Manuscrito; 8 folios (1 folio en blanco); Castellano; Buena

416 ADME/BA-CONVENTO-455-18304n³

1802,mayo,16.Almendralejo/1 802,mayo,23.F. del Maestre

Elección de abadesa en el convento de la Concepción de la Fuente del Maestre.

Manuscrito; 7 folios (1 folio en blanco); Castellano; Buena

417ADME/BA-CONVENTO-455-18304n ${ }^{\circ} 4$

1821,julio,14.Llerena/1827,agosto,2. F. Maestre-F. Cantos

Elección de abadesa y oficialas en el convento de la Concepción de la Fuente del Maestre.

Manuscrito; 6 folios y 2 cuartillas; Castellano; Buena

418 ADME/BA-CONVENTO-455-18304n 5

1835,julio,1.Llerena-(Fuente del Maestre)

Entrada en el convento de la Concepción de Fuente del Maestre de Isabel María Sánchez y Cándida Sánchez en calidad de educandas.

Manuscrito; 5 folios (2 folios en blanco); Castellano y Latín; R (incompleto)

419 ADME/BA-CONVENTO-455-18304n5 5 bis

1827,mayo,19.Llerena/1827,mayo,30. Fuente del Maestre

Elección de abadesa y oficialas en el convento de la Concepción de la Fuente del Maestre.

Manuscrito; 5 folios; Castellano; Buena

420 ADME/BA-CONVENTO-455-18304n ${ }^{\circ} 6$

1826,(sm),(sl).Fuente del Maestre

Profesión perpetua de María Granada Ruiz en el convento de la Concepción de Fuente del Maestre.

Manuscrito; 1 folio; Castellano; R (incompleto)

421 ADME/BA-CONVENTO-455-18304n ${ }^{\circ} 7$

1826,marzo,19.Fuente del Maestre/ 1826,marzo,21.Llerena

Profesión perpetua de Julia Mármol en el convento de la Concepción de Fuente del Maestre.

Manuscrito; 1 folio; Castellano; R (incompleto)

422 ADME/BA-CONVENTO-455-18307n ${ }^{0} 1$

1677,(sm),(sd).Fuente del Maestre

Cuentas del convento de la Concepción de Fuente del Maestre.

Manuscrito; Libro; Castellano; Buena 
423 ADME/BA-CONVENTO-455-18307n² 1770,mayo,10.Fuente del Maestre

Cuentas del convento de la Concepción de Fuente del Maestre formadas por Diego García. Manuscrito; 40 folios; Castellano; Buena

424 ADME/BA-CONVENTO-455-18307n'3 1760,mayo,13/1760, mayo,14.Fuente del Maestre Elección de abadesa y oficialas en el convento de la Concepción de la Fuente del Maestre.

Manuscrito; 7 folios; Castellano; Buena

425 ADME/BA-CONVENTO-455-18307n³bis

(sd).Fuente del Maestre

Entrada al convento de la Concepción de Fuente del Maestre de un abogado de las Reales Consejos. Manuscrito; 1 folio; Castellano; R (incompleto)

426 ADME/BA-CONVENTO-455-18307n³bis 1770 ,enero,31/1770,julio,31.(Fuente del Maestre) Pleito del convento de la Concepción de Fuente del Maestre.

Manuscrito; 1 folio; Castellano; R (incompleto)

427 ADME/BA-CONVENTO-455-18308 1824,marzo,27.Llerena/1824, abril,26.Fuente del Maestre Elección de abadesa y oficialas en el convento de la Concepción de la Fuente del Maestre.

Manuscrito; 6 folios; Castellano; Buena

428 ADME/BA-CONVENTO-455-18309 1826,marzo,6.Zafra/(sd).(sl)-Llerena-Fuente del Maestre Dote a favor de una religiosa del convento de la Concepción de Fuente del Maestre.

Manuscrito; 3 folios; Castellano; Buena

429 ADME/BA-CONVENTO-455-18310

1788,agosto,2.Llerena-(Fuente del Maestre)

Dote a favor de una religiosa del convento de la Concepción de Fuente del Maestre.

Manuscrito; 3 folios (1 folio en blanco); Castellano; R (roturas)

430 ADME/BA-CONVENTO-455-18313n²

1787,enero,22.Madrid/1787,febrero,3. (Fuente del Maestre)

Liquidación de cuentas de mayordomía en el convento de la Concepción de Fuente del Maestre.

Manuscrito; 8 folios (2 folios en blanco); Castellano; Buena

431 ADME/BA-CONVENTO-455-18313n5

1784,febrero,6.Fuente del Maestre

Dote a favor de una religiosa del convento de la Concepción de Fuente del Maestre.

Manuscrito; 2 folios (1 folio en blanco); Castellano; Buena

Hispania Sacra, LXVII

135, enero-junio 2015, 61-168, ISSN: 0018-215X, doi: 10.3989/hs.2015.003 
432 ADME/BA-CONVENTO-455-18313nº5bis

(sd).(Fuente del Maestre)/1789,abril,20.Llerena

Profesión de Gregoria Fernández en el convento de la Concepción de Fuente del Maestre.

Manuscrito; 2 folios; Castellano; R (incompleto)

433 ADME/BA-CONVENTO-674-24815

1708,septiembre,13/1708,diciembre,2.

Fuente del Maestre

Dote a favor de una religiosa del convento de la Concepción de Fuente del Maestre.

Manuscrito; 6 folios; Castellano; Buena

434 ADME/BA-CONVENTO-674-24822 (sd).Fuente del Maestre)/1678,noviembre,20. Calzadilla División de una celda en el convento de la Concepción de Fuente del Maestre.

Manuscrito; 13 folios (2 folios en blanco); L. Procesal; R (varios folios ilegibles por desgaste de tintas)

435 ADME/BA-CONVENTO-771-27654

1627,junio,16.Los Santos /1627,agosto,3. Fuente del Maestre

Pleito de Alonso Bolaños contra el convento de la Concepción de Fuente del Maestre.

Manuscrito; 20 folios; L. Procesal; Buena

436 ADME/BA-CONVENTO-771-27655

1784,marzo,8.Fuente del Maestre

Cuentas de cargo y data del convento de la Concepción de Fuente del Maestre.

Manuscrito; 27 folios; Castellano; Buena

437 ADME/BA-CONVENTO-886-30521

1653,(sm),(sd).Fuente del Maestre

Cuentas del convento de la Concepción de Fuente del Maestre.

Manuscrito; 56 folios; L. Procesal; Buena

438 ADME/BA-CONVENTO-886-30522n ${ }^{\circ} 1$

1668,(sm),(sd).Fuente del Maestre

Cuentas del convento de la Concepción de Fuente del Maestre.

Manuscrito; 105 folios; L. Procesal; Buena

439 ADME/BA-CONVENTO-886-30522n ${ }^{2} 2$

1699,octubre,11.Fuente del Maestre

Cuentas del convento de la Concepción de Fuente del Maestre.

Manuscrito; Libro; L. Procesal; Buena

440 ADME/BA-CONVENTO-886-30522n 3

1706,mayo,12.Fuente del Maestre

Cuentas del convento de la Concepción de Fuente del Maestre.

Manuscrito; Libro; Castellano; Buena 
441 ADME/BA-CONVENTO-886-30522n ${ }^{\circ} 4$ 1740,(sm),(sd).Fuente del Maestre

Cuentas del convento de la Concepción de Fuente del Maestre.

Manuscrito; Libro; Castellano; Buena

442 ADME/BA-CONVENTO-886-30522n ${ }^{05}$

1762,(sm),(sd).Fuente del Maestre

Cuentas del convento de la Concepción de Fuente del Maestre.

Manuscrito; Libro; Castellano; Buena

443 ADME/BA-CONVENTO-1004-33156n ${ }^{0} 1$

1689,(sm),(sd).Fuente del Maestre

Cuentas del convento de la Concepción de Fuente del Maestre.

Manuscrito; Libro; L. Procesal; Buena

444 ADME/BA-CONVENTO-1004-33156n²

1689,(sm),(sd).Fuente del Maestre

Cuentas del convento de la Concepción de Fuente del Maestre.

Manuscrito; 36 folios; L. Procesal; Buena

445 ADME/BA-CONVENTO-1004-33156n 3

1690,(sm),(sd).Fuente del Maestre

Cuentas del convento de la Concepción de Fuente del Maestre.

Manuscrito; 11 folios (1 folio en blanco); L. Procesal; Buena

446 ADME/BA-CONVENTO-1004-33157

(sd).Fuente del Maestre

Testamento a favor del convento de la Esperanza de Fuente del Maestre.

Manuscrito; 119 folios; Castellano; R (manchas, roturas)

447 ADME/BA-CONVENTO-1005-33168

1688,(sm),(sd).Fuente del Maestre

Cuentas del convento de la Concepción de Fuente del Maestre.

Manuscrito; 111 folios; L. Procesal; Buena

448 ADME/BA-CONVENTO-1113-35530

1657,mayo,30/1657,mayo,31.Fuente del Maestre

Dote que una novicia entrega para ingresar en el convento de la Concepción de Fuente del Maestre.

Manuscrito; 1 folio; L. Procesal; R (incompleto)

449 ADME/BA-CONVENTO-1172-37259

1724,enero,19.Fuente del Maestre

Cuentas de cargo y data del convento de la Concepción de Fuente del Maestre.

Manuscrito; 43 folios (1 folio en blanco); Castellano; R (desgaste de tintas)

Hispania Sacra, LXVII

135, enero-junio 2015, 61-168, ISSN: 0018-215X, doi: 10.3989/hs.2015.003 
450 ADME/BA-CONVENTO-1188-38050

(sd).(Fuente del Maestre)/1813,octubre,10.Llerena

Venta de unas tierras pertenecientes al convento de la Concepción de Fuente del Maestre.

Manuscrito; 20 folios y 1 cuartilla; Castellano; Buena

451 ADME/BA-CONVENTO-1273-42336

1770,agosto,10.Mérida

Visita realizada para inspección del convento de la Concepción de Fuente del Maestre.

Manuscrito; 27 folios (1 folio en blanco); Castellano; Buena

452 ADME/BA-CONVENTO-1400-48088

1793,mayo,7.Fuente del Maestre

Cuentas de cargo y data del convento de la Concepción de Fuente del Maestre.

Manuscrito; 35 folios; Castellano; Buena

453 ADME/BA-CONVENTO-1428-50055bis

1634,enero,13.Fuente del Maestre

Entrada de la viuda de María de Samprona en el convento de la Concepción de Fuente del Maestre.

Manuscrito; 3 folios (1 folio en blanco); L. Procesal; Buena

454 ADME/BA-CONVENTO-23-440n9

1836,abril,24/ 1836,abril,28.Llerena

Nómina de religiosas enclaustradas en los conventos de Llerena.

Manuscrito; 13 folios (5 folios en blanco); Castellano; Buena

455 ADME/BA-CONVENTO-91-3936

1779,mayo,7/1779,mayo,12.Llerena

Misa en el convento de la Concepción de Llerena.

Manuscrito; 1 folio; Castellano; Buena

456 ADME/BA-CONVENTO-91-3938

1712,abril,30.Llerena

Pleito contraído por el convento de la Concepción de Llerena.

Manuscrito; 1 folio; Castellano; R (incompleto)

457 ADME/BA-CONVENTO-91-3940

1712,junio,8.Llerena

Pleito contraído por el convento de la Concepción de Llerena.

Manuscrito; 1 folio; Castellano; R (incompleto)

458 ADME/BA-CONVENTO-254-11088

1744,agosto,12/1744,agosto,19.Llerena

Pleito del convento de la Concepción de Llerena contra Lucas Domínguez.

Manuscrito; 8 folios; Castellano; R (pliegues) 
459 ADME/BA-CONVENTO-785-28082

1746,(sm),(sd).Llerena

Pleito del mayordomo del convento de la Concepción de Llerena por deudas.

Manuscrito; 16 folios; Castellano; Buena

460 ADME/BA-CONVENTO-482-19027n ${ }^{0} 1$

1677,abril,2.Llerena

Exploración de la voluntad de Ana Mencía en el convento de la Concepción de Llerena para su profesión.

Manuscrito; 2 folios; L. Procesal; R (roturas)

461 ADME/BA-CONVENTO-482-19027n²

1670,enero,14/1671,octubre,12.Llerena

Exploración de voluntades de novicias próximas a su profesión en conventos de Llerena.

Manuscrito; 20 folios (5 folios en blanco); L. Procesal; Buena

462 ADME/BA-CONVENTO-482-19027n² bis

1672,febrero,14.Llerena

Exploración de la voluntad de Marina Contador en el convento de la Concepción de Llerena para su profesión realizada por el provisor Francisco Carvajal y Luna.

Manuscrito; 2 folios; L. Procesal; R (incompleto)

463 ADME/BA-CONVENTO-482-19027n² ${ }^{\circ}$ is

1681,octubre, 17.Llerena

Exploración de la voluntad de María de Godoy en el convento de la Concepción de Llerena para su profesión realizada por el provisor Gonzalo Guerrero.

Manuscrito; 2 folios; L. Procesal; R (incompleto)

464 ADME/BA-CONVENTO-482-19027n²bis

1741 ,septiembre,4.Llerena

Exploración de la voluntad de Josefa de San Lorenzo en el convento de la Concepción de Llerena para su profesión realizada por el abogado de los Reales Consejos Juan de Arroyo.

Manuscrito; 2 folios; Castellano; R (incompleto)

465 ADME/BA-CONVENTO-482-19027n² 2 is

1742,octubre,26.Llerena

Exploración de la voluntad de María Teresa Barragán en el convento de la Concepción de Llerena para su profesión realizada por el abogado de los Reales Consejos Juan de Arroyo.

Manuscrito; 2 folios; Castellano; R (incompleto)

466 ADME/BA-CONVENTO-482-19028

1669,mayo,2/1669,mayo,12.Llerena

Sustitución del Santísimo Sacramento en el convento de la Concepción de Llerena.

Manuscrito; 4 folios (1 folio en blanco); L. Procesal; Buena

Hispania Sacra, LXVII

135, enero-junio 2015, 61-168, ISSN: 0018-215X, doi: 10.3989/hs.2015.003 
467 ADME/BA-CONVENTO-482-19029 1743,mayo,14.Almendralejo/1743, agosto,28.Llerena

Dote de la religiosa Inés Contador del convento de la Concepción de Llerena.

Manuscrito; 6 folios; Castellano; Buena

468 ADME/BA-CONVENTO-482-19030

1793,junio,14.Badajoz-Llerena

Reparaciones en el convento de la Concepción de Llerena.

Manuscrito; 2 folios (1 folio en blanco); Castellano; Buena

469 ADME/BA-CONVENTO-482-19031

1799,junio,7/1799,junio,12.Llerena

Devolución de la dote de una religiosa del convento de la Concepción de Llerena.

Manuscrito; 9 folios; Castellano; Buena

470 ADME/BA-CONVENTO-482-19032

1821,julio,13.Llerena

Salida de una religiosa del convento de la Concepción de Llerena.

Manuscrito; 2 folios; Castellano; Buena

471 ADME/BA-CONVENTO-482-19032bis

1821 ,noviembre,25/1822,junio,3.Llerena-Madrid

Secularización perpetua de Juana Nepomuceno del convento de la Concepción de Llerena.

Manuscrito; 5 folios (1 folio en blanco); Castellano y Latín; Buena

472 ADME/BA-CONVENTO-482-19033

1821,abril,6/1821,diciembre,17.Llerena-Madrid

Secularización perpetua de Antonia Dolores Zambrano del convento de la Concepción de Llerena.

Manuscrito; 5 folios; Castellano y Latín; Buena

473 ADME/BA-CONVENTO-482-19034

1829,(sm),(sd).(Madrid)/1829, abril,28.Llerena

Entrada de la educanda María Dolores Cabrera en el convento de la Concepción de Llerena.

Manuscrito; 3 folios (1 folio en blanco); Castellano y Latín; Buena

474 ADME/BA-CONVENTO-482-19035

1784,abril,15.Llerena

Sustitución del Santísimo Sacramento en el convento de la Concepción de Llerena.

Manuscrito; 4 folios (2 folios en blanco); Castellano; Buena

475 ADME/BA-CONVENTO-482-19038

1642,mayo,28/1642,noviembre,8.Llerena

Herencia, procedente de una obra pía, a favor del convento de Santa Clara de Llerena.

Manuscrito; 12 folios; L. Procesal; R (roturas, folio ilegible, manchas, pliegues) 
476 ADME/BA-CONVENTO-482-(6)

1753,julio,1.Llerena

Exploración de la voluntad de Inés Contador en el convento de la Concepción de Llerena.

Manuscrito; 2 folios; Castellano; Buena

477 ADME/BA-CONVENTO-482-(7)

1730,mayo,8.Llerena

Exploración de la voluntad de Ignacia Conde en el convento de la Concepción de Llerena, para su profesión, por el provisor Diego Ortega.

Manuscrito; 2 folios; Castellano; Buena

478 ADME/BA-CONVENTO-483-19067 1807,octubre,22.Jerez de los Caballeros/(sd).(sl)-Llerena

Distribución de enseres del convento de Santo Domingo de Llerena al convento de la Concepción.

Manuscrito; 33 folios (6 folios en blanco); Castellano; Buena

479 ADME/BA-CONVENTO-693-25277

1609,julio,4/1609,octubre,20.Llerena

Deuda a favor del convento de la Concepción de Llerena.

Manuscrito; 14 folios (1 folio en blanco); L. Procesal; R (roturas)

480 ADME/BA-CONVENTO-1128-35971bis

(sd).(Llerena)

Salida de la clausura de una religiosa del convento de la Concepción de Llerena.

Manuscrito; 1 cuartilla; Castellano; R (incompleto)

481 ADME/BA-CONVENTO-1183-37817

1613,(sm),(sd).Llerena

Pleito del convento de la Concepción de Llerena contra Juan Antonio Amargo por 800 ducados de una casa que compró.

Manuscrito; 22 folios; L Procesal; Buena

482 ADME/BA-CONVENTO-1189-38100bis

1834,octubre,6.Llerena

Exploración de la voluntad de María de los Dolores Martín en el convento de Concepción de Llerena.

Manuscrito; 2 folios; Castellano; Buena

483 ADME/BA-CONVENTO-1292-43167

$1621,(\mathrm{sm}),(\mathrm{sd})$. Llerena

Autos formados por el sacerdote Francisco Larios Peguero contra el convento de la Concepción de Llerena sobre salarios.

Manuscrito; 616 folios (1 folio en blanco); L. Procesal; R (manchas)

Hispania Sacra, LXVII

135, enero-junio 2015, 61-168, ISSN: 0018-215X, doi: 10.3989/hs.2015.003 
484 ADME/BA-CONVENTO-1428-50185 1634 ,diciembre,14/1635,febrero,19.Llerena

Elección de abadesa en el convento de la Concepción de Llerena.

Manuscrito; 6 folios (1 folio en blanco); L. Procesal; Buena

485 ADME/BA-CONVENTO-23-439

1837,octubre,8.Mérida/ 1837,octubre,20.Zafra

Secularizados de la provincia de Badajoz en el año 1837.

Manuscrito; 5 folios y 1 folio doble; Castellano; Buena

486 ADME/BA-CONVENTO-106-4530

1858.Mérida

Cuentas de cargo y data del convento de la Concepción de Mérida.

Manuscrito; 3 folios y 11 cuartillas; Castellano; Buena

487 ADME/BA-CONVENTO-106-4531

1859.Mérida

Cuentas de cargo y data del convento de la Concepción de Mérida.

Manuscrito; 4 folios y 25 cuartillas; Castellano; Buena

488 ADME/BA-CONVENTO-106-4532

1864,diciembre,3.Mérida

Cuentas de cargo y data del convento de la Concepción de Mérida.

Manuscrito; 3 folios y 18 cuartillas; Castellano; Buena

489 ADME/BA-CONVENTO-106-4533

1867,enero,1.Mérida

Cuentas de cargo y data del convento de la Concepción de Mérida.

Manuscrito; 4 folios (1 folio en blanco) y 23 cuartillas; Castellano; Buena

490ADME/BA-CONVENTO-106-4534

1856,enero,3.Mérida

Cuentas de cargo y data del convento de la Concepción de Mérida.

Manuscrito; 3 folios y 8 cuartillas; Castellano; Buena

491 ADME/BA-CONVENTO-277-11738

1845, mayo,18.Rambla/ 1862,septiembre,9.Mérida-Llerena

Toma de hábito de Juana Bautista Osuna en el convento de la Concepción de Mérida.

Manuscrito; 11 folios; Castellano; Buena

492 ADME/BA-CONVENTO-277-11738bis

1860,junio,30.Mérida

Índice de religiosas del convento de la Concepción de Mérida.

Manuscrito; 1 folio doble; Castellano; Buena 
493 ADME/BA-CONVENTO-277-11738bis

1857,mayo,14.Mérida

Estado ruinoso del convento de la Concepción de Mérida.

Manuscrito; 2 folios; Castellano; Buena

494 ADME/BA-CONVENTO-277-11738bis

1852,julio,24.Mérida

Composición del convento de la Concepción de Mérida.

Manuscrito; 2 folios; Castellano; Buena

495 ADME/BA-CONVENTO-277-11738bis

(sd).Mérida

Pago de pensiones del convento de la Concepción de Mérida.

Manuscrito; 2 folios; Castellano; Buena

496 ADME/BA-CONVENTO-277-11738bis

(sd).Mérida

Estado ruinoso del convento de la Concepción de Mérida.

Manuscrito; 1 folio; Castellano; Buena

497 ADME/BA-CONVENTO-277-11739

1860,noviembre,11.Sevilla/1862,abril,21. Llerena-Mérida

Toma de hábito y profesión perpetua de Juana Berruta en el convento de la Concepción de Mérida.

Manuscrito; 18 folios y 2 cuartillas; Castellano; Buena

498 ADME/BA-CONVENTO-277-11740

1862,mayo,20.Sevilla/1862,septiembre,9. Mérida-Llerena

Toma de hábito de Ana María Moreno en el convento de la Concepción de Mérida.

Manuscrito; 9 folios (1 folio blanco); Castellano; Buena

499 ADME/BA-CONVENTO-277-11740 bis

1863,diciembre,30. Palma del Río/ 1864,mayo,3.Mérida

Toma de hábito de Ana María Zamora en el convento de la Concepción de Mérida.

Manuscrito; 12 folios (1 folio en blanco); Castellano; Buena

500 ADME/BA-CONVENTO-277-11740 bis

1863,diciembre,31.Mérida

Índice de religiosas del convento de la Concepción de Mérida.

Manuscrito; 1 folio doble; Castellano; Buena

Hispania Sacra, LXVII

135, enero-junio 2015, 61-168, ISSN: 0018-215X, doi: 10.3989/hs.2015.003 
501 ADME/BA-CONVENTO-277-11740 bis $\quad$ 1866,agosto,2.Feria/1867,marzo,3.Mérida-Llerena

Toma de hábito de María de los Dolores Muñoz en el convento de la Concepción de Mérida.

Manuscrito; 10 folios (2 folios en blanco); Castellano; Buena

502 ADME/BA-CONVENTO-180-7106

1636,diciembre,11.Mérida

Cuentas de cargo y data del convento de la Concepción de Mérida.

Manuscrito; 68 folios; L. Procesal; Buena

503 ADME/BA-CONVENTO-504-20038

1792,mayo,18/1792,mayo,23.Mérida

Exploración de la voluntad de Josefa Monago del convento de la Concepción de Mérida.

Manuscrito; 4 folios; Castellano; Buena

504 ADME/BA-CONVENTO-504-20038bis

1667,enero,3.Mérida

Exploración de la voluntad de Rita de Oces del convento de la Concepción de Mérida para su profesión.

Manuscrito; 2 folios; Castellano; Buena

505 ADME/BA-CONVENTO-504-20038bis

1671,mayo,3.Mérida

Exploración de la voluntad de una novicia del convento de la Concepción de Mérida para su profesión.

Manuscrito; 4 folios; L. Procesal; Buena

506 ADME/BA-CONVENTO-504-20042

(sd).(Mérida)/1855,febrero,23.Llerena

Toma de hábito de Josefa Caballero en el convento de la Concepción de Mérida.

Manuscrito; 2 folios y 1 cuartilla; Castellano; Buena

507 ADME/BA-CONVENTO-504-20042bis 1856,noviembre,4.Mérida/1856,noviembre,13.Llerena Renuncia del capellán del convento de la Concepción de Mérida.

Manuscrito; 3 folios; Castellano; Buena

508 ADME/BA-CONVENTO-504-20042bis

1856,julio,7.Mérida/1856,julio,10.Llerena

Toma de hábito de Isabel Pin en el convento de la Concepción de Mérida.

Manuscrito; 1 folio; Castellano; Buena

509 ADME/BA-CONVENTO-504-20042bis

1857,diciembre,31.Mérida

Índice de religiosas del convento de la Concepción de Mérida.

Manuscrito; 1 pliego; Castellano; Buena 
510 ADME/BA-CONVENTO-504-20038 1692,septiembre,19/1692,septiembre,20.Mérida

Elección de abadesa en el convento de la Concepción de Mérida.

Manuscrito; 6 folios (1 folio en blanco); L. Procesal; Buena

511 ADME/BA-CONVENTO-604-22835

1870,enero,1.Mérida

Cuentas de cargo y data del convento de la Concepción de Mérida.

Manuscrito; 2 folios (1 folio en blanco); Castellano; Buena

512 ADME/BA-CONVENTO-933-31427

1622,(sm),(sd).Mérida

Cuentas del convento de Nuestra Señora de la Antigua de Mérida.

Manuscrito; 47 folios; L. Procesal; R (roturas)

513 ADME/BA-CONVENTO-1059-34214

1808,junio.2.Los Santos de Maimona

Traslado de una religiosa del convento de la Concepción de los Santos al de Mérida.

Manuscrito: 5 folios (1 folio en blanco); Castellano; Buena

514 ADME/BA-CONVENTO-1146-36495n²

1815,diciembre,7/1816,(sm),21.Madrid-Mérida

Petición de religiosas para seguir habitando el convento de la Concepción de Mérida.

Manuscrito; 8 folios (1 folio en blanco); Castellano; Buena

515 ADME/BA-CONVENTO-1146-(1)

1856,enero,12.Mérida

Pleito del convento de la Concepción de Mérida contra el párroco de la Iglesia de Santa María.

Manuscrito; 3 folios; Castellano; Buena

516 ADME/BA-CONVENTO-1146-(2)

1837,junio,18/1840,septiembre,10.Llerena-Mérida

Reelección en el cargo de abadesa del convento de la Concepción de Mérida.

Manuscrito; 2 folios y 2 cuartillas; Castellano; R (roturas)

517 ADME/BA-CONVENTO-1146-(4)

1858,junio,30.Mérida/1858,junio,5.Llerena

Nombramiento de sacristán en el convento de la Concepción de Mérida.

Manuscrito; 1 folio; Castellano; Buena

518 ADME/BA-CONVENTO-1146-(5)

1859,febrero,2.Mérida

Pago de nóminas atrasadas de dos religiosas del convento de la Concepción de Mérida.

Manuscrito; 2 folios (1 folio en blanco); Castellano; Buena

Hispania Sacra, LXVII

135, enero-junio 2015, 61-168, ISSN: 0018-215X, doi: 10.3989/hs.2015.003 
519 ADME/BA-CONVENTO-1146-(6)

1858,junio,30.Mérida

Relación del número de religiosas del convento de la Concepción de Mérida.

Manuscrito; 2 cuartillas (1 cuartilla en blanco); Castellano; M (sólo se conserva la parte introductoria)

520 ADME/BA-CONVENTO-1146-(7)

1867,junio,30.Mérida

Relación de religiosas en el convento de la Concepción de Mérida en el primer semestre de 1867.

Manuscrito; 1 folio doble; Castellano; Buena

521 ADME/BA-CONVENTO-1146-(8)

1864,diciembre,31.Mérida

Relación de religiosas en el convento de la Concepción de Mérida en el segundo semestre de 1864.

Manuscrito; 1 folio doble; Castellano; Buena

522 ADME/BA-CONVENTO-1146-(9)

1863,junio,30.Mérida

Relación de religiosas en el convento de la Concepción de Mérida en el primer semestre de 1863.

Manuscrito; 1 folio doble; Castellano; Buena

523 ADME/BA-CONVENTO-1146-(10)

1870,diciembre,31.Mérida

Relación de religiosas en el convento de la Concepción de Mérida en el segundo semestre de 1870.

Manuscrito; 1 folio doble; Castellano; Buena

524 ADME/BA-CONVENTO-1146-(11)

1857,diciembre,31.Mérida

Gastos de culto de la Iglesia del convento de la Concepción de Mérida.

Manuscrito; 2 cuartillas (1 cuartilla en blanco); Castellano; M (sólo se conserva la parte introductoria)

525 ADME/BA-CONVENTO-1146-(12)

1873,octubre,18/1873,octubre,20.Mérida

Defunciones de religiosas del convento de la Concepción de Mérida.

Manuscrito; 2 folios; Castellano; Buena

526 ADME/BA-CONVENTO-1146-(13)

1873,junio,30.Mérida

Relación de religiosas en el convento de la Concepción de Mérida en el primer semestre de 1873.

Manuscrito; 1 folio doble; Castellano; Buena

527 ADME/BA-CONVENTO-1146-(14)

1873,diciembre,31.Mérida

Relación de religiosas en el convento de la Concepción de Mérida en el segundo semestre de 1873.

Manuscrito; 1 folio doble; Castellano; Buena 
528 ADME/BA-CONVENTO-1146-(15)

1872,diciembre,31.Mérida

Relación de religiosas en el convento de la Concepción de Mérida en el segundo semestre de 1872.

Manuscrito; 1 folio doble; Castellano; Buena

529 ADME/BA-CONVENTO-1146-(17)

1867,junio,23.Mérida/1867,junio,30.Llerena

Salida de clausura de la religiosa profesa María Bravo del convento de la Concepción de Mérida.

Manuscrito; 4 folios (2 folios en blanco); Castellano; Buena

530 ADME/BA-CONVENTO-1146-(18)

1865,noviembre,9.Mérida

Toma de hábito de Sebastiana Pimentel en el convento de la Concepción de Mérida.

Manuscrito; 2 folios (1 folio en blanco); Castellano; Buena

531 ADME/BA-CONVENTO-1146-(19)

1865,mayo,8.Mérida/1865,mayo,19.Llerena

Salida de la clausura del convento de la Concepción de Mérida de María Bravo.

Manuscrito; 4 folios (2 folios en blanco); Castellano; Buena

532 ADME/BA-CONVENTO-1146-(30)

Toma de hábito de Francisca Vélez en el convento de la Concepción de Mérida.

Manuscrito; 15 folios; Castellano; Buena

533 ADME/BA-CONVENTO-1146-(31)

1857,abril,29.Badajoz/1859,mayo,18.Mérida-Llerena

Toma de hábito y profesión perpetua de Gabriela Ávalos en el convento de la Concepción de Mérida. Manuscrito; 23 folios (2 folios en blanco); Castellano; Buena

534 ADME/BA-CONVENTO-1146-(32) 1861 , noviembre,9.Feria/1865, abril,22.Mérida-Llerena Toma de hábito y profesión perpetua de Gabriela Muñoz en el convento de la Concepción de Mérida. Manuscrito; 23 folios (3 folios en blanco); Castellano; Buena

535 ADME/BA-CONVENTO-1146-(33) (1852),noviembre,17. Llerena/1852, noviembre,19.Mérida Cumplimiento de clausura en el convento de la Concepción de Mérida.

Manuscrito; 7 cuartillas (1 cuartilla en blanco); Castellano; Buena

536 ADME/BA-CONVENTO-1172-37251

1867,marzo,24.Mérida/1867,abril,4.Llerena

Nombramiento de sacristán en el convento de la Concepción de Mérida.

Manuscrito; 2 folios; Castellano; Buena

Hispania Sacra, LXVII

135, enero-junio 2015, 61-168, ISSN: 0018-215X, doi: 10.3989/hs.2015.003 
537 ADME/BA-CONVENTO-1172-37254 1866,febrero,16/1867,mayo,6.Mérida-Llerena

Toma de hábito y profesión perpetua de Sebastiana Pimentel como lega en el convento de la Concepción de Mérida.

Manuscrito; 33 folios (3 folios en blanco); Castellano; Buena

538 ADME/BA-CONVENTO-1172-37255

1867,junio,2.Almodóvar del Campo/

1867,noviembre,28.Mérida-Llerena

Toma de hábito de Petra Viso en el convento de la Concepción de Mérida.

Manuscrito; 12 folios (2 folios en blanco); Castellano; Buena

539 ADME/BA-CONVENTO-1172-37257

1871,marzo,19/1871,septiembre,11.Mérida-Llerena

Nombramiento de capellán del convento de la Concepción de Mérida.

Manuscrito; 4 folios (2 hojas en blanco); Castellano; Buena

540 ADME/BA-CONVENTO-1226-40056bis 1865,enero,26.Almendralejo/1867,febrero,29.Mérida

Toma de hábito y profesión de Francisca Gertrudis Torrado en el convento de la Concepción de Mérida.

Manuscrito; 24 folios (4 folios en blanco); Castellano; Buena

541 ADME/BA-CONVENTO-1273-42340

1633,(sm),(sd).Mérida

Cuentas de cargo y data del convento de la Concepción de Mérida.

Manuscrito; 51 folios; L. Procesal; Buena

543 ADME/BA-CONVENTO-1273-42347n²

1633,septiembre,4.Mérida

Cuentas de cargo y data del convento de la Concepción de Mérida.

Manuscrito; 7 folios; L. Procesal; Buena

544 ADME/BA-CONVENTO-20 bis-(75) 1828,agosto,24/ 1828,septiembre,13.Jerez -Badajoz

Profesión perpetua de Micaela Marín en el convento de la Luz de Jerez de los Caballeros.

Manuscrito; 4 folios y 1 cuartilla; Castellano; Buena

545 ADME/BA-CONVENTO-20 bis-(83)

1830,mayo,20/ 1830,junio,9. Jerez de los Caballeros -Badajoz

Profesión perpetua de Joaquina Manjo en el convento de la Luz de Jerez de los Caballeros.

Manuscrito; 3 folios y 1 cuartilla; Castellano; Buena 
546 ADME/BA-CONVENTO-20 bis-(92)

1818 ,octubre, $17 / 1818$,noviembre, 4 . Jerez de los Caballeros

Profesión perpetua de María Ángeles Bermejo en el convento de la Luz de Jerez de los Caballeros. Manuscrito; 4 folios y 1 cuartilla; Castellano; Buena

547 ADME/BA-CONVENTO-23-440n 17

[19--].(Jerez de los Caballeros)

Nómina de religiosas enclaustradas en los conventos de Jerez de los Caballeros.

Manuscrito; 11 folios (6 folios en blanco); Castellano; Buena

548 ADME/BA-CONVENTO-41-1152

1864,febrero,26.Jerez /1864,marzo,13.Badajoz-Oliva

Salida de la clausura de la religiosa María Borrego del convento de la Luz de Jerez de los Caballeros.

Manuscrito; 6 folios; Castellano y Latín; R (manchas)

549 ADME/BA-CONVENTO-41-1154bis

1813,abril,8.Jerez de los Caballeros

Admisiones en el convento de la Luz de Jerez de los Caballeros.

Manuscrito; 1 cuartilla; Castellano; R (incompleto)

550 ADME/BA-CONVENTO-42-1175n² 1821 ,enero,6/1821, diciembre,31.Badajoz-Madrid-Jerez Secularización perpetua de la religiosa Ana Soto del convento de la Luz de Jerez de los Caballeros. Manuscrito; 3 folios y 1 cuartilla; Castellano y Latín; Buena

551 ADME/BA-CONVENTO-42-1175n 3

1821,noviembre,6/1821,diciembre, 23 . Badajoz-Jerez-Madrid

Secularización perpetua de la religiosa Josefa López del convento de la Luz de Jerez.

Manuscrito; 3 folios y 1 cuartilla; Castellano y Latín; Buena

552 ADME/BA-CONVENTO-42-1175n5 1821 ,enero,6.Jerez/1821, diciembre,23.Badajoz-Madrid

Secularización perpetua de Vicenta Triviño del convento de la Luz de Jerez de los Caballeros.

Manuscrito; 3 folios y 1 cuartilla; Castellano y Latín; Buena

553 ADME/BA-CONVENTO-42-1178n³

1821 ,abril,10/1822,agosto,2.Badajoz-Jerez

Secularización perpetua de la religiosa María Jara del convento de la Luz de Jerez de los Caballeros.

Manuscrito; 4 folios; Castellano y Latín; Buena

Hispania Sacra, LXVII

135, enero-junio 2015, 61-168, ISSN: 0018-215X, doi: 10.3989/hs.2015.003 
554 ADME/BA-CONVENTO-20 bis-(71) 1827,noviembre,29/1827, diciembre,25.Jerez -Badajoz

Profesión perpetua de María Josefa Galván en el convento Madre de Dios de Jerez de los Caballeros.

Manuscrito; 3 folios y 1 cuartilla; Castellano; Buena

555 ADME/BA-CONVENTO-20 bis-(72)

1827,marzo,3/1827,marzo,17. Jerez de los Caballeros -Badajoz

Profesión de Josefa Barreto en el convento Madre de Dios de Jerez de los Caballeros.

Manuscrito; 3 folios y 1 cuartilla; Castellano; Buena

556 ADME/BA-CONVENTO-20 bis-(87)

1826,agosto,2/ 1826,agosto,16.Jerez-Badajoz

Profesión perpetua de María Martínez en el convento Madre de Dios de Jerez de los Caballeros.

Manuscrito; 4 folios; Castellano; Buena

557 ADME/BA-CONVENTO-20 bis-(90) 1833,noviembre,10/ 1833,noviembre,28.Jerez-Badajoz

Profesión perpetua de Rosalía Navarro en el convento Madre de Dios de Jerez de los Caballeros.

Manuscrito; 4 folios y 1 cuartilla; Castellano; Buena

558 ADME/BA-CONVENTO-42-1173

1820,julio,15.Roma/1820,noviembre,20.Jerez

Salida de la clausura del convento de Madre de Dios de la religiosa Brígida Quevedo durante un trienio.

Manuscrito; 9 folios y 2 cuartillas; Castellano y Latín; Buena

559 ADME/BA-CONVENTO-42-1173bis $\quad$ 1821, mayo,10/1821,octubre,26.Badajoz-Jerez -Madrid Secularización perpetua de Brígida Quevedo del convento Madre de Dios de Jerez de los Caballeros. Manuscrito; 4 folios; Castellano y Latín; Buena

560 ADME/BA-CONVENTO-42-1173bis 1821,mayo,6/1821,octubre,26.Badajoz-Madrid-Jerez

Secularización perpetua de la religiosa María de la Concepción Quevedo del convento Madre de Dios de Jerez de los Caballeros.

Manuscrito; 4 folios; Castellano y Latín; Buena

561 ADME/BA-CONVENTO-42-1175n4 $\quad$ 1821, mayo,11/1821, octubre,26.Badajoz-Jerez -Madrid Secularización perpetua de Marciana Coba del convento de Madre de Dios de Jerez de los Caballeros.

Manuscrito; 4 folios; Castellano y Latín; Buena 
562 ADME/BA-CONVENTO-42-1178n²

1821,mayo,17/1822,septiembre,14. Badajoz-Jerez -Madrid

Secularización perpetua de María Pilar Conejo del convento de Madre de Dios de Jerez.

Manuscrito; 5 folios; Castellano y Latín; Buena

563 ADME/BA-CONVENTO-20 bis-(44) （sd).(Burguillos)/ 1827, agosto,28.Burguillos-Badajoz

Toma de hábito y profesión de Josefa Navarro en el convento de la Purísima Concepción de Burguillos.

Manuscrito; 11 folios y 1 cuartilla; Castellano; Buena

564 ADME/BA-CONVENTO-20 bis-(45)

1826,septiembre,10/ 1826,septiembre,27. Burguillos-Badajoz

Toma de hábito de Isabel María Martínez en el convento de la Purísima Concepción de Burguillos. Manuscrito; 5 folios y 1 cuartilla; Castellano; Buena

565 ADME/BA-CONVENTO-20 bis-(46)

1826,noviembre,13/ 1826,noviembre,29. Burguillos-Badajoz

Profesión perpetua de Ana María Arteaga en el convento de la Purísima Concepción de Burguillos.

Manuscrito; 5 folios y 1 cuartilla; Castellano; Buena

566 ADME/BA-CONVENTO-20 bis-(47)

1824,agosto,11/ 1824,noviembre,30.Burguillos

Toma de hábito de Carmen Carvajal en el convento de la Purísima Concepción de Burguillos.

Manuscrito; 4 folios (1 folio en blanco) y 1 cuartilla; Castellano; Buena

567 ADME/BA-CONVENTO-20 bis-(48) 1824,octubre,11/ 1825,octubre,16.Burguillos-Badajoz

Toma de hábito y profesión perpetua de María Josefa Carretero en el convento de la Purísima Concepción de Burguillos.

Manuscrito; 13 folios y 1 cuartilla; Castellano; Buena

568 ADME/BA-CONVENTO-20 bis-(49) 1819, marzo,25.Burguillos/ 1819, abril,28.Jerez-Oliva Toma de hábito de Basilia Galván en el convento de la Purísima Concepción de Burguillos.

Manuscrito; 8 folios (1 en blanco) y 1 cuartilla; Castellano; Buena

569 ADME/BA-CONVENTO-20 bis-(50)

1815 ,octubre,4.Valle de Sta Ana/ 1815 ,noviembre, 24.Burguillos

Profesión perpetua de Beatriz Piña en el convento de la Purísima Concepción de Burguillos.

Manuscrito; 6 folios y 1 cuartilla; Castellano; Buena

Hispania Sacra, LXVII

135, enero-junio 2015, 61-168, ISSN: 0018-215X, doi: 10.3989/hs.2015.003 
570 ADME/BA-CONVENTO-20 bis-(51)

1815,octubre,25.Fregenal / 1815,octubre,31. Burguillos-Badajoz

Profesión perpetua de María Caballero en el convento de la Purísima Concepción de Burguillos.

Manuscrito; 6 folios; Castellano; Buena

571ADME/BA-CONVENTO-23-440n²

1836,abril,17.Burguillos

Nómina de religiosas enclaustradas en el convento de la Concepción de Burguillos.

Manuscrito; 5 folios (2 folios en blanco); Castellano; Buena

572 ADME/BA-CONVENTO-14-248

1708,mayo,12/ 1708,mayo,17.Badajoz.

Pleito de los conventos de Santa Catalina, San Onofre y Santa Lucía de Badajoz contra Diego Jaramillo, por deudas.

Manuscrito; 10 folios; Castellano; R (manchas)

573ADME/BA-CONVENTO-15-251

1813, diciembre,5/ 1814,enero,13.Badajoz.

Venta de una roza del convento de Santa Lucía de Badajoz.

Manuscrito; 5 folios; Castellano; Buena

574 ADME/BA-CONVENTO-15-256n ${ }^{\circ} 1$

1779,marzo,17.Badajoz

Elección de abadesa en el convento de Santa Lucía de Badajoz, 1779.

Manuscrito; 5 folios; Castellano; Buena

575 ADME/BA-CONVENTO-15-256n²

1766,marzo,20.Badajoz

Elección de abadesa en el convento de Santa Lucía de Badajoz, 1766.

Manuscrito; 4 folios y 1 cuartilla; Castellano; Buena

576 ADME/BA-CONVENTO-15-256n 3

1773,diciembre,15/ 1773,diciembre,17.Badajoz

Toma de hábito de Rosa de Logrisa en el convento de Santa Lucía de Badajoz.

Manuscrito; 3 folios; Castellano; Buena

577 ADME/BA-CONVENTO-15-256n 4

1755 ,enero,24.Badajoz.

Toma de hábito de Joaquina Rita en el convento de Santa Lucía de Badajoz.

Manuscrito; 3 folios y 1 cuartilla; Castellano; Buena

578 ADME/BA-CONVENTO-15-262

1683 ,septiembre,2.Badajoz/1683,septiembre,10. Jerez

Carencia de celdas en el convento de Santa Lucía de Badajoz para lo que se solicita una reparación. Manuscrito; 8 folios (3 folios en blanco); L. Procesal; Buena 
579 ADME/BA-CONVENTO-15-263 1696,julio,10/1709,mayo,16.Badajoz

Pleito del convento de Santa Lucía de Badajoz contra el Hospital de la Concepción por deuda. Manuscrito; 157 folios; L. Procesal; Buena

580 ADME/BA-CONVENTO-15-269 1812,julio,17/ 1812,agosto,13.Badajoz.

Devolución de una casa perteneciente al convento de Santa Lucía de Badajoz.

Manuscrito; 4 folios; Castellano; Buena

581 ADME/BA-CONVENTO-15-270

1816,agosto,5.Badajoz

Elección de priora y oficialas en el convento de Santa Lucía de Badajoz. 1816.

Manuscrito; 2 folios; Castellano; Buena

582 ADME/BA-CONVENTO-15-(2)

1819,julio,23.Badajoz.

Elección de priora y oficialas en el convento de Santa Lucía de Badajoz. 1819.

Manuscrito; 2 folios; Castellano; Buena

583 ADME/BA-CONVENTO-15-(3) 1830,enero,27 /1830,febrero,11.Oliva de la Frontera-Badajoz Elección de abadesa y oficialas en el convento de Santa Lucía de Badajoz. 1830.

Manuscrito; 4 folios; Castellano; Buena

584 ADME/BA-CONVENTO-17-318

1620 ,septiembre,16/ 1620,octubre,24.Badajoz

Pleito de Juan Sánchez contra Paula Amor de Dios, religiosa del convento de Santa Lucía de Badajoz.

Manuscrito; 21 folios y 1 cuartilla; L. Procesal; R (bordes rotos)

585 ADME/BA-CONVENTO-17-319

1632,septiembre,9/ 1638,enero,18.Badajoz.

Pleito de María Maldonado del convento de Santa Lucía de Badajoz contra Pedro Moscozo sobre deudas.

Manuscrito; 64 folios y 1 cuartilla; L. Procesal; R (desgaste de tintas)

586 ADME/BA-CONVENTO-17-320

1618,junio,7.Badajoz

Pleito del convento de Santa Lucía contra Pedro Sánchez por incumplimiento de testamento.

Manuscrito; 15 folios y 1 cuartilla; L. Procesal; Buena

587 ADME/BA-CONVENTO-17-322

1813 ,agosto,12.Badajoz

Elección de abadesa y oficialas en el convento de Santa Lucía de Badajoz, 1813.

Manuscrito; 5 folios (1 folio en blanco); Castellano; Buena

Hispania Sacra, LXVII

135, enero-junio 2015, 61-168, ISSN: 0018-215X, doi: 10.3989/hs.2015.003 
588 ADME/BA-CONVENTO-20-396

1730,febrero,9.(sl) /1729,septiembre,20.Badajoz

Pleito del convento de Santa Lucía de Badajoz contra el rector del colegio de la Compañía de Jesús. Manuscrito; 72 folios; Castellano y Latín; R (desgaste de tintas)

589 ADME/BA-CONVENTO-11-440

1628,mayo,3/ 1628,mayo,4.Badajoz

Visita al convento de Santa Lucía de Badajoz del obispo Juan Roco Campofrío para inspección. Manuscrito; 30 folios (2 folios en blanco); Castellano; Buena

\section{ADME/BA-CONVENTO-11-445}

1680,agosto,3.Badajoz

Visita al convento de Santa Lucía de Badajoz del obispo Juan Marín de Rodezno, para inspección. Manuscrito; 8 folios; Castellano; Buena

591 ADME/BA-CONVENTO-11-447

1840,diciembre,1/ 1840,diciembre,9.Badajoz

Traslado de religiosas del convento de Santa Lucía de Badajoz al convento de Santa Ana de Badajoz.

Manuscrito; 3 folios (1 folio en blanco) y 1 cuartilla; Castellano; Buena

592 ADME/BA-CONVENTO-23-440nº20

1836,abril,19/ 1336,julio,7.Badajoz

Nómina de religiosas enclaustradas en los conventos de Badajoz.

Manuscrito; 14 folios (8 folios en blanco); Castellano; Buena

593 ADME/BA-CONVENTO-25bis-(65)

1827,marzo,6/1828,junio,5.Badajoz

Toma de hábito y profesión de Isabel Josefa de los Dolores en el convento de Santa Lucía de Badajoz.

Manuscrito; 8 folios; Castellano; Buena

594 ADME/BA-CONVENTO-25bis-(66)

1833 ,enero,8/ 1834,enero,16.Badajoz

Toma de hábito y profesión de Rosa María Águeda en el convento de Santa Lucía de Badajoz.

Manuscrito; 7 folios; Castellano; Buena

595 ADME/BA-CONVENTO-11-446n 33

1836,septiembre,26.Zafra-Bienvenida

Secularización perpetua de Antonia Juana Vemero en el convento de la Concepción de Bienvenida.

Manuscrito; 2 folios; Castellano; Buena

596 ADME/BA-CONVENTO-62-3037

(sd).(Bienvenida)/1740, diciembre,14.Llerena-Usagre

Interposición del alcalde de Usagre en la administración de unos bienes del convento de la Concepción de Bienvenida.

Manuscrito; 2 folios; Castellano; Buena 
597 ADME/BA-CONVENTO-62-3038

Interposición del alcalde de Usagre en la venta de unas tierras del convento de la Concepción de Bienvenida.

Manuscrito; 2 folios; Castellano; Buena

598 ADME/BA-CONVENTO-62-3040

1741,junio,14.Bienvenida

Pleito contra el convento de la Concepción de Bienvenida.

Manuscrito; 1 folio; Castellano; R (incompleto)

599 ADME/BA-CONVENTO-62-3047

1741,mayo,16.Bienvenida

Pleito contra el convento de la Concepción de Bienvenida.

Manuscrito; 1 folio; Castellano; R (incompleto)

600 ADME/BA-CONVENTO-437-17824

1847, noviembre,15.Bienvenida/

1847,diciembre,11.Llerena

Sobre unas campanas del convento suprimido de la Concepción de Bienvenida.

Manuscrito; 2 folios y 2 cuartillas; Castellano; Buena

601 ADME/BA-CONVENTO-437-17823n ${ }^{0} 1$

1731, diciembre,2.Llerena/

1731 , diciembre,4.Bienvenida

Exploración de la voluntad de Juana Macías del convento de la Concepción de Bienvenida.

Manuscrito; 4 folios; Castellano; Buena

602 ADME/BA-CONVENTO-437-17823bis

Exploración de la voluntad de Leonor Herrera del convento de la Concepción de Bienvenida.
603 ADME/BA-CONVENTO-437-17823bis

1734,junio,16.Llerena/1734,junio,31.Bienvenida

Manuscrito; 4 folios; Castellano; Buena

604 ADME/BA-CONVENTO-437-17823n²

1748,junio,16.Llerena/1748,junio,16.Bienvenida

Exploración de la voluntad de Gervasia Álvarez del convento de la Concepción de Bienvenida.

Manuscrito; 4 folios; Castellano; Buena

Hispania Sacra, LXVII

135, enero-junio 2015, 61-168, ISSN: 0018-215X, doi: 10.3989/hs.2015.003 
605 ADME/BA-CONVENTO-437-17823n 3

1822,enero,12/1822,abril,20. Bienvenida-Llerena-Madrid

Secularización perpetua de Juana Benero en el convento de la Concepción de Bienvenida . Manuscrito; 7 folios; Castellano y Latín; Buena

606 ADME/BA-CONVENTO-437-17823nº 4

1792,diciembre,7.Madrid/ 1792,diciembre,19.Bienvenida

Dispensa de la clausura de Teresa y María José Chaves del convento de la Concepción de Bienvenida.

Manuscrito; 11 folios (2 folios en blanco); Castellano; Buena

607 ADME/BA-CONVENTO-437-17823n5 $\quad$ 1804,marzo,10.Llerena/1804,marzo,12.Bienvenida

Dispensa de la clausura de María Antonia Estirado del convento de la Concepción de Bienvenida.

Manuscrito; 2 folios; Castellano; Buena

608 ADME/BA-CONVENTO-437-17823nº $\quad$ 1796,junio,23.Bienvenida/1796,junio,18.Llerena

Salida temporal de la clausura de María Antonia Estirado del convento de la Concepción de Bienvenida.

Manuscrito; 2 folios; Castellano; Buena

609 ADME/BA-CONVENTO-629-23633

Pleito entre el convento de la Concepción de Bienvenida y el del mismo título de Usagre.

Manuscrito; 23 folios (1 folio en blanco); Castellano; Buena

610 ADME/BA-CONVENTO-868-30099 1724,septiembre,29.Llerena/1724,septiembre,29.Usagre Deuda a favor del convento de la Concepción de Bienvenida.

Manuscrito; 21 folios (1 folio en blanco); Castellano; Buena

611ADME/BA-CONVENTO-868-30100

(sd).(Bienvenida)/1726,febrero,15.Llerena

Usurpación de tierras del convento de la Concepción de Bienvenida.

Manuscrito; 6 folios (1 folio en blanco); Castellano; Buena

612ADME/BA-CONVENTO-1183-(1)

1748,mayo,9.Bienvenida/1748,mayo,9.Llerena

Pleito entre el convento de la Concepción de Bienvenida y Diego (?) Moreno.

Manuscrito; 1 folio; Castellano; R (incompleto) 
613 ADME/BA-CONVENTO-1183-(2) 1798, junio,11.Madrid/1798, junio,26.Llerena-Bienvenida Secularización perpetua de María del Carmen Pardillo del convento de la Concepción de Bienvenida. Manuscrito; 5 folios (1 folio en blanco); Castellano y Latín; R (manchas de humedad)

614 ADME/BA-CONVENTO-23-440n ${ }^{\circ} 15$ 1836,abril.9.Villanueva de la Serena

Nómina de religiosas enclaustradas en el convento de Villanueva de la Serena.

Manuscrito; 4 folios (2 folios en blanco); Castellano; Buena

615 ADME/BA-CONVENTO-20 bis-(103)

1857.(sd)/ 1857,abril,11.Valencia del Ventoso.

Entrada en calidad de educanda en el convento de la Concepción de Valencia del Ventoso de Isabel María Hidalgo, María de la Natividad Delgado y Durán, menores de edad.

Manuscrito; 6 folios ( 3 folios en blanco) y 1 cuartilla; Castellano y Latín; Buena

616 ADME/BA-CONVENTO-20 bis-(104) 1857.(sd)/1857, diciembre,14.Valencia del Ventoso

Entrada de educanda en el convento de la Concepción de Valencia del Ventoso de Sabina Barroso.

Manuscrito; 5 folios (1 folio en blanco) y 1 cuartilla; Castellano y Latín; Buena

617 ADME/BA-CONVENTO-20 bis-(105)

1833,noviembre,24/1835,febrero,3. Valencia del Ventoso

Toma de hábito de Gregoria García en el convento de la Concepción de Valencia del Ventoso.

Manuscrito; 8 folios y 1 cuartilla; Castellano; Buena

618 ADME/BA-CONVENTO-20 bis-(106)

1832,marzo,4/ 1833,abril,18. Valencia del Ventoso-Badajoz

Toma de hábito y profesión de Dolores Sánchez en el convento de la Concepción de Valencia del Ventoso.

Manuscrito; 7 folios y 1 cuartilla; Castellano; Buena

619 ADME/BA-CONVENTO-20 bis-(107)

Toma de hábito y profesión de Alejandra Noriega en el convento de la Concepción de Valencia del Ventoso.

Manuscrito; 7 folios y 1 cuartilla; Castellano; Buena

620 ADME/BA-CONVENTO-20 bis-(108)

Toma de hábito y profesión perpetua de Aureliana Abuja como novicia lega en el cargo de cocinera, en el convento de la Concepción de Valencia del Ventoso.

Manuscrito; 7 folios y 1 cuartilla; Castellano; Buena
1832 ,agosto, $23 / 1833$,octubre, 24 .

Valencia del Ventoso-Badajoz

1832,marzo,23.Alconera/ 1833,julio,27. Valencia del Ventoso

Hispania Sacra, LXVII

135, enero-junio 2015, 61-168, ISSN: 0018-215X, doi: 10.3989/hs.2015.003 
621 ADME/BA-CONVENTO-20 bis-(109) 1829, noviembre,12/ 1829, diciembre, 13. Valencia del Ventoso

Toma de hábito de María Marín como novicia de coro en el convento de la Concepción de Valencia del Ventoso.

Manuscrito; 3 folios y 1 cuartilla; Castellano; Buena

622 ADME/BA-CONVENTO-20 bis-(110)

1829 ,enero,11/ 1829,octubre,16. Valencia del Ventoso

Profesión de María de Santa Teresa en el convento de la Concepción de Valencia del Ventoso.

Manuscrito; 4 folios y 1 cuartilla; Castellano; Buena

623 ADME/BA-CONVENTO-20 bis-(111)

Toma de hábito de María del Carmen Cordero en el convento de la Concepción de Valencia del Ventoso.

Manuscrito; 4 folios y 1 cuartilla; Castellano; Buena

624 ADME/BA-CONVENTO-20 bis-(112)

Toma de hábito y profesión perpetua de María del Rosario Sanz en el convento de la Concepción de Valencia del Ventoso.

Manuscrito; 7 folios y 1 cuartilla; Castellano; Buena

625 ADME/BA-CONVENTO-20 bis-(113)

1827,abril,25/ 1827,mayo,10.Valencia del Ventoso

Toma de hábito de María Soriano en el convento de la Concepción de Valencia del Ventoso.

Manuscrito; 3 folios y 1 cuartilla; Castellano; Buena

626 ADME/BA-CONVENTO-20 bis-(114)

1826,mayo,13/ 1827,agosto,16.

Valencia del Ventoso-Badajoz

Toma de hábito y profesión perpetua de María Bellido como religiosa de velo blanco en el cargo de cocinera en el convento de la Concepción de Valencia del Ventoso.

Manuscrito; 11 folios; Castellano; Buena

\section{ADME/BA-CONVENTO-23-440nº 16}

[19--].(Valencia del Ventoso)

Nómina de religiosas enclaustradas en el convento de la Concepción de de Valencia del Ventoso.

Manuscrito; 5 folios (2 folios en blanco); Castellano; Buena 
628 ADME/BA-CONVENTO-23-440n 14 1836,abril,30.Segura de León

Nómina de religiosas enclaustradas en el convento de la Concepción de Segura de León. Manuscrito; 4 folios (1 folio en blanco); Castellano; Buena

629 ADME/BA-CONVENTO-122-5176

1669,enero,6.Segura de León

Cuentas del convento de la Concepción de Segura de León presentadas en la visita de Juan Macías Nieto en 1669.

Manuscrito; 54 folios; L. Procesal; R (manchas de humedad)

630 ADME/BA-CONVENTO-122-5177

1701,(sm),(sd).Segura de León

Cuentas de cargo y data del convento de la Concepción de Segura de León.

Manuscrito; 63 folios (3 folios en blanco); Castellano; R (roturas y manchas de humedad)

631 ADME/BA-CONVENTO-122-5178

1712,(sm),(sd).(Segura de León)

Deuda del convento de la Concepción de Segura de León.

Manuscrito; 2 folios (1 folio en blanco); Castellano; R (incompleto)

632 ADME/BA-CONVENTO-122-5179

(sd).(sl)/1741,octubre,6.Segura de León-Llerena

Entrega de llaves, cuentas y libros del convento de la Concepción de Segura de León.

Manuscrito; 8 folios; Castellano; Buena

633 ADME/BA-CONVENTO-122-5180

(sd).(Segura de León)/1813,octubre,18.Llerena

Venta de fincas para subsistencia del convento de la Concepción de Segura de León.

Manuscrito; 6 folios; Castellano; Buena

634 ADME/BA-CONVENTO-122-5181

1855,mayo,26.Segura de León

Cuentas de cargo y data del convento de la Concepción de Segura de León.

Manuscrito; 2 folios y 14 cuartillas; Castellano; Buena

635 ADME/BA-CONVENTO-122-5182

1870,enero,13.Segura de León

Cuentas de cargo y data del convento de la Concepción de Segura de León.

Manuscrito; 2 folios (1 folio en blanco) y 12 cuartillas; Castellano; Buena

636 ADME/BA-CONVENTO-122-5183

1791,marzo,19.Segura de León

Cuentas del convento de la Concepción de Segura de León.

Manuscrito; 25 folios (1 folio en blanco); Castellano; R (roturas)

Hispania Sacra, LXVII

135, enero-junio 2015, 61-168, ISSN: 0018-215X, doi: 10.3989/hs.2015.003 
637 ADME/BA-CONVENTO-205-8143

Cuentas del convento de la Concepción de Segura de León.

Manuscrito; 6 folios; L. Procesal; R (manchas de humedad, pliegues)

638 ADME/BA-CONVENTO-50-2509

(sd).(Segura de León)/1749,julio,19.Segura de León

Denuncia contra el antiguo mayordomo del convento de la Concepción de Segura de León.

Manuscrito; 7 folios (1 folio en blanco); Castellano; Buena

639 ADME/BA-CONVENTO-50-2509bis

(sd).(Segura de León)/1738,agosto,22.Segura de León Reducción de la dote para ingreso de religiosas en el convento de la Concepción de Segura de León. Manuscrito; 2 folios; Castellano; Buena

640 ADME/BA-CONVENTO-50-2510

(sd).(Segura de León)/1739,julio,26.Segura de León

Disminución de cargas de una religiosa del convento de la Concepción de Segura de León.

Manuscrito; 2 folios; Castellano; Buena

641 ADME/BA-CONVENTO-306bis-13912

1622,noviembre, $9 / 1623$,enero,2. Llerena-Segura de León

Toma de hábito de María Ramírez en el convento de la Concepción de Segura de León.

Manuscrito; 7 folios; L. Procesal; Buena

642 ADME/BA-CONVENTO-306bis-13913

1633,(sm),(sd).Segura de León

Cuentas del convento de la Concepción de Segura de León.

Manuscrito; 40 folios; L. Procesal; R (manchas, pliegues)

643 ADME/BA-CONVENTO-306bis-13914

1637,(sm),(sd).Segura de León

Cuentas del convento de la Concepción de Segura de León.

Manuscrito; 20 folios; L. Procesal; R (manchas y pliegues)

644 ADME/BA-CONVENTO-306bis-13915 1651,junio,13.Llerena/1651,junio,15.Segura de León Elecciones de priora y oficialas en el convento de la Concepción de Segura de León.

Manuscrito; 4 folios; L. Procesal; Buena

645 ADME/BA-CONVENTO-306bis-13918

1644,septiembre,31.Segura de León/ 1644,octubre,8.Llerena

Residencia en el convento de la Concepción de Segura de León de una mujer casada.

Manuscrito; 10 folios (1 folio en blanco) y 1 folio doble; L. Procesal y Latín; Buena 
646 ADME/BA-CONVENTO-306bis-13919 1667,agosto,25/1668,junio,5.Segura de León

Vacancia de dos plazas para novicias sin dote en el convento de la Concepción de Segura de León. Manuscrito; 8 folios; L. Procesal; Buena

647 ADME/BA-CONVENTO-306bis-13920 1629,(sm),(sd).Segura de León Cuentas del convento de la Concepción de Segura de León.

Manuscrito; 23 folios; L. Procesal; Buena

648 ADME/BA-CONVENTO-306bis-13923

1732,junio,22/1732,junio,23.Segura de León Elección de abadesa en el convento de la Concepción de Segura de León.

Manuscrito; 4 folios; Castellano; Buena

649 ADME/BA-CONVENTO-306bis-13928

1777,febrero,6/1777,febrero,14.Segura de León

Visita para inspección de cuentas en el convento de la Concepción de Segura de León.

Manuscrito; 18 folios (1 folio en blanco); Castellano; Buena

650 ADME/BA-CONVENTO-306bis-13931

1857,mayo,28.Segura de León/ 1857,junio,23.Madrid

Estado ruinoso del convento de la Concepción de Segura de León.

Manuscrito; 3 folios (1 folio en blanco); Castellano; Buena

651 ADME/BA-CONVENTO-306bis-13931bis 1 861,noviembre,29.Segura/1861, diciembre, 25. Llerena Estado ruinoso del convento de la Concepción de Segura de León.

Manuscrito; 6 folios; Castellano; Buena

652 ADME/BA-CONVENTO-413-17138

(sd).(Segura de León)/1618,mayo,16.Segura de León Toma de hábito de María Rodríguez en el convento de la Concepción de Segura de León.

Manuscrito; 4 folios (1 folio en blanco); L. Procesal; Buena

653 ADME/BA-CONVENTO-413-17138bis

1646,(sm),(sd).Segura de León

Cuentas del convento de la Concepción de Segura de León.

Manuscrito; 36 folios (1 folio en blanco); L. Procesal; R (parte superior deteriorada)

654 ADME/BA-CONVENTO-413-17138bis

1768,junio,1.Segura de León

Visita general al convento de la Concepción de Segura de León para inspección de clausura.

Manuscrito; 23 folios; L. Procesal; R (manchas de humedad)

Hispania Sacra, LXVII

135, enero-junio 2015, 61-168, ISSN: 0018-215X, doi: 10.3989/hs.2015.003 
655 ADME/BA-CONVENTO-204-8141

(sd).(Segura de León)/1812,noviembre,9.Llerena

Enajenación de bienes del convento de la Concepción de Segura de León.

Manuscrito; 4 folios y 1 cuartilla; Castellano; Buena

656 ADME/BA-CONVENTO-204-8142

1612.Segura de León

Pleito del convento de la Concepción de Segura de León.

Manuscrito; 30 folios; L. Procesal; R (roturas)

657 ADME/BA-CONVENTO-51-2582 1635,octubre,6/1635,octubre,9.Segura de León-Llerena

Profesión perpetua de María Garrido en el convento de la Concepción de Segura de León.

Manuscrito; 5 folios; L. Procesal; R (roturas)

658 ADME/BA-CONVENTO-51-2583 1690,septiembre,13/1690,septiembre,14.Segura de León Elecciones de abadesa en el convento de la Concepción de Segura de León.

Manuscrito; 4 folios (1 folio blanco); L. Procesal; Buena

659 ADME/BA-CONVENTO-524-20651 1614,febrero,12.Aracena/1614,mayo,25.Segura de León Prebenda vacante en el convento de la Concepción de Segura de León.

Manuscrito; 12 folios (1 folio en blanco); L. Procesal; R (roturas y desgaste de tinturas)

660 ADME/BA-CONVENTO-524-20652 (sd).(Segura de León)/1635, agosto,18.Segura de León Admisión en el convento de la Concepción de Segura de León de una lega sargenta.

Manuscrito; 4 folios (1 folio en blanco); L. Procesal; Buena

661 ADME/BA-CONVENTO-524-20652bis

1789,febrero,18.Segura de León

Profesión perpetua de Antonia de Cristo en el convento de la Concepción de Segura de León.

Manuscrito; 2 folios; Castellano; Buena

662 ADME/BA-CONVENTO-524-20652bis (sd).(Segura de León)/1665,junio,8.Segura de León

Toma de hábito de María de Velasco en el convento de la Concepción de Segura de León.

Manuscrito; 4 folios; L. Procesal; Buena

663 ADME/BA-CONVENTO-524-20652bis (sd).(Segura de León)/1674,agosto,18.Segura de León Toma de hábito de Josefa Espinosa en el convento de la Concepción de Segura de León.

Manuscrito; 5 folios (1 folio en blanco); L. Procesal; R (roturas) 
664 ADME/BA-CONVENTO-524-20652bis

1674,marzo,3/1674,marzo,20.Segura de León

Profesión perpetua de Catalina de Santa Teresa en el convento de la Concepción de Segura de León. Manuscrito; 6 folios (1 folio en blanco); L. Procesal; Buena

665 ADME/BA-CONVENTO-524-20652bis

(sd).(Segura de León)/1730,octubre,24. Segura -Llerena

Profesión perpetua de Catalina de la Asunción en el convento de la Concepción de Segura de León. Manuscrito; 4 folios; Castellano; Buena

666 ADME/BA-CONVENTO-524-20652bis

1876,marzo,18/1876,marzo,19.Segura de León

Entrada al convento de la Concepción de Segura de León de la educanda María Ramona Carrasco.

Manuscrito; 2 folios; Castellano; Buena

667 ADME/BA-CONVENTO-524-20652bis

1865,abril,9/1865,abril,12.Segura de León

Entrada al convento de la Concepción de Segura de León de la educanda Francisca Lergo.

Manuscrito; 2 folios; Castellano; Buena

668 ADME/BA-CONVENTO-524-20652bis

1865,marzo,3/1865,abril,3.Segura de León

Entrada al convento de la Concepción de Segura de León de la educanda María de la Concepción.

Manuscrito; 2 folios; Castellano; Buena

669 ADME/BA-CONVENTO-524-20652bis

1853,julio,12/1853,agosto,26.

Segura de León-Llerena

Profesión perpetua de Juana Rodríguez en el convento de la Concepción de Segura de León.

Manuscrito; 4 folios; Castellano; Buena

670 ADME/BA-CONVENTO-524-20652bis

1835,enero,15.Llerena/1835,enero,20. Segura de León

Toma de hábito de Ángela Mellado en el convento de la Concepción de Segura de León.

Manuscrito; 3 folios; Castellano; Buena

671 ADME/BA-CONVENTO-524-20652bis

1835,enero,22/1835,febrero,20. Segura de León-Llerena

Toma de hábito de María Dolores Márquez en el convento de la Concepción de Segura de León.

Manuscrito; 3 folios; Castellano; Buena

Hispania Sacra, LXVII

135, enero-junio 2015, 61-168, ISSN: 0018-215X, doi: 10.3989/hs.2015.003 
Entrada al convento de la Concepción de Segura de León de dos mujeres en los cargos de enfermera y sacristana.

Manuscrito; 3 folios; Castellano; Buena

673 ADME/BA-CONVENTO-524-20653

1666,julio,13.Segura de León

Elecciones de priora y oficialas en el convento de la Concepción de Segura de León.

Manuscrito; 5 folios; L. Procesal; Buena

674 ADME/BA-CONVENTO-524-20653bis

1831,enero,25.Llerena/1831,enero,29.

Segura de León

Elecciones de abadesa y oficialas en el convento de la Concepción de Segura de León.

Manuscrito; 4 folios; Castellano; Buena

675 ADME/BA-CONVENTO-524-20653bis

(sd).(Segura de León)/1729,junio,12.

Segura de León.

Elecciones de priora y oficialas en el convento de la Concepción de Segura de León.

Manuscrito; 8 folios (1 folio en blanco); Castellano; Buena

676 ADME/BA-CONVENTO-524-20653bis

1828,enero,15.Llerena/1828,enero,23.

Segura de León.

Elecciones de abadesa y oficialas en el convento de la Concepción de Segura de León.

Manuscrito; 6 folios; Castellano; Buena

677 ADME/BA-CONVENTO-524-20653bis

(sd).(Segura de León)/1804,noviembre,10.

Segura de León

Elecciones de abadesa y oficialas en el convento de la Concepción de Segura de León.

Manuscrito; 6 folios; Castellano; Buena

678 ADME/BA-CONVENTO-524-20653bis

1823,septiembre,22.Llerena/1823,septiembre,26.

Segura de León

Elecciones de abadesa y oficialas en el convento de la Concepción de Segura de León.

Manuscrito; 5 folios y 1 cuartilla; Castellano; Buena

679 ADME/BA-CONVENTO-524-20653bis

1777,agosto,28.Segura de León

Elecciones de abadesa y oficialas en el convento de la Concepción de Segura de León.

Manuscrito; 8 folios (1 folio en blanco); Castellano; Buena 
680 ADME/BA-CONVENTO-524-20654 1704,(sm),(sd).Segura de León

Cuentas del convento de la Concepción de Segura de León de 1704.

Manuscrito; 10 folios; Castellano; Buena

681 ADME/BA-CONVENTO-524-20655

(sd).(Segura de León)/1735,septiembre,20.Llerena

Carga de misas a favor del convento de la Concepción de Segura de León.

Manuscrito; 6 folios; Castellano; Buena

682 ADME/BA-CONVENTO-524-20655bis

(sd).(Segura de León)/1735,julio,29.

Segura de León

Carga de misas a favor del convento de la Concepción de Segura de León.

Manuscrito; 2 folios; Castellano; Buena

683 ADME/BA-CONVENTO-524-20656

1740,septiembre,24.Almendralejo/1741,junio,20. Segura de León

Pleito del marqués de la Encomienda contra el convento de la Concepción de Segura de León por unas tierras.

Manuscrito; 54 folios; Castellano; Buena

684 ADME/BA-CONVENTO-524-20657

1742,enero,11/1742,febrero,21.Segura de León

Dote de una religiosa del convento de la Concepción de Segura de León.

Manuscrito; 6 folios; Castellano; Buena

685 ADME/BA-CONVENTO-524-20658

1788,noviembre,25. Campillo de Llerena/ 1789,septiembre,29.Segura de LeónMadrid-Llerena-Ahillones-Berlanga

Pago de cuentas de mayordomía en el convento de la Concepción de Segura de León.

Manuscrito; 37 folios (3 folios en blanco); Castellano; Buena

686 ADME/BA-CONVENTO-524-20659

(sd).(Segura de león)/1789,marzo,23.Llerena

Voluntades de los fundadores del convento de la Concepción de Segura de León.

Manuscrito; 8 folios (1 folio en blanco); Castellano; Buena

687 ADME/BA-CONVENTO-524-20659bis

(sd).(Segura de León)/1789,abril,22.Segura de León

Voluntades de los fundadores del convento de la Concepción de Segura de León.

Manuscrito; 2 folios; Castellano; Buena

Hispania Sacra, LXVII

135, enero-junio 2015, 61-168, ISSN: 0018-215X, doi: 10.3989/hs.2015.003 
688 ADME/BA-CONVENTO-524-20660

(sd).(Segura de León)/1824,febrero,12.Llerena

Conductas indebidas en el convento de la Concepción de Segura de León.

Manuscrito; 22 folios y 10 cuartillas; Castellano; Buena

689 ADME/BA-CONVENTO-524-20661

1857,junio,30/1869,julio,1.Segura de León

Composición del convento de la Concepción de Segura de León.

Manuscrito; 2 cuartillas y 3 folios dobles; Castellano; Buena

690 ADME/BA-CONVENTO-524-(1)

1803,mayo,20.Segura de León

Elección de nuevo mayordomo para el convento de la Concepción de Segura de León.

Manuscrito; 1 folio; Castellano; Buena

691 ADME/BA-CONVENTO-524-(2)

1856,enero,9.Segura de León

Cuentas de cargo y data del convento de la Concepción de Segura de León.

Manuscrito; 2 folios y 11 cuartillas; Castellano; Buena

692 ADME/BA-CONVENTO-524-(3)

1812,agosto,18.Segura de León

Deuda del convento de la Concepción de Segura de León a su capellán.

Manuscrito; 4 folios y 1 cuartilla; Castellano; Buena

693 ADME/BA-CONVENTO-624-23486

1725,(sm),(sd).Segura de León

Cuentas del convento de la Concepción de Segura de León.

Manuscrito; Libro; Castellano; Buena

694 ADME/BA-CONVENTO-624-23487

1763,junio,7.Llerena/(sd).(Segura de León)

Apertura del arca de caudales del convento de la Concepción de Segura de León.

Manuscrito; 8 folios (1 folio en blanco); Castellano; Buena

695 ADME/BA-CONVENTO-624-23488

1861,(sm),(sd)/1862,enero,13.Segura de León

Cuentas del convento de la Concepción de Segura de León.

Manuscrito; 2 folios y 13 cuartillas; Castellano; Buena

696 ADME/BA-CONVENTO-736-26275

1690,noviembre, $8 / 1690$,noviembre, 23 .

Segura de León

Autos ocasionados por la administración del convento de la Concepción de Segura de León.

Manuscrito; 17 folios; L. Procesal; Buena 
697 ADME/BA-CONVENTO-962-31983

(sd).(Segura de León)/1596,noviembre,20. Segura de León

Dote a favor del convento de la Concepción de Segura de León.

Manuscrito; 2 folios; L. Procesal; Buena

698 ADME/BA-CONVENTO-962-31984

(sd).(Segura de León)/1656,diciembre,20.

Fuentes de León

Profesión perpetua de Beatriz Núñez en el convento de la Concepción de Segura de León.

Manuscrito; 5 folios (1 folio en blanco); Castellano; Buena

699 ADME/BA-CONVENTO-962-31985n¹

1671,(sm),(sd).Segura de León

Cuentas del convento de la Concepción de Segura de León.

Manuscrito; 52 folios; L. Procesal; R (manchas)

700 ADME/BA-CONVENTO-962-31985n²

1746,(sm),(sd).Segura de León

Cuentas del convento de la Concepción de Segura de León.

Manuscrito; 35 folios; Castellano; Buena

701 ADME/BA-CONVENTO-962-31985n 3

1771,julio,17.Segura de León

Cuentas del convento de la Concepción de Segura de León.

Manuscrito; 20 folios; Castellano; Buena

702 ADME/BA-CONVENTO-962-31985nº 4

1859,(sm),(sd).Segura de León

Cuentas del convento de la Concepción de Segura de León.

Manuscrito; 2 folios y 11 cuartillas; Castellano; Buena

703 ADME/BA-CONVENTO-1062-34245

1786,septiembre,28.Llerena-Segura de León

Toma a censo de unos caudales del convento de la Concepción de Segura de León.

Manuscrito; 2 folios; Castellano; Buena

704 ADME/BA-CONVENTO-1062-34245bis

(sd).(Segura de León)/1704,febrero,15.

Segura de León

Toma de hábito de María Ignacia Velasco en el convento de la Concepción de Segura de León.

Manuscrito; 2 folios; Castellano; R (desgaste de tintas)

Hispania Sacra, LXVII

135, enero-junio 2015, 61-168, ISSN: 0018-215X, doi: 10.3989/hs.2015.003 
705 ADME/BA-CONVENTO-1062-34246n ${ }^{\circ}$

(sd).(Segura de León)/1705,abril,30. Segura de León-Llerena

Profesión perpetua de Catalina Rodríguez en el convento de la Concepción de Segura de León. Manuscrito; 4 folios; Castellano; Buena

706 ADME/BA-CONVENTO-1062-34246n²

(sd).(Segura de León)/1704,abril,25. Segura de León

Profesión perpetua de Catalina Domínguez en el convento de la Concepción de Segura de León. Manuscrito; 2 folios; Castellano; R (desgaste de tintas)

\section{ADME/BA-CONVENTO-1062-34246n³}

1790,septiembre,23.Segura/ 1790,octubre,27.Llerena

Secularización perpetua de María de San Francisco en el convento de la Concepción de Segura de León.

Manuscrito; 10 folios (2 folios en blanco); Castellano; R (manchas)

708 ADME/BA-CONVENTO-1027-(6)

1858,junio,11.Madrid/1858,junio,16. Segura de León

Abono de la pensión de una religiosa del convento de la Concepción de Segura de León.

Manuscrito; 1 folio; Castellano; R (incompleto)

709 ADME/BA-CONVENTO-1027-(11)

1741,octubre,14/1741,octubre,20.Llerena

Obligación de continuación en el cargo de granera de una religiosa del convento de la Concepción de Segura de León.

Manuscrito; 2 folios; Castellano; Buena

710 ADME/BA-CONVENTO-1027-31985 1869,junio,28.Segura de León/1869,junio,30.Llerena Celebración de misas en el convento de la Concepción de Segura de León.

Manuscrito; 2 folios; Castellano; Buena

711 ADME/BA-CONVENTO-1273-42349

1675,octubre,3.Segura de León

Cuentas de cargo y data del convento de la Concepción de Segura de León.

Manuscrito; 61 folios; L. Procesal; Buena

712 ADME/BA-CONVENTO-1330-44985

1791,abril,16/1791,mayo,7.Segura de León

Venta de tierras pertenecientes al convento de la Concepción de Segura de León.

Manuscrito; 6 folios; Castellano; Buena 
713 ADME/BA-CONVENTO-1330-44976

Cuestionario que las religiosas del convento de la Concepción de Segura de León envían para el interrogatorio de testigos con relación al traslado de religiosas.

Manuscrito; 5 folios; L. Procesal; Buena
(sd).(Segura de León)/1659,noviembre,4. Fuente del Maestre-Ribera del Fresno

714 ADME/BA-CONVENTO-1331-44994

1636,mayo,6.Segura de León

Cuentas de cargo y data del convento de la Concepción de Segura de León.

Manuscrito; 43 folios (1 folio en blanco); L. Procesal; Buena

715 ADME/BA-CONVENTO-1400-48072

1758,(sm),(sl).Segura de León

Verificación de condiciones de las integrantes del convento de la Concepción de Segura de León.

Manuscrito; 2 folios; Castellano; Buena

716 ADME/BA-CONVENTO-1416-49068 1789,julio,29/1789,agosto,29.Llerena-Segura de León

Permuta de huertas entre el convento de la Concepción de Segura de León y Fernando Romero.

Manuscrito; 10 folios; Castellano; Buena

717 ADME/BA-CONVENTO-1428-50055

1627,noviembre,8.Segura de León

Visita para inspección al convento de la Concepción de Segura de León.

Manuscrito; 14 folios; L. Procesal; R (desgaste del documento) 